\title{
Improving decision making processes in intellectual disability care : systems thinking and problem structuring techniques to support stakeholders' engagement in decision making
}

Citation for published version (APA):

Duryan, M. (2014). Improving decision making processes in intellectual disability care : systems thinking and problem structuring techniques to support stakeholders' engagement in decision making. [Doctoral Thesis, Maastricht University]. Datawyse / Universitaire Pers Maastricht.

https://doi.org/10.26481/dis.20140129md

Document status and date:

Published: 01/01/2014

DOI:

10.26481/dis.20140129md

Document Version:

Publisher's PDF, also known as Version of record

\section{Please check the document version of this publication:}

- A submitted manuscript is the version of the article upon submission and before peer-review. There can be important differences between the submitted version and the official published version of record. People interested in the research are advised to contact the author for the final version of the publication, or visit the DOI to the publisher's website.

- The final author version and the galley proof are versions of the publication after peer review.

- The final published version features the final layout of the paper including the volume, issue and page numbers.

Link to publication

\footnotetext{
General rights rights.

- You may freely distribute the URL identifying the publication in the public portal. please follow below link for the End User Agreement:

www.umlib.nl/taverne-license

Take down policy

If you believe that this document breaches copyright please contact us at:

repository@maastrichtuniversity.nl

providing details and we will investigate your claim.
}

Copyright and moral rights for the publications made accessible in the public portal are retained by the authors and/or other copyright owners and it is a condition of accessing publications that users recognise and abide by the legal requirements associated with these

- Users may download and print one copy of any publication from the public portal for the purpose of private study or research.

- You may not further distribute the material or use it for any profit-making activity or commercial gain

If the publication is distributed under the terms of Article 25fa of the Dutch Copyright Act, indicated by the "Taverne" license above, 


\section{IMPROVING DECISION MAKING PROCESSES IN INTELLECTUAL DISABILITY CARE}

Systems Thinking and Problem Structuring Techniques to Support Stakeholders' Engagement in Decision Making

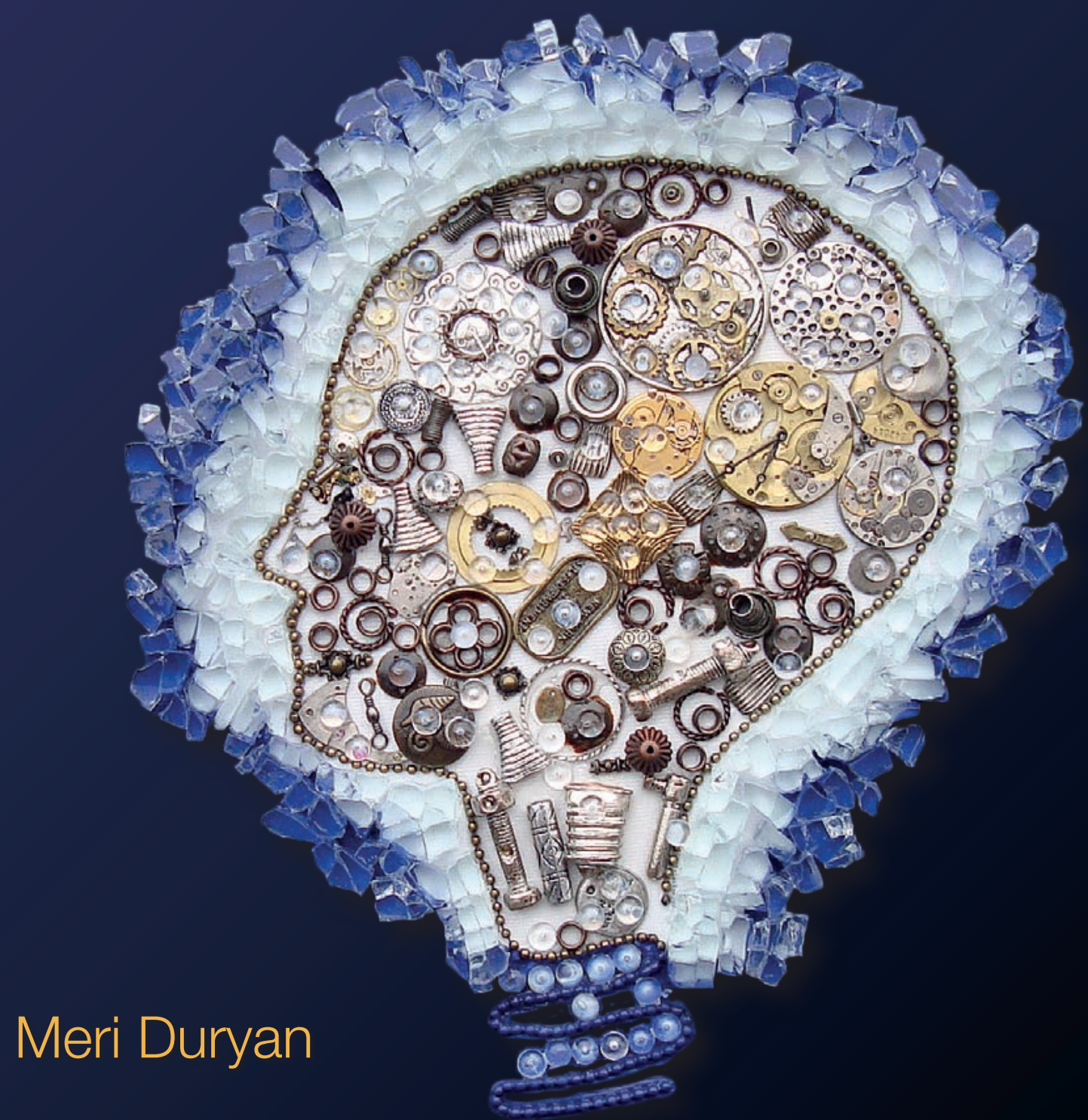





\section{IMPROVING DECISION MAKING PROCESSES IN INTELLECTUAL DISABILITY CARE}

Systems Thinking and Problem Structuring Techniques to Support Stakeholders' Engagement in Decision Making 
The research presented in this thesis was conducted at the Gouverneur Kremers Centrum (GKC) - Maastricht University Medical Centre. The project was carried out in collaboration with, and with the financial support of the Koraal Groep.

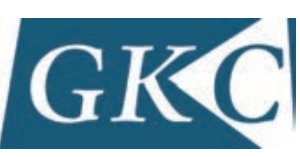

caphri

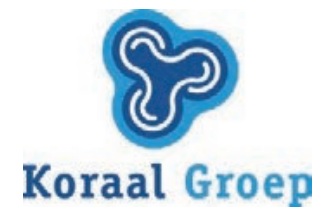

Maastricht UMC+
$0_{\text {ax }}^{2} \overline{\bar{M}}-\mid \nabla_{d}$ Mastricht University

CC 2014 Meri Duryan, Maastricht

ISBN 9789461593054

Cover design: Meri Duryan (the painting "Human Mind")

Production: Datawyse | Universitaire Pers Maastricht 


\section{IMPROVING DECISION MAKING PROCESSES IN INTELLECTUAL DISABILITY CARE}

Systems Thinking and Problem Structuring Techniques to Support Stakeholders' Engagement in Decision Making

\section{PROEFSCHRIFT}

ter verkrijging van de graad van doctor

aan de Universiteit Maastricht, op gezag van de Rector Magnificus, Prof. dr. L.L.G. Soete, volgens het besluit van het College van Decanen,

in het openbaar te verdedigen

op woensdag 29 januari 2014 om 12:00 uur

door

Meri Duryan

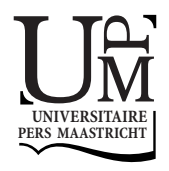




\section{Promoters}

Prof. dr. L.M.G. Curfs

Prof. dr. G.G. Van Merode

Prof. dr. D.A. Nikolik

\section{Assessment Committee}

Prof. dr. G. Kok (voorzitter)

Prof. dr. W.N.J. Groot

Prof. dr. H.L.G.R. Nies

Prof. dr. J. Scheres 


\section{CONTENTS}

$\begin{array}{lll}\text { Chapter } 1 & \text { Introduction } & 7\end{array}$

Chapter 2 System Dynamics Modelling for Intellectual Disability Services:

A Case Study

Chapter 3 Reflecting on the Efficacy of Cognitive Mapping for Decision Making in Intellectual Disability Care: A Case Study

Chapter 4 Using cognitive mapping and qualitative system dynamics to support decision making in intellectual disability care

Chapter 5 Facilitating Bottom-Up Knowledge to Support Decision-Making in Service Organisations

Chapter 6 Discussion

Summary

Samenvatting

Acknowledgements

Curriculum Vitae 

CHAPTER 1

Introduction 


\section{Introduction}

The central focus of this thesis is to understand whether the use of visual and structured representation of the key stakeholders' views can support the senior management of long-term healthcare service providers in decision making related to efficiency of resource allocation policies. Identifying the factors that influence the decision making process is important to understanding what decisions are made and how they may impact the outcomes. For that, we explored the understandings and practices around decision-making processes in a long-term healthcare provider in the Netherlands.

Healthcare industry in the Netherlands is effective but costly. According to the OECD (2013), in 2009, the Netherlands was the second largest health spender after the United States. The Netherlands, as other OECD countries, faces the challenge of providing high quality health and long-term care services to an ageing population in a cost-efficient manner (OECD, 2013). In 2010, public expenditure on long-term care in the country accounted for about $3.7 \%$ of GDP (OECD, 2013). Intellectual Disability (ID) care providers can serve as an example of complex healthcare service organisations.

A large share of total healthcare costs in the Netherlands is taken up by healthcare for people with ID comprising $10.3 \%$ of the total costs of healthcare nationally (Jansen et al., 2006; Van der Kwartel, 2009). Funding for ID services in the Netherlands is provided on the basis of the Exceptional Medical Expenses Act, AWBZ (Algemene Wet Bijzondere Ziektekosten). The Association for Care of the Disabled, VGN (Vereniging Gehandicaptenzorg Nederland), is the umbrella Dutch association representing individual provider organisations that provide professional care and support to persons with mental, physical, sensory, and/or communication disabilities.

VGN encompasses 173 privately run institutions providing care to about 110,000 clients and accounts for a budget of about $€ 4.8$ billion. Community-based services in the Netherlands have evolved as alternatives to institutional residential care, however, the existing service structure remains dominated by institutional models (WHO, 2010).

It is a challenging task for the big institutions that offer residential care to ID patients to deliver quality care because of the complexity of organisations, specifics of care, and diminished financial resources. Hence, the decision makers need approaches that can not only help them see complex interconnections between parts of the complex system but also provide better understanding of the stakeholders' interests (Adam and de Savigny, 2012). Different stakeholders have varying perspectives on valuecreating processes and their outcomes, so understanding their individual perceptions is important for the success of a service provider.

Many of ID patients are placed in the institutions for their entire life beginning in childhood. They are highly restricted in their social networks: limited to interactions with other patients, their family members and the care workers (Bigby and Fyffe, 2012). Hence, ID organisations are challenged, not only to give a prompt response to 
the patients' needs related to their physical health but also to enable them to experience a good quality of life.

People with ID have certain limitations in communication and social skills and some of them have difficulties in caring for themselves. ID patients residing in congregate settings develop attachment behaviour towards care staff and they may develop emotional insecurity in case of discontinuities in the care and insufficient personal attention (Schuengel et al., 2010; De Schipper \& Schuengel, 2010).

Lately ID care providers have become increasingly person-centred in their approach, so their deeper long-term involvement with the family members of patients in inevitable (Bigby and Fyffe, 2012). Due to the specifics of the care, ID institutions need to be more sensitive towards the patients' and their families' wishes, concerns, values and priorities. They also need to ensure that there is an environment of comfort and security for the frontline workers who deal with the patients and their families on a daily basis.

ID institutions need to utilize a high level of planning for resources which involves the families of the patients and the frontline staff in decision making process. Without considering the viewpoints of the key stakeholders who are the ID clients, their families and the front-line workers (group leaders/personal coaches, personnel who work with the clients every day), any managerial decision can escalate tension at the front line and can bring short-term remediation at the expense of longer-term systemic improvements. However, there are no well-established mechanisms to guide the institutions in strengthening that collaboration (Bigby and Fyffe, 2012).

Therefore, a study was conducted in one ID care organisation to learn about decision making processes and to determine how collaboration with the key stakeholders can assist senior management in decision making.

Since service output in long-term care providers strongly depends on collaborative input of clients and frontline workers, their participation in decision making related to allocation of resources is crucial. Therefore, the series of interviews and focus groups with the family members of ID patients and the frontline staff were conducted to determine the gap between the mental models of the management and the beneficiaries of services and those who directly deal with the patients and their families. It was important to learn about the impact of managerial decisions on the working floor and about the biggest challenges in the organisation from the perspectives of the clients and the frontline staff.

In order to make the best decision in a complex world, the managers must evaluate each choice according to its projected outcome based on the amount of information and time available. However, there can be a huge amount of data which is difficult to convert into meaningful information for decision making. Furthermore, most people are not consciously aware of their mental models and of the effects they have on their behaviour. The leaders of the organisations need the tools that can help eliciting clients' and employees' mental models. 
The possibility of assisting the managers in understanding their current reality was explored with the help of cognitive maps and System Dynamics (SD) causal loop diagrams (CLD). The methodologies were combined to promote stakeholders' representation in modelling process which in its turn assisted senior management in revising their decisions taking into account the clients' and employees' concerns.

The first chapter of this thesis introduces the methodology used for the research followed by research questions. In Chapters 2-5 we reflect on decision making processes and the importance of considering soft factors for improvement of patients' quality of life and frontline workers' working environment. We discussed the practical implications of the applied methodology, which is based on case study research, Systems Thinking, and problem structuring techniques. Limitations, recommendations and suggestions for future research are discussed in Chapter 6 and summarized at the end of this thesis.

\section{Systems Thinking}

Systems Thinking is a way of thinking in approaching problems and designing solutions (Checkland, 1985). It is a general concept that considers interrelationships between parts and their connections to a whole system. "Systems Thinking is the art and science of making reliable inferences about behaviour by developing an increasingly deep understanding of underlying structure" (Richmond, 1994). Emergence and interrelatedness are the fundamental ideas of Systems Thinking theory, which emerged through a critique of reductionism (Flood, 2010).

Reductionism, the traditional scientific method for studying organisations, seeks to understand the organisation as a whole system via breaking it down into constituent parts and then studying them in terms of cause and effect (Flood, 2010). The method suggests reducing the complexity of the organisation by dividing it into manageable parts. However, the whole is more than just the sum of its segments. The system cannot be recognized from its parts because it emerges of the interaction between them (Jackson, 2003). It is the whole that gives meaning to the parts and their interactions (Jackson, 2003). It is a theory addressing the interrelationships between variables and their connections to a whole system. Bertalanffy (1950) demonstrated that the concepts of reductionism are not able to consider the dynamics of systems.

System Thinking can be viewed as a reaction to the failure of traditional approaches when confronted with complex problems in social systems (Checkland, 1981).

Systems Thinking has proven itself "more suitable for getting to grips with realworld management problems than that of any other single discipline" (Jackson, 2003). Most decision making in today's world deals with complex problem situations. No problem ever exists in complete isolation. Every problem interacts with other prob- 
lems and is, therefore, part of a set of interrelated problems, a system of problems (Ackoff, 1974). In dealing with a set of problems in a complex system, the managers must have understanding of the how the parts of the system function, and how they interrelate. Hence, for any changes in the organisation to be long-term, managers must approach the problems considering the impact of their solution on the whole system. Systems approaches help managers to simplify the process of their thinking about complex realities and overcome the feeling of helplessness, when confronted with complex problems. The core aspects of Systems Thinking are gaining a bigger picture and appreciating other people's perspectives (Reynolds and Holwell, 2010).

It is important, however, not to misjudge the dynamic behaviour of the system and to fail to understand "how that behaviour would be altered by new policies" (Senge, 1987). The mental models of managers are not always able to see the feedbacks that determine the dynamics of a system. SD models with causal loop diagrams are useful in capturing the mental models and in communicating the important feedbacks that could be responsible for a problem (Sterman, 2000).

\section{System Dynamics modelling}

SD is a method of studying complex systems (Sterman, 2000). SD approach involves simulation of situations by visualising how the elements fit together, interact, and change over time. The hallmark of good SD practice is the skill of seeing the big picture, while not losing sight of operating detail (Senge, 1990). SD modelling offers a unique opportunity for decision makers to understand the sources of low performance in the organisation with the help of both qualitative and quantitative analysis.

The fundamentals were developed in the late 1950s by Jay Forrester of the MIT Sloan School of Management with the establishment of the MIT System Dynamics Group (Forrester, 1961). Feedback control, understanding decision-making processes, simulation and computer modelling are the foundation of SD. Forrester (1961), as well as Senge (1990), has emphasized the effect of time delays on the dynamic behavior of the system. They found that what distorts the apparent performance of the system are the multiple delays between events and responses. Thus when we fail to understand the systemic source of problems, we try to give solution to the symptoms, rather than to underlying causes (Senge', 1990).

A key emphasis within System Dynamics models is placed on the presence of feedback loops that have a critical impact on the behaviour of complex systems and must be considered when designing policies to control those systems (Senge, 1990). Systems are controlled by feedback loops that provide information flows on the state of the system.

Causal loop diagrams (CLD) are seen as being part of SD practice. "A causal loop diagram is a visual tool for the feedback systems thinker" (Reynolds and Holwell, 
2010). Organisations (systems) are entities with consistent patterns of behaviour. They all can be modelled using reinforcing processes, balancing processes and delays. CLDs are advantageous to managers of the organisations by helping them to identify where and why the organisations do not effectively operate.

\section{Systems archetypes}

Systems Thinking gives insight into the phenomena that certain patterns of systems behaviour recur over and over again (Senge, 1990). It has produced a variety of principles and tools for analyzing and changing systems. System archetypes play an important role in the process of Systems Thinking (Wolstenholme, 1993). "Diagnostically, archetypes help managers recognize patterns of behaviour that are already present in their organisations" (Braun, 2002). "System archetype" modelling approach make it possible to experiment on strategic and tactic levels with different realistic scenarios and compare outcomes before making real life changes. Archetypes are fundamentally important to SD modelling, since they capture the essence of "thinking" in Systems Thinking (Wolstenholme, 2004).

The archetypes suggest that the problems managers come across are not unique. They can serve as an effective tool for the managers to analyse what causes the same problem to occur repeatedly over time. The template shows the basic structural form of the archetype and allows managers to describe their own situation using their variables. Archetypes do not describe any one problem specifically. They describe families of problems generically.

\section{Cognitive mapping}

Cognitive mapping (CM) is a visual mapping technique that helps to elicit people' perception of a problematic situation (Ackermann and Eden, 2010). Essentially, a cognitive map is a graph composed of nodes and links connecting the nodes. The maps provide a comprehensive picture of an individual's overall perspective, at the same time keeping all the details. The links between the concepts in cognitive maps do not imply causeeffect relations, rather they indicate the way in which one concept can affect the other.

$\mathrm{CM}$ technique is a fundamental part of the strategic options development and analysis (SODA) approach developed by Colin Eden (1989). The method is well suited for dealing with complex, messy problems considering their qualitative and quantitative aspects (Wolstenholme, 1995; Ackermann and Eden, 2010).

The underlying essence of SODA is that it is an approach that allows the analysis of problematic situations before making a decision. SODA uses interviews and CM to 
capture individual views of an issue. Group maps constructed through the aggregation of individual cognitive maps are used to facilitate negotiation about the key strategic issues (Ackermann and Eden, 2010). The technique has been used to represent managerial cognition at both the individual and group levels. Axelrod (1976) first used cognitive maps as an approach to understanding managerial decision-making processes in organisations.

\section{Combined methodology}

When combining $\mathrm{CM}$ and SD methodologies, it is fundamental to understand the distinction between convergent and divergent thinking in decision making (Montibeller et al., 2001). The goal of divergent thinking is to generate many different ideas and accept many possible solutions related to a topic. Convergent thinking helps to keep focus on the single, well-established answer to a problem (Cropley, 2006).

The identification of key concepts is fundamental to understanding the stakeholders' perceptions. CM can support divergent thinking by facilitating the debate among decision makers and stakeholders. A significant strength of CMs is that it supports elicitation of mental models and generation of creative ideas using the language participants used to make their argumentation. However, cognitive maps do not allow seeing dynamic behavior of the system because they do not demonstrate feedback processes and time delays. Managerial decision making is a dynamic process and that is why CLD can be useful in demonstrating cause-effects links describing multiple feedback cycles (Mingers and Rosenhead, 2004).

The use of $\mathrm{CM}$ allows unravel complex ideas and obtain a richer understanding of people's mental models provided a level of specificity that can support the development of CLDs to see complex interactions between the ideas discussed. The capability of CLD to model the impacts of management actions, considering the complexity of the real world, may be used to move towards a single solution during the convergent phase.

\section{A case study approach}

In order to objectively examine how an organisation might employ strategic decision making in optimizing resource allocations, we used a case study approach.

A case study approach has been defined as an empirical inquiry that investigates a phenomenon within its real-life context, when the multiple sources of evidence are used and when the boundaries between phenomenon and context cannot be clearly seen (Yin, 1984). 
One of the reasons for applying a case study research method is that quantitative methods do not provide in-depth explanations of some phenomena. Case study method allows a researcher to go beyond the quantitative analysis. It provides detailed analysis of contemporary real life events and investigates the relationship among them. The choice of the approach was driven by the possibility it would provide numerical information regarding strategy development, an understanding of the reasons for a particular strategy choice, and the processes that lead to a particular decision.

The choice of a single-case design is justifiable when the case represents a critical test of existing theory or where the case serves a revelatory purpose (Yin, 1984). The information obtained in a case study enables a researcher to look at and examine the findings in real-life environment, which can be difficult to do through survey research.

One of the main arguments against case study method is that case studies do not provide enough evidence to permit scientific generalization, as a number of subjects is small (Cronbach,1975; Schofield, 1990; Yin, 1984). However, Cronbach (1975) argues that generalizations like predictions require continuous update, especially when the context of research changes. An alternative solution was proposed by some social science experts. According to their concepts generalizability is possible, when the case is compared to another case or theory and to prior knowledge and experience (Becker, 2000; Yin, 2003). Yin (1993) and Hamel et al. (1993) argue that in a case study method the objective of the research is more important than a sample size. Based on a case study research guidelines, the most important sources of the information are the interviews, participant observations, focus groups, and archival records (Yin, 1984). The same importance to interviews with clients and senior- and middle-level management of the organisation, is given by SD modelling and CM problem structuring techniques used for this research.

\section{Research questions}

Our main interest was: "How can alignment between the interests of the various stakeholders in long-term healthcare organisations be improved to support managerial decision making related to resource allocation?"

The research questions are summarised as follows:

1. How the management of ID care providers can get support to better understand the impact of their decisions?

2. How to get feedback from the front-line workers and the clients in a structured way relevant for decision making?

3. Can a combination of problem structuring tools facilitate bottom-up knowledge to support decision-making in long-term health service providers? 
Chapter 2 describes the possibilities of Systems Thinking to address the interrelationships between parts of the system and their interaction were explored with the help of a case study in an ID care provider in the Netherlands. The main goal of the study was to see how SD modelling, one of Systems Thinking approaches, could be used to help the senior management of an ID organisation to study the dynamic behaviour of the complex system they manage, in order to understand the reasons for inefficiency of resource allocation policies.

Chapter 3 describes the process of elicitation of mental models of the families of ID patients and the frontline workers, representatives of two groups of the key stakeholders of an ID care provider. CM techniques were used to analyze subjective perspectives of the key stakeholders.

In Chapter 4, the combination of qualitative SD modelling and CM techniques was used to see how collaborative representation of the stakeholders' views related to resource allocation policies in the organisation can assist senior management in their decision making.

In Chapter 5, the model for facilitating bottom-up knowledge to support decision making in traditional healthcare service providers is presented. The model is based on combined CM and SD techniques and is tested in one of the biggest ID care providers in the Netherlands.

The findings of the four chapters, as well as limitations and recommendations for future research are discussed in Chapter 6 and are summarized at the end of this thesis. 


\section{References}

Ackermann, F., Eden, C. (2010). Strategic Options Development and Analysis. In: M. Reynolds, \& S. Holwell (Eds.), Systems Approaches to Managing Change: A Practical Guide (pp. 135-190). London, UK: Springer.

Ackoff, R. L. (1974). Redesigning the Future: A Systems Approach to Societal Problems. Sydney, Canada: John Wiley \& Sons, Inc.

Adam, T., de Savigny, D. (2012). Systems Thinking for strengthening health systems in LMICs: need for a paradigm shift. Health Policy and Planning, 27(4), iv1-iv3.

Axelrod, R. (1976). The analysis of cognitive maps. In: Axelrod R, (ed.) Structure of decision - the cognitive maps of political elites. Princeton, NJ: Princeton University Press, p. 55-73 (chapter 3).

Becker, H., (2000). Generalizing From Case Studies. In Eisner E. and Peshkin A. (eds), Qualitative Inquiry in Education: The Continuing Debate. New York: Teachers

College Press, 233-242.

Von Bertalanffy, L. (1950). British Journal for the Philosophy of Science, 1, 134-165.

Bigby, C. \& Fyffe, C. (2012). Services and Families Working Together to Support Adults with Intellectual Disability. Proceedings of the Sixth Roundtable on Intellectual Disability Policy. Bundoora: La Trobe University.

Braun, W. (2002). The Systems Archetypes. Available at: http://my.ewb.ca/site_media/static/attachments/group_topics_grouptopic/86984/systemarchetypes.pdf.pdf

Checkland, P. (1981). Systems Thinking, Systems Practice. Wiley: Chichester, UK.

Checkland, P. (1985). A Development of Systems Thinking for the 1990s. The Journal of Operational Research Society, 36, 757-767.

Cronbach, L.,(1975). Beyond the Two Disciplines of Scientific Psychology. American Psychologist, 30(2), 116127.

Cropley, A. (2006). In Praise of Convergent Thinking. Creativity Research Journal 18(3), 391-404.

Eden, C. (1989). Using Cognitive Mapping for Strategic Options Development and Analysis (SODA). In: J. Rosenhead (ed.), Rational Analysis for a Problematic World, pp. 21-42. Wiley, Chichester.Forrester, J. W. (1961). Industrial Dynamics. MIT Press: Cambridge, MA.

Flood, R. (2010). The relationship of 'Systems Thinking' to action research. System Practise Action Research, 23, 269-284. http://link.springer.com/content/pdf/10.1007\%2Fs11213-010-9169-1.pdf

Forrester, J. (1961). Industrial dynamics. Cambridge, MA: MIT Press.

Hamel, J., Dufour, S. and Fortin, D., (1993). Case Study Methods. Newbury Park, CA: Sage Publications.

Jansen, D., Krol, B., Groothoff, J., Post, D. (2006). Towards improving medical care for people with intellectual disability living in the community: possibilities of integrated care. Journal of Applied Research in Intellectual Disabilities 19, 214-218.

Jackson, M. (2003). Systems Thinking: Creative Holism for Managers. Chichester, UK: Wiley

Mingers, J. and Rosenhead, J. (2004). Problem structuring methods in action. European Journal of Operational Research, 152, 530-554.

Montibeller, G., Ackermann, F., Belton, V. and Ensslin, L. (2001). Reasoning Maps for

Decision Aid: A Method to Help Integrated Problem Structuring and Exploring of Decision Alternatives. ORP3, Paris, September 26-29.

Organisation for Economic Co-operation and Development (OECD). (2013), "Health Care Reform and LongTerm Care in the Netherlands", Economic Department Working Paper No. 1010, available at: http://www.oecd-ilibrary.org/economics/health-care-reform-and-long-term-care-in-thenetherlands_5k4dlw04vx0n-en;jsessionid=5gq6e7o7w8v38.x-oecd-live-01 (accessed 3 July, 2013).

Reynolds, M. and Holwell, S. (2010). Systems Approaches to Managing Change: A Practical Guide. London, UK, Springer.

Richmond, B. (1994). System Dynamics/Systems Thinking: Let's Just Get On With It. International Systems Dynamics Conference. Sterling, Scotland. 
Senge, P.M. (1987). Catalyzing Systems Thinking within organisations. System Dynamics Group, Sloan School of Management, Massachusetts Institute of Technology.

Senge, P. M. (1990). The Fifth Discipline: The Art \& Practice of the Learning Organisation. Dell Publishing Group, Inc.

Senge', P. M. (1990). The Leader's New Work: Building Learning Organisations. MIT Sloan Management Review 32(1), 16.

Schofield, J. (1990). Increasing the Generalizability of Qualitative Research. In Eisner, E. and Peshkin, A. Edition, Qualitative Inquiry in Education: The Continuing Debate. New York: Teachers College Press, 201-232.

De Schipper, J. C., \& Schuengel, C. (2010). Attachment behaviour towards support staff in young people with intellectual disabilities: associations with challenging behaviour. Journal of Intellectual Disability Research, 54, 584-596.

Schuengel, C., Kef, S., Damen, S., \& Worm, M. (2010). People who need people: Attachment and professional caregiving. Journal of Intellectual Disability Research, 54, 38-47.

Sterman, J. (2000). Business dynamics: Systems Thinking and modelling for a complex world. New York: McGraw-Hill.

Van der Kwartel, A. (2009). Brancherapport Gehandicaptenzorg (Branch report Care for Disables) 2008. Prismant: Utrecht.

World Health Organisation. (2010). Better health, better lives: children and young people with intellectual disabilities and their families. Retrieved 11 Nov., 2012 from http://www.euro.who.int/_data/assets/pdf_file/0003/126570/e94430.pdf

Wolstenholme, E. F. (2004). Using generic system archetypes to support thinking and modelling. System Dynamics Review, 20(4), 341-356.

Wolstenholme, E. F. (1993). Towards the definition and use of a core set of archetypal structures in system dynamics. System Dynamics Review, 19, 7-26.

Wolstenholme E. 1995. Systems Thinking, System Dynamics. System Dynamics Conference. Tokyo, Japan.

Yin, R. K. (1984). Case study research: Design and methods. Beverly Hills, CA: SAGE Publications, Inc.

Yin, K. (2003). Case Study Research - Design and Methods. Thousand Oaks, London, New Dehli: SAGE Publications. 


\section{CHAPTER 2}

\section{System Dynamics Modelling for Intellectual Disability Services: A Case Study}

Duryan, M., Nikolik, D., van Merode, G., Curfs, L. M. G. (2012). System Dynamics Modelling for Intellectual Disability Services: A Case Study.

Journal of Policy and Practice in Intellectual Disabilities, 9, 112-119. 


\begin{abstract}
Organisations providing services to persons with intellectual disabilities (ID) are complex because of many interacting stakeholders with often different and competing interests. The combination of increased consumer demand and diminished resources makes organisational planning a challenge for the managers of such organisations. Such challenges are confounded by significant demands for the optimization of resources and the goal to reduce expenses and to more effectively and efficiently use existing resources while at the same time providing high quality services. The authors explore the possibilities of using "system dynamics modelling" in organisational decision-making processes related to resource allocations. System dynamics suggests the application of generic systems archetypes as a first step in interpreting complex situations in an organisation. The authors illustrate the application of this method via a case study in one provider organisation in the Netherlands. The authors contend that such a modelling approach can be used by the management of similar organisations serving people with ID as a tool to support decision making that can result in optimal resource allocation.
\end{abstract}




\section{Introduction}

Healthcare organisations are complex entities as they have multiple stakeholders with often conflicting objectives and goals (Drucker, 1993). Provider organisations specializing in intellectual disabilities (ID) are also complex because of the nature of the care and supports they provide and how they are organized. Some of the complexities relate to the difficulties that adults with ID might have in expressing themselves. Moreover, the specifics of the care often require a deeper involvement of carers with respect to their relationships with families and other sectors of society. Because of their complexity, ID provider organisations, compared with healthcare providers, often require a higher level of resource planning, collaboration, and cooperation among social, health, and education services, mental health services, and other sectors (WHO, 2010).

To manage the complexities and challenges ID provider organisations face, managers need to analyze and understand complex interdependencies among the systems with which they are dealing. In order to achieve that, ID provider managers need to examine and shift their mental models regarding their role in managing the organisation and in establishing relationships with all the stakeholders involved. However, as Forrester (1980) has noted, traditional management generally does not have other ways to manipulate its mental models but by intuition. The question is, how to go beyond intuition? We posit that many challenges related to decision making in ID provider organisations may be effectively addressed with a "system dynamics modelling" (SD) approach. While SD modelling has been shown to be applicable in many industries (van Ackere, Larsen, \& Morecroft, 1993; Braun, 2002; Davenport, 2009; Senge, 1990; Sterman, 2000), it also has been applied in healthcare (Dumas, 1985; Homer \& Hirsch, 2006; Kommer, 2002; van Merode, Groothuis, Schoenmakers, \& Boersma, 2002; Rohleder et al., 2007; Trochim, Cabrera,Milstein, Gallagher, \& Leischow, 2006; Vissers, 1998; Wolstenholme, 2004).

The objective of this article is to explore the application of SD modelling when analyzing decision-making processes within an ID provider organisation, with the intent of optimizing allocation of existing resources so as to improve efficiency and effectiveness of resource utilization. Specifically, the focus is on the use of systems archetypes, a class of Systems Thinking tools, which capture challenges common for any organisation. One generic systems archetype, "shifting the burden," can be used to gain insight into the nature of the dealing with the dilemma of waiting lists (i.e., the backup of admission to a service because of under-capacity and excess demand), a prevalent problem among many such organisations. To illustrate the application of SD modelling, we choose to use a case study conducted in one ID provider organisation in the Netherlands. The case study demonstrates the need for a better resource allocation policy, especially considering increased consumer demand and diminishing resources in ID care in the Netherlands as well as in other nations. 
Systems Thinking is a theory addressing the interrelationships between parts and their connections to a whole system. As Richmond (1994) noted, Systems Thinking is the art and science of drawing conclusions about behaviour as a result of deep understanding of the underlying structure of the system. Within the constructs of this theory, goals and resources are established with a view toward the whole system, rather than artificially allocating them to parts of the system (Plsek \& Wilson, 2001; Richmond, 1994; Senge, 1990). The originator of "general systems theory" is Ludwig von Bertalanffy, an Austrian biologist, who in 1954 formed the Society of General Systems Research along with four Nobel Prize winners from economics, physiology, physics, and mathematics (Haines, 2007).

There are a number of approaches that can apply Systems Thinking to a better understanding and improvement of systems. Those approaches have been characterized by Checkland (1981) as "hard systems" and "soft systems" approaches. The soft systems approach is defined mainly as a learning process designed to determine what needs to be done in not clearly or distinctly defined (i.e., ill defined) problem situations (Checkland, 1981).

The hard systems approach is used to determine how to make improvements to a well-defined problem. Hard Systems Thinking helps us to analyze knowledge directly relevant to clients. It also allows for testing hypotheses related to system behaviour via the development of models (Jackson, 2009). In this article, the hard Systems Thinking approach, termed SD, is applied.

\section{System Dynamics}

SD is a method of studying complex systems (Sterman, 2000). A hallmark of good SD practice is the skill of seeing the big picture while not losing sight of an operating detail (Senge, 1990). The fundamentals of SD were developed in the late 1950s by Jay Forrester, of the MIT Sloan School of Management, with the establishment of the MIT System Dynamics Group (Forrester, 1961).A key emphasis within SD models is placed on the presence of feedback loops that have a critical impact on the behaviour of complex systems and must be considered when designing policies to control those systems (Morecroft, 2007; Senge, 1990; Sterman, 2000).

SD modelling offers a unique opportunity for decision makers to understand the sources of, for instance, low performance in the organisation. Many top companies, governments, consulting firms, and educational institutions use SD modelling while dealing with complex issues (Sterman, 2000). Forrester (1961) and Senge (1990) emphasized the effect of time delays on the dynamic behaviour of the system. They noted that as often there is no explicit connection between cause and effect because of delays, this makes the management of the organisation think that the changes made were ineffective. Consequently, such decisions may lead to more changes, which can cause side effects that eventually may throw the system out of balance. For this rea- 
son, when managers do not get the desired effect, SD practitioners recommend first seeing whether there is a delay involved.

SD involves mapping of system behaviour with the help of causal loop diagrams to understand interdependencies between parts of the system. To be able to see the dynamics of the complex systems over time, SD suggests the use of computer simulation of the problem situation using stocks and flows. Once the computer model is developed, available data are used to quantify the model so that it can be used to simulate various "what-if" scenarios. The final step in model building is validation of the model via its initialization at past points in time and comparison of results they produce with historical data (Hirsch, 1979).

SD has a number of strengths that make this approach especially useful in healthcare settings applications. First, the dynamic modelling approach involves decision makers with the goal to make the model more realistic. Moreover, decision makers' involvement ensures that they will use the results produced with the model (Hirsch, 1979). Second, a key strength of SD is that it helps users understand the situation even when there is insufficient data. With the help of causal description of a system, "a model can be developed around important variables regardless of whether or not good data on those variables exist" (Hirsch, 1979; p. 40). The mental models of managers are not always able to see the feedbacks that determine the dynamics of a system. Causal loop diagrams are useful in capturing the mental models of individuals or teams and in communicating the important feedbacks that could be responsible for a problem (Sterman, 2000).

\section{Causal loop diagrams}

Causal loop diagrams are analytical tools widely used in SD modelling. According to Reynolds and Holwell (2010; p. 32), "a causal loop diagram is a visual tool for the feedback systems thinker." The diagrams provide a language for articulating our understanding of the dynamic nature of the system studied. Any organisation can be viewed as made up of two kinds of system building blocks-reinforcing (positive) and balancing (negative) processes. Arrows can denote the direction of causality between a cause and its effect, and the symbols " $\mathrm{s}$ " and "o" at the arrowhead represent "same" and "opposite" directions of causality.

Thus, causal loop diagrams can describe the organisation as a system via combination of reinforcing and balancing loops connected together with arrows. Reinforcing processes create exponential growth and collapse; balancing processes keep a situation at equilibrium. Particular combinations of reinforcing and balancing processes within the system can be the reason for system's complexity (Senge, 1990). Thus, system thinking gives insight into the phenomena that certain patterns of systems behaviour recur repeatedly (Senge, 1990). These causal loop structures that capture challenges common for any organisation are known as system archetypes. 


\section{System archetypes}

System archetypes were first identified in the 1930s by biologist Bertalanffy and expanded in the 1990s by Senge. They are fundamentally important to SD modelling as they capture the essence of "thinking" in Systems Thinking (Wolstenholme, 2004). All archetypes are made up of causal loops with delays. The archetypes can serve as an effective tool for the organisation to analyze what causes the same problem to occur repeatedly over time. Difficulties in solving problems often stem from the fact that problems do not occur in isolation but in relation to each other. Archetypes do not describe any one problem specifically; they describe families of problems generically. As Braun (2002; p. 1) has noted, "diagnostically, archetypes help managers recognize patterns of behaviour that are already present in their organisations."

Generic archetypes ${ }^{1}$ can help with the creation of dynamic hypotheses in the beginning of the modelling process. It is often beneficial to use the archetypes in parallel throughout the process of detailed modelling. When managers start thinking in terms of the systems archetypes, their perceptions will recondition, and so they will find it easier to identify leverages to solve complex management situations. An archetype modelling approach provides opportunity to experiment on strategic and tactical levels with different realistic scenarios and compare outcomes before making real life changes. Thus, this approach can help to model different resource allocation scenarios in order to find the one that is the most effective and efficient. A number of researchers have used generic systems archetypes as a first step in interpreting complex situations in healthcare (e.g., Dumas, 1985; Homer \& Hirsch, 2006; Kommer, 2002; Rohleder et al., 2007; Trochim et al., 2006; van Merode et al., 2002; Vissers, 1998; Wolstenholme, 2004).

\section{Modelling in Healthcare}

Modelling helps decision makers better understand the complexity of an organisation. Decision makers in healthcare organisations need a model that can help them allocate resources optimally and increase performance with existing resources. It is very important to develop an organisation's capacity to work with mental models as they are too often not made explicit (Senge, 1990). Having a language that everyone across the organisation can understand will definitely enhance performance improvement. For several decades, SD modelling has been used to more effectively understand the challenges that healthcare managers face (Harper, 2002; Harper \& Gamlin, 2003; Hirsch \& Miller, 1974; Homer \& Hirsch, 2006; Lane, Monefeldt, \& Rosenhead, 2000; Levin \& Roberts, 1976; Sundaramoorthi, Chen, Rosenberger, Kim, \& Buckley-Behan, 2010).

One of the success stories related to simulation modelling in healthcare settings is the redesign and implementation of patient service centres in Calgary, Canada (Rohleder,

\footnotetext{
${ }^{1}$ Tools that reveal patterns of behaviour in systems.
} 
Bischak, \& Baskin, 2007), in which a simulation model application was used to suggest ways to reduce demand variability and improve resource utilization in the city's laboratory services. More directly relevant to ID, in the Netherlands, a waiting list model was developed for residential services for adults with ID (Kommer, 2002). The model helped find the critical factors influencing waiting lists for services. The model became an "eye-opener" for local policymakers as it revealed clearly that older and aged adults with ID also need to be considered in residential provision. It was found that there was a greater demand by older aged adults with ID for more intensive care in comparison with that evidenced by younger aged adults with ID. After the Dutch Ministry of Health, Welfare, and Sports used the model in developing strategies to address the waiting list problem, there was a $34 \%$ smaller waitinglist (Kommer, 2002).

Another successful example of simulation modelling was nurse-to-patient assignment in a hospital in Texas, USA (Dumas, 1985). As the healthcare system in the United States has a shortage of nurses (noted to be about 12\% in 2010), it was important to optimize the nurse-to-patient assignments to avoid nurse burnouts. The research made a significant contribution to the scientific management of nurse-to-patient assignments. It was done by introducing a tool to evaluate different nurse-to-patient assignment policies with the goal to identify the one that was most optimal.

The World Health Organisation (de Savigny \& Adam, 2009) report on "Systems Thinking for Health Systems Strengthening" suggests that application of Systems Thinking does not necessarily mean that the challenges organisations come across will be easily solved without considerable changes in the nature of the organisations. However, it will help to identify where some serious challenges lie. SD modelling has been considered to be an appropriate method for improving healthcare systems and has been used in healthcare environments to explore policies for ongoing operations (Sundaramoorthi et al., 2009). As such, the approaches suggested can be used by senior managers of even more complex forms of healthcare provider organisations, like those designed to provide for adults with ID, as a tool to support resource allocation decision making.

\section{ID Services Provision}

\section{Complexity of ID provider organisations}

Healthcare providers are complex forms of provider organisations. However, there are specifics related to healthcare services for adults with ID that add to the complexity. It is well known that many adults with ID have certain limitations in communication and social skills and some have difficulties in caring for themselves. Thus, ID provider organisations should utilize a higher level of planning for resources, should have better trained staff, and should collaborate more both with families and with other stakeholders. The involvement of family members of adults with ID in the process of care is 
crucial. Moreover, the family members and carers of the adult are themselves considered as a high-risk group with a significant need for support (WHO, 2010).

Some challenges that healthcare organisations face are common in nearly all developed countries (Akcali, Coté, \& Lin, 2006; Carter, 2002; Harper \& Gamlin, 2003; Polder, Meerding, Bonneux,\&van derMaas, 2002; Smits\&van der Pijl, 1999;Vissers, 1998). In the Netherlands specifically, ID service providers are under pressure because of planned reforms and changes in society, politics, and consumer expectations. The combination of increased consumer demand and diminished resources is progressively a more urgent challenge for ID provider organisations that aim to improve the services they provide via delivering more person-focused care. One solution could be effective and efficient resource capacity planning. The approach can give managers more insight into their own decision-making processes and help them apply a new way of thinking through resource allocation problems.

\section{ID services in the Netherlands}

A large share of total healthcare costs in the Netherlands is taken up by healthcare for people with ID. Funding for ID services in the Netherlands is provided on the basis of the Exceptional Medical Expenses Act (Algemene Wet Bijzondere Ziektekosten (AWBZ)). Over the last decade, the expenditure on the AWBZ care has risen from just $€ 14$ billion in 2000 to over $€ 23$ billion in 2010. All parties participating in the AWBZ need to express the healthcare they supply in so-called indexed care packages (Zorg Zwaarte Pakket (ZZP) (severity of care packages)) that are combinations of different services and care functions. For long-term care, these ZZPs range from ZZP1 (sheltered living with some assistance) to ZZP8 (sheltered living with very intensive care) (ZZPs 9 and 10 concern rehabilitative care and palliative care, respectively) (Mot, 2010). To initiate funding, every request submitted to AWBZ funding must be assessed by an independent organisation, the Care Assessment Centre (Centrum Indicatiestelling Zorg or $\mathrm{CIZ}$ ). The Association for Care of the Disabled (Vereniging Gehandicaptenzorg Nederland (VGN)) is the umbrella Dutch association representing individual provider organisations that provide professional care and support to persons with mental, physical, sensory, and/or communication disabilities. The VGN encompasses some 173 member organisations providing care to about 110,000 clients and accounts for a budget of $€ 4,8$ billion.

Community-based services in the Netherlands have evolved as alternatives to institutional residential care, although the existing service structure remains dominated by institutional models (WHO, 2010). In 2010, more than 600,000 people in the Netherlands made use of long-term care ${ }^{2}$. However, it is projected that the prevalence of people with ID needing specialized long-term care in the Netherlands is going to

\footnotetext{
${ }^{2}$ Program letter concerning long-term care. Parliamentary document, Ministry of Health, Welfare and Sport, June 1, 2011.
} 
increase because of the growth in the number of older and aging adults with ID (Kommer, 2002). Thus, ID services provision in the Netherlands, as in many other countries, is confronted today with pressures associated with a growing demand for medically oriented care and services (because of such factors as a "greying" population) and by a growing emphasis on standards for quality of life (Smits \& van der Pijl, 1999).

Given that the costs of healthcare for people with ID as well as for those with mental disorders will inevitably increase (Jansen et al., 2004), there is currently a demand for the optimization of resource allocations - with the goal of reducing expenses and more effectively using the existing resources, while at the same time providing high-quality services. One of the solutions to this challenge can be a SD approach in analyzing healthcare systems, as suggested in the WHO report on health systems strengthening (de Savigny \& Adam, 2009). The WHO promotes Systems Thinking as a core approach to health systems analysis (de Savigny \& Adam, 2009).

\section{A Case Study on Underutilization of Resources}

\section{Background information}

According to the WHO European Ministerial Conference on Health Systems, particular attention should be given to improvement of the performance of health service delivery by making health systems more "patient-focused" (WHO, 2008). With this approach, it is important to keep the client in the centre of focus especially in ID services provision and to respect his or her wishes, concerns, values, and priorities. It is equally important to give a prompt response to the needs of adults with ID and to reduce waiting times for their seeing health practitioners. That is a challenging task for ID care providers facing diminished financial resources when they have to ensure optimal utilization of existing resources.

Given this, a study was conducted in one ID provider organisation in the Netherlands to determine how such outcomes could be best attained. This organisation provides AWBZ-funded care for about 1,591 persons in a number of discrete residential facilities. The services are provided through nine divisions that are geographically positioned in different provinces of the Netherlands. The complexity of the ID organisation evolved not only from the critical nature of the organisation's mission to deliver a full package of services (i.e., "full-service concept") but also by the diversity of services needed and geographic locales as well as the variety of stakeholders and employees. In order to manage the complexities and challenges arising from being a multi-location organisation operating in a dynamic environment, managers needed to analyze and understand the complex interdependencies among the systems with which they were dealing. Resource capacity planning was thus essential for this kind of organisation because ID services and supports are dynamic and not commodities that can be stocked and stored. 
The study was conducted within one of three divisions of the organisation that provided similar kinds of services in the areas of living, working, day care, leisure, treatment, and support. Specifically studied were the processes related to dealing with budget gaps when there was a shortage of clientele in one division of the organisation and when there was a surfeit of persons on waiting lists in other divisions of the organisation. We found that when a client applied to any division of the organisation with appropriate indication from $\mathrm{ClZ}$ that he or she required 24-h residential supports in that division, there may not have been free space at that moment. When this occurred, the intake team of that division put the client on a waiting list, even if there was an empty bed in a residence in one of the other divisions. This happened because the waiting lists were not shared among the organisation's divisions. We determined that one reason they did not share the waiting lists was because of the funds that the client brought to the division. To be able to obtain and retain the funds, the division could keep the client by putting him or her on a waiting list while providing alternative care services (e.g., home visits). However, if the client disagreed with the suggested alternative services and did not want to, or could not, wait some 3 months until there was a free space, then he or she would leave the division and, most of the time, the organisation (thus resulting in a loss of funds for the organisation). There are many competitors in the field and considering the fact that adults with ID are free to choose their provider organisation, it is critically important for ID providers to improve their services and to avoid putting clients on a waiting list for an extended period of timeespecially when there are residential spaces in other divisions. As there could be different scenarios for the organisation to use to overcome this challenge and to utilize resources more effectively, SD tools could help to model different "what-if scenarios" to see the outcome of a strategic decision before its actual implementation.

\section{Methodology}

To see how this organisation might employ strategic decision making in optimizing resource allocations, we used a case study approach. Such a case study approach has been defined as an empirical inquiry that "investigates a contemporary phenomenon within its real-life context when the boundaries between phenomenon and context are not clearly evident and in which multiple sources of evidence are used" (Yin, 1984; p. 13). SD methodology, the same as a case study research, uses qualitative data to develop quantitative simulation models. Data gathering techniques such as observations, interviews with clients and senior- and middle-level management of the organisation, focus groups, and archival records were used. Following a case study research guidelines, the most important sources of the information were the interviews (Yin, 1984). We translated the interview scripts into the SD language of feedback loops.

As the organisation's senior management indicated that resource sharing issues (particularly waiting list sharing) were of primary importance due to the scarcity of resources and increasing consumer demand, we started our research with the chal- 
lenge that concerns the managers the most. The logic of causal loops was revised in collaboration with the senior management of the organisation to ensure that the processes were clearly understood by the modeller. Following the causal loop design, we found patterns related to one of the generic archetypes, "shifting the burden." The archetype describes a situation when people take actions in response to the problem using quick fixes (Kim, 1999). The "shifting the burden" archetype helped to map the implications of the decisions made to solve the problem related to underutilization of resources. This approach helped decision makers identify additional data needed to provide a complete picture of the forces affecting the performance of the system they managed.

\section{Description of "shifting the burden" system archetype}

"Shifting the burden" is one of the generic SD's archetypes that demonstrate the tension between short-term (symptomatic) solutions to visible problems and the longterm impact of fundamental solutions that consider the pattern of behaviour (Kim, 1999; Senge, 1990). The archetype is composed of two balancing loops (B1 and B2) and a reinforcing loop ( $R$ ) (see Figure 1). As Figure 1 demonstrates, there are two options to solve the problem. The first and the quick one is application of a short-term fix to the symptom. The second option, application of a long-term fix to the fundamental issue, is more time consuming and is harder to implement (Kim, 1999).

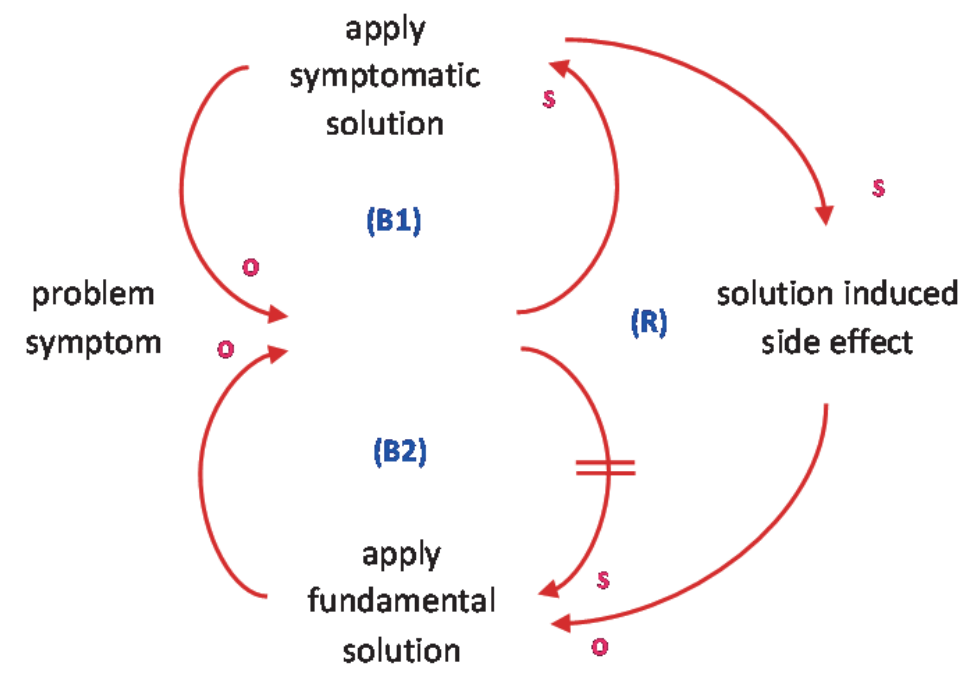

Figure 1. "Shifting the Burden" systems archetype.

Short-term solutions relieve the symptom only and do not fix the problem. Moreover, quick solutions lead to unintended consequences that make the situation even worse in the long run, because the underlying problem persists and so the problem will reap- 
pear over time. Decision makers do not anticipate solutions induced side effects as they act as if cause and effect are always closely connected in time and space (Sterman, 2000). Side effects worsen the situation in the long run, because symptomatic solutions reduce the tendency toward the fundamental solution and also they reinforce the perceived need for the symptomatic solution.

As Braun (2002; p. 4) noted, it "hypothesizes that once a symptomatic solution is used, it alleviates the problem symptom and reduces pressure to implement a fundamental solution, a side effect that undermines fundamental solutions." The long-term fix (fundamental solution) requires building new capacity. It takes time because of delay before its effects will be visible and requires deeper understanding of the underlying problem as well as more commitment and patience (Braun, 2002). Considering the pressure managers usually face, they prefer fixing problems as soon as possible and move on. So, they do not see the need for extensive efforts and resources to identify and solve the fundamental, systemic problem (Braun, 2002).

\section{Illustration of "underutilization of resources" problem via systems archetype}

The "shifting the burden" archetype in Figure 2 demonstrates the tension between fundamental and symptomatic solutions in relation to the issues that arise from not sharing the waiting lists between divisions. The problem symptom in this particular case is periodic shortage of clients, which means that the organisation has resources in terms of beds and workforce that are not used efficiently.

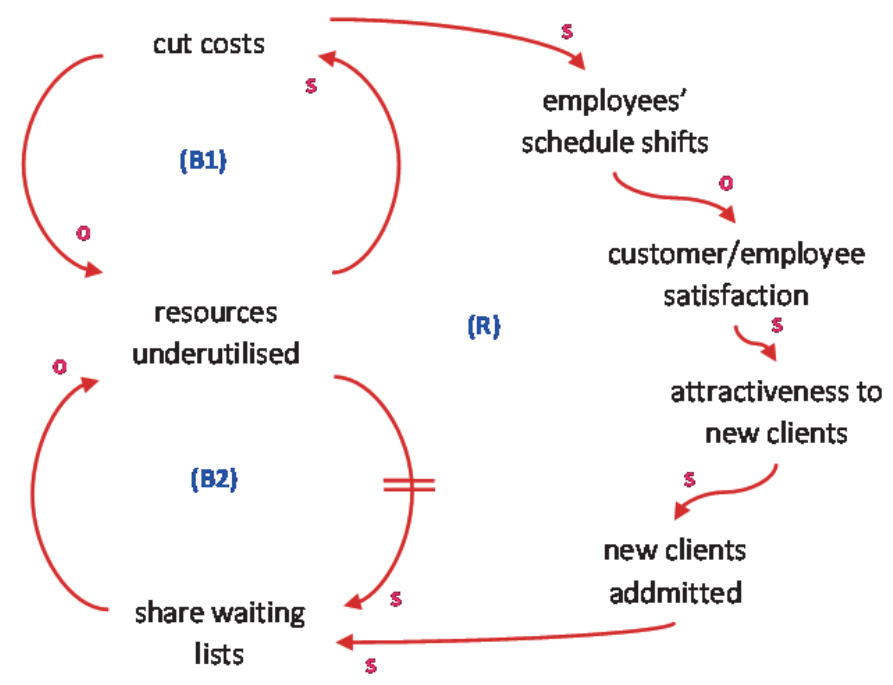

Figure 2. Causal-loop diagram of the case study

The shortage of clients leads to budget gaps, and the division must react as soon as possible in order not to incur significant losses of funds. 
The easiest and fastest (symptomatic) solution in this case is to cut costs (loop B1) via reduction of the workload of employees that have flexible contracts or via their temporal reallocation. Reduction of the workload leads to reduction of income, and employees have to look for part-time jobs in other places. The employee reallocation leads to changes in their schedules, which can cause client and employee dissatisfaction. Employees feel uncomfortable as they have to organize their lives around new schedules. In the long run, shifts in schedule and salary reduction may bring tension and may even cause employees to question their loyalty to organisation, which can cause increases in employee turnover. Clients may not be satisfied with the shifts as they get stressed because of the discontinuity in relation with care workers and frequent changes of people with whom they interact.

Adults with ID, especially those residing in congregate settings, "may develop emotional insecurity as a result of discontinuities in the care, as well as competition for limited amounts of personal attention" (Schuengel et al., 2010; p. 39). The research on personal attachment has shown that "an attachment figure may be especially important for people with intellectual disability, because they are less adept in dealing with stressful situations on their own" (De Schipper \& Schuengel, 2010; p. 585). Attachment behaviour may be "part of young persons' adaptation to the stresses and challenges of group care" (De Schipper \& Schuengel, 2010; p. 584).

In ID care situations, the care worker also serves as the point of contact between parents and the service system and plays an important role in the effectiveness of the delivery of services (WHO, 2010). Thus, the established relations between a care worker and the adult with ID are very important, and the negative impact of frequent shifts cannot be underestimated. Relations of trust between the care worker and the client become a very important indirect resource, especially in ID support situations. That intangible resource that reflects clients' feelings and expectations takes time to accumulate; however, it can be destroyed rapidly. Warren (2002; p. 120) noted that "damage to intangible resources has powerful effects on tangible factors." In this particular situation, it may affect the number of clients who apply for admission. The organisation may no longer seem attractive to new clients, which in turn can lead to a lower level of people seeking its services (i.e., admission). Reduction in client admissions reinforces the need for a fundamental solution while at the same time making it less feasible, thus less favourable and hence overdue.

If consideration is not given to the side effects of budget cuts and employee shift changes, any attempts to stabilize the system may destabilize it even more. The fundamental solution to this problem (loop B2) might be the sharing of information among the divisions about individuals on the waiting lists. The solution can be considered fundamental because it influences the problem's cause rather than the problem's symptom. If information about the clients who are on the waiting lists is shared among the divisions, the organisation as a whole will not lose the clients. Moreover, the division will be able to provide a client with quick information on potential accommoda- 
tions in other divisions. By doing this, the organisation will provide better customer services, especially in cases where there is an urgent need for residential care.

This fundamental solution can also bring about the need to share information on schedules of employees with flexible contracts, which will improve the organisation's flexibility to adapt better to changes caused by reduction in funding. As any other fundamental solution, this one will have time delays and will require changes in attitudes of the management. The decision makers have to see the problem not only from the perspectives of their divisions but also from the perspective of the whole organisation. In order to apply a fundamental solution, the heads of divisions should develop a vision of the organisation they want to build up because problem-solving attitudes will always push them to apply quick fixes.

There is a common outcome from the application of symptomatic solutions over time, which is "addiction" to the symptomatic solution and desire to see immediate results, even though they are short term and do not contribute to the vision of the organisation. There are clients who leave the divisions of the organisation as they do not feel comfortable with getting alternative services (home visits) instead of permanent residential care. By suggesting alternative services to patients, the division attracts additional funds to the organisation. Moreover, it helps to fill the budget gaps when there are empty beds. Thus the division tries to keep the clients by providing alternative services to avoid budget gaps in the future, and so it has no incentives in suggesting their clients apply to any other division of the organisation. As the division does not have empty beds at that moment, it does not incur losses but the organisation as a whole does.

\section{Discussion}

We all tend to look for causes near the events we want to understand. Moreover, we pay more attention to symptoms rather than the underlying causes of the problem (Sterman, 2000). However, in complex systems like organisations providing services to people with ID, cause and effect are distant in time and space. SD modelling helps determine the dynamics of a system through learning about feedback processes, time delays, and nonlinearities in the system.

SD modelling also takes into account the multiple perspectives of all the stakeholders involved. Thus, considering the fact that one of the major reasons for the ID provider organisations' complexity is having multiple stakeholders with conflicting objectives and goals, the SD approach can be quite feasible. The generic system archetypes with causal loop diagrams provided the language that helped explore thinking around complex situations in ID services, for instance, phenomena such as sharing of waiting lists. SD approaches can help develop the capacity to get a better understanding of the situation to an extent where, in collaboration with the relevant stakeholders 
(e.g., organisation's management, care workers, and persons with ID and their families), a strategy may be developed that will address the problem in a way to minimize the likelihood of unintended consequences.

SD modelling is considered to be appropriate for the case example described in this article as it also allowed considering the intangible resources that reflected clients' feelings and expectations. Those resources are of significant importance in ID services provision as they have powerful effects on tangible factors. The process of mapping the problem with the help of systems archetypes facilitated sharing of mental models of the management of the organisation. It also demonstrated that systems approaches may help ID care managers to simplify the process of their thinking about complex realities and to overcome the feeling of helplessness when confronted with complex problems. Systems archetypes facilitated understanding of the full range of feedbacks operating in the system. They helped to realize that the fundamental solution (i.e., sharing waiting lists) can help to minimize side effects caused by quick fixes.

To understand system behaviour over time, it is necessary to visualize the dynamics of system behaviour using real data. Available data can be used to quantify the model and observe real world systems via computer simulation. The simulated system model can be validated by initializing it at past points in time and comparing the results it produces with historical data. Afterward, it can be used to simulate various "what-if" scenarios before their actual implementation (Hirsch, 1979; Morecroft, 2007). 


\section{References}

van Ackere, A., Larsen, E., \& Morecroft, J. (1993). Systems Thinking and business process redesign. European Management Journal, 11, 412-423.

Akcali, E., Coté, M., \& Lin, C. (2006). A network flow approach to optimizing hospital bed capacity decisions. Health Care Management Science, 9, 391-404.

Braun, W. (2002). The systems archetypes. Retrieved from http://wwwu.uni-klu.ac.at/gossimit/pap/sd/wb_sysarch.pdf

Carter, M. (2002). Diagnosis: Mismanagement of resources. ORMS Today, 29, 26-32.

Checkland, P. (1981). Systems Thinking, systems practice. Chichester, UK: John Wiley \& Sons Ltd.

Davenport, T. H. (2009).Make better decisions. Harvard Business Review, 87, 77-87.

Drucker, P. (1993). The new realities. New York: Harper \& Row.

Dumas, B. (1985). Hospital bed utilization: An implemented simulation approach to adjusting and maintaining appropriate levels. Health Services Research, 20, 43-61.

Forrester, J. (1961). Industrial dynamics. Cambridge, MA: MIT Press.

Forrester, J. W. (1980). Information Sources for Modelling the National Economy. Journal of the American Statistical Association, 75, 555-566.

Haines, S. (2007). Strategic and Systems Thinking: The winning formula.

San Diego, CA: Systems Thinking Press.

Harper, P. (2002). A framework for operational modelling of hospital resources. Health Care Management Science, 5, 165-173.

Harper, P., \& Gamlin, H. (2003). Reduced outpatient waiting times with improved appointment scheduling: A simulation modelling approach. OR Spectrum, 25, 207-222.

Hirsch, G.,\&Miller, S. (1974). Evaluating HMO policies with a computer simulation model. Medical Care, 12, 668-671.

Hirsch, G. (1979). System Dynamics modelling in health care. ACM SIGSIM Simulation Digest, 10, 38-43.

Homer, J., \& Hirsch, G. (2006). System dynamics modelling for public health: Background and opportunities. American Journal of Public Health, 96, 452-458.

Jackson, M. (2009). Fifty years of Systems Thinking for management. The Journal of the Operational Research Society, 60, 24-32.

Jansen, D., Krol, B., Groothoff, J., \& Post, D. (2004). People with intellectual disability and their health problems: A review of comparative studies. Journal of Intellectual Disability Research, 48, 93-102.

Kim, D. (1999). Shifting the burden: Moving beyond a reactive orientation. The Systems Thinker, 10, 5-6.

Kommer, G. J. (2002). A waiting list model for residential care for the mentally disabled in the Netherlands. Health Care Management Science, 5, 285-290.

Lane, D., Monefeldt, C., \& Rosenhead, J. (2000). Looking in the wrong place for healthcare improvements: A system dynamics study of an accident and emergency department. The Journal of the Operational Research Society, 51, 518-531.

Levin, G., \& Roberts, E. (1976). The dynamics of human service delivery. Cambridge, MA: Ballinger Pub.

Van Merode, G., Groothuis, S., Schoenmakers, M., \& Boersma, H. (2002). Simulation studies and the alignment of interests. Health Care Management Science, 5, 97-102.

Morecroft, J. (2007). Strategicmodelling and business dynamics: A feedback systems approach. Chichester, UK: John Wiley \& Sons.

Mot, E. (2010). The Dutch system of long-term care. CPB Netherlands Bureau for Economic Policy Analysis. Hague, the Netherlands. Retrieved from http://www.cpb.nl/en/publication/dutch-systemlong-termcare

Plsek, P., \& Wilson, T. (2001). Complexity science: Complexity, leadership, and management in healthcare organisations. British Medical Journal, 323, 746-749.

Polder, J.,Meerding,W., Bonneux, L., \& van der Maas, P. (2002). Healthcare costs of intellectual disability in the Netherlands: A cost-of-illness perspective. Journal of Intellectual Disability Research, 46, 168-178. 
Reynolds, M., \& Holwell, S. (2010). Systems approaches to managingchange: A practical guide. London: Springer.

Richmond, B. (1994, July). System dynamics/systems thinking: Let's just get on with it. Paper presented at the $12^{\text {th }}$ International Conference of the Systems Dynamics Society, Stirling, Scotland.

Rohleder, T., Bischak, D., \& Baskin, L. (2007). Modelling patient service centres with simulation and system dynamics. Health Care Management Science, 10, 1-12.

De Savigny, D., \& Adam, T. (2009). Systems Thinking for health systems strengthening. Geneva: WHO.

De Schipper, J. C., \& Schuengel, C. (2010). Attachment behaviour towards support staff in young people with intellectual disabilities: associations with challenging behaviour. Journal of Intellectual Disability Research, 54, 584-596.

Schuengel, C., Kef, S., Damen, S., \& Worm, M. (2010). People who need people: Attachment and professional caregiving. Journal of Intellectual Disability Research, 54, 38-47.

Senge, P. (1990). The fifth discipline: The art and practice of the learning organisation. New York: Bantam Doubleday, Dell Publishing Group, Inc.

Smits, M., \& van der Pijl, G. (1999, January). Developments in hospital management and information systems. Paper presented at the 32th Hawaii International Conference on System Sciences, Maui, Hawaii.

Sterman, J. (2000). Business dynamics: Systems Thinking and modelling for a complex world. New York: McGraw-Hill.

Sundaramoorthi, D., Chen, V., Rosenberger, J., Kim, S. B., \& Buckley-Behan, D. (2009). A data-integrated simulation model to evaluate nurse-patient assignments. Health Care Management Science, 12, 252268.

Sundaramoorthi, D., Chen, V., Rosenberger, J., Kim, S. B., \& Buckley-Behan, D. (2010). A data-integrated simulation-based optimization for assigning nurses to patient admissions. Health Care Management Science, 13, 210-221.

Trochim, W., Cabrera, D., Milstein, B., Gallagher, R., \& Leischow, S. (2006). Practical challenges of systems thinking and modelling in public health. American Journal of Public Health, 96, 538-546.

Vissers, J. (1998). Patient flow-based allocation of inpatient resources: A case study. European Journal of Operational Research, 105, 356-370.

Warren, K. (2002). Competitive strategy dynamics. New York: John Wiley \& Sons.

WHO. (2008). European ministerial conference on health systems: Health systems, health and wealth. Retrieved from http://www.euro.who.int/_data/assets/pdf_file/0006/78918/E92150.pdf

WHO. (2010). Better health, better lives: Children and young people with intellectual disabilities and their families. Retrieved from http://www.euro.who.int/_data/assets/pdf_file/0003/126570/e94430.pdf

Wolstenholme, E. (2004). Using generic system archetypes to support thinking and modelling. System Dynamics Review, 20, 341-356.

Yin, R. K. (1984). Case study research: Design and methods. Beverly Hills, CA: SAGE Publications, Inc. 



\section{CHAPTER 3}

\section{Reflecting on the Efficacy of Cognitive Mapping for Decision Making in Intellectual Disability Care: A Case Study}

Duryan, M., Nikolik, D., van Merode, G., Curfs, L. M. G. (2013). Reflecting on the Efficacy of Cognitive Mapping for Decision Making in Intellectual Disability Care: A Case Study. International Journal of Health Planning and Management: Epub ahead of print (http://onlinelibrary.wiley.com/doi/10.1002/hpm.2215/abstract) 


\begin{abstract}
The central aspect of this study is a set of reflections on the efficacy of soft operational research techniques in understanding the dynamics of a complex system such as intellectual disability (ID) care providers. Organisations providing services to ID patients are complex and have many interacting stakeholders with often different and competing interests. Understanding the causes for failures in complex systems is crucial for appreciating the multiple perspectives of the key stakeholders of the system. Knowing the factors that adversely affect delivery of a patient-centred care by ID provider organisations offers the potential for identifying more effective resource allocation solutions. The authors suggest cognitive mapping as a starting point for system dynamics modelling of optimal resource-allocation projects in ID care. The application of the method is illustrated via a case study in one of the ID care providers in the Netherlands. The paper discusses some of the practical implications of applying problemstructuring methods that support gathering feedback from vulnerable service users and frontline workers. The authors concluded that cognitive mapping technique can assist the management of healthcare organisations in strategic decision making.
\end{abstract}




\section{Introduction}

Complexity of healthcare systems is widely acknowledged (Morrison, 2000; World Health Organisation, 2009). It is reflected by the number of stakeholders involved: customers, professionals, provider organisations, insurers and suppliers (Begun et al., 2002). Taking into account that the relationships among stakeholders are nonlinear and discontinuous, even small changes in variables can have significant impact on the whole system.

Intellectual disability (ID) care providers can serve as an example of complex healthcare service organisations. What adds to their complexity is that the specifics of care require deeper involvement of caretakers in their relations with the patients' families and other parts of society (Duryan et al., 2012).

Since the introduction of various forms of patient-centred planning in the late 1980s, ID care providers are obliged to provide services to persons with IDs on the basis of some form of patient-centred planning (Vlaskamp and van der Putten, 2009). In order to deliver patient-centred care, ID organisations are challenged not only to give a prompt response to the patients' needs related to their physical health but also to be sensitive towards their and their families' wishes, concerns, values and priorities.

Uncertainty of resource availability is another challenge for ID organisations. Considering the increasing cost of long-term residential care because of continuously growing patient population, the Dutch government faces a pressing demand for efficiency in the management of ID care providers (Jansen et al., 2006).

The main reason for managements' failure in finding a solution to the problem in their organisations often lies in getting the wrong solution to the right problem rather than in solving the wrong problem (Ackoff, 1974). Managers' knowledge about their organisation is often incomplete and is based on assumptions about the different parts of a real system. They try to combine those parts of knowledge in order to understand how things change and what will be the consequence of a proposed action (Forrester, 1994). At the end, many solutions that seem to be obvious can cause even more damage to the system.

Survival of the organisation depends on satisfying the key stakeholders according to their definition of what is valuable (Moore, 1995). Because of their complexity, ID care organisations need a higher level of resource planning, collaboration and cooperation among all the stakeholders (Jansen et al., 2006; World Health Organisation, 2010).

As different stakeholders have varying perspectives on value-creating processes and their outcomes, understanding their individual perceptions is important for the success of operational research (OR) intervention (Ackermann et al., 1992). It is also important to gain shared understanding among stakeholders related to the challenges the organisation is facing. Without consensus among all the stakeholders, policy 
changes often bring short-term gains at the expense of longer-term outcomes (Ghaffarzadegan et al., 2011).

The authors claim that application of cognitive mapping techniques suggested by strategic options development and analysis (SODA), structuring method of soft OR could assist the management of healthcare organisations to include the key stakeholders in strategic decision-making.

Strategic options development and analysis uses cognitive mapping as a technique useful for dealing with 'messy' problems (Ackermann et al., 1992). The rationale behind cognitive maps is that people make sense of the world through a 'construct system'. Cognitive mapping techniques have been used to analyse subjective perspectives in case studies (Eden and Spender, 1998). The technique allows revealing multiple conflicting individual views and assists in reducing the level of conflict during subsequent discussions (Ackermann and Eden, 1994).

The case study described in this article was conducted in one of the divisions of an ID care provider in the Netherlands. In-depth semi-structured interviews with the key stakeholders of the ID provider, family members of the patients and group leaders/personal coaches were conducted with the help of the cognitive maps that allowed structured representation of their ideas.

The maps proved to be an effective way of capturing the main problem areas. They offered the possibility to the families of the patients and the group leaders to exchange views in a structured manner. This helped them develop a more comprehensive view of the organisation. The maps also clarified the issues from the perspectives of the senior management, which allowed the interviewees to provide constructive feedback.

The main conclusion of the case study is that cognitive mapping promoted shared understanding among the key stakeholders and enhanced their participation by improving the quality of their input.

\section{The methodology}

In this case study, we deal with multiple perspectives and bounded rationality, and that is why it is very important to have the tools that can help fully represent all the perspectives and views. Soft interpretive OR approaches and techniques recognize the importance of human perceptions, interpretations and worldviews while dealing with subjectivity and uncertainty (Rosenhead and Mingers, 2001). For this study, the authors apply one of the problem-structuring methods of soft OR, the SODA developed by Colin Eden in the late 1980s. Decision Explorer software (http://www.banxia.com, Banxia Software Ltd., Registered in England) was used for the analysis of cognitive maps. The challenges these organisations face involve interconnected sets of variables, and the relationships between those variables can be more important than the nature of the variables themselves (Jackson, 2002). 
Systems Thinking is a theory addressing the interrelationships between variables and their connections to a whole system. The theory can be viewed as a reaction to failure of traditional approaches when confronted with complex problems in social systems (Checkland, 1981). There are a number of approaches that apply Systems Thinking to a better understanding and improvement of systems. Those approaches have been categorized by Checkland (1981) as 'hard systems' and 'soft systems'. Soft OR can be characterised as just Systems Thinking and hard OR as analytical Systems Thinking (Checkland, 1981, 1985). As a general rule, the hard OR (operational research, system engineering and structural system analysis) is suitable in dealing with well-defined problems. The soft systems approach is a learning process designed to determine what needs to be done in ill-defined problem situations (Checkland, 1981). The advantage of 'soft' Systems Thinking is that it helps obtain a comprehensive view of problem situations and, according to Checkland (1985, p. 765), "keeps in touch with the human content of problem situations'. The method is suited for dealing with complex problems considering their qualitative and quantitative aspects (Wolstenholme, 1995). SODA gives equal importance to the process of discussion with stakeholders and to its context. It allows concentrating on participant's interpretation of events rather than the perception of an objective reality.

The grounding theory of SODA arises from cognitive psychology and the theory of personal constructs by Kelly (Wolstenholme, 1995). Personal construct theory proposes that people make sense of their world by seeking to manage and control the conditions and environment around them. One of the aspects of Kelly's theory is that 'we make sense of situations through similarities and differences' (Eden, 2004, p. 674). The concepts identified with the help of SODA are bipolar (Eden, 2004). According to Kelly, bipolar constructs are the only way to understand the meaning of something. One of the advantages of applying the cognitive mapping technique is that it allows having two contrasting poles per statement. Bipolar concepts give us more information about what an interviewee really thinks about a particular issue.

In OR, a cognitive map is a two-dimensional directed graph that represents the issue from the perspectives of an interviewee (Eden and Ackermann, 2001). These maps have been widely used to represent subjective knowledge about perceived causes and effects and the perceived links between them (Eden, 1992). Cognitive mapping is designed to support decision makers in dealing with the complexity inherent in many organisational problem findings. They provide a comprehensive picture of an individual's perspective and at the same time keeping all the details. They represent those beliefs that are mentioned as the most important by the stakeholders. Cognitive maps help structuring gathered information in a way that demonstrates whether the concepts are relevant (Eden et al., 1983). Moreover, they facilitate transparency by 'allowing checking of the analytical basis of conclusions developed by a researcher or interventionist' (Eden, 1992, p. 262). 
The SODA methodology has been well documented and includes guidelines on the cognitive mapping process (Eden, 1990; Ackermann et al., 1992; Eden and Ackermann, 2001). The main approach for data collection consists of the administration of personal semi-structured interviews (Eden, 1990). The interviews are mapped to identify clusters of similar or related concepts. The concepts in the nodes of the map are expressed in the interviewees' own language. The meaning of every concept is contextual.

There are rules described in cognitive mapping guidelines that restrict each concept to 8-10 words. The links between the nodes represent logical implications between the concepts that are structured into a hierarchy that demonstrates the cause and effect between them. The individual cognitive maps are merged into a bigger one with the goal of observing a comprehensive definition of the problem. The merged map represents the richness of different perspectives of the problem and also secures agreement about its nature among the interviewees. The main reason for choosing SODA is that it helps avoid the traps of reductionism and dogmatism during the research process (Ackermann and Eden, 2010). The method allows multiple conflicting individual views to be revealed and reduces the level of conflict during subsequent discussions (Ackermann and Eden, 1994). Intellectual disability care stakeholders have different perceptions on how various factors interact. SODA can help during the knowledge acquisition processes. Cognitive mapping technique allows various ideas to be organized in a structured way, and it also supports the evaluation of alternative ideas. As such, the suggested approach can be used by the senior management of healthcare organisations, such as ID care providers, as a tool to support strategic decision-making.

\section{Intellectual disability care in the Netherlands}

In the Netherlands, ID care costs are highest among other healthcare costs comprising $10.3 \%$ of the total costs of healthcare nationally (Jansen et al., 2006; Van der Kwartel, 2009). The care for people with disabilities (intellectual disabilities, physical disabilities and sensory disabilities) is provided and funded through the Exceptional Medical Expenses Act (AWBZ), which also covers the nursing and care sector and mental healthcare services. Almost 150000 people in the Netherlands were entitled to AWBZfunded care on the basis of their ID (Ras et al., 2010). The expenditure for the disabilities sector totalled around $€ 4.7 \mathrm{bn}$, roughly a quarter of the total AWBZ-funded expenditure (Van der Kwartel, 2009; Ras et al., 2010).

There are 135 large institutions that offer 24-h residential care for intellectually disabled people in the Netherlands (Schoonheim, 2009). Long-term residential care for people with ID is expensive, and, in accordance with demographic projections, it will increase with annual growth rate of about $0.4 \%$ (Polder et al., 2002). Adding to this increasing demand for the use of ID services and spending cuts in the ID care sector, ID 
service organisations face increasingly more urgent challenge to deliver patientcentred care.

The modern healthcare claims that it is 'patient-centred'. In the National Healthcare Quality and Disparities Reports (2011), patient-centredness is defined as healthcare that establishes a partnership among practitioners, patients and their families, with the common goal of ensuring that all patients get support to participate in decisions related to their care. The Institute of Medicine identifies patient-centred care as one of the essential elements of high-quality care. However, often, patient-centred planning is mainly a paper exercise (Mansell and Beadle-Brown, 2004). Unfortunately, many patients are still struggling for their share of involvement in their care (World Health Organisation, 2009).

In order to deliver patient-centred care, the managers need to analyse and understand complex interdependencies among the elements of systems they are dealing with (Duryan et al., 2012). One solution could be a better resource capacity planning with close collaboration of all parties: patients and their families, other carers, primary healthcare professionals and specialist services (Jansen et al., 2006). For this paper, the system under scrutiny is one of the divisions of an ID care provider in the Netherlands.

\section{The case study in one of the intellectual disability care providers in the Netherlands}

The complexity of the ID care provided evolved not only from the critical nature of its mission to deliver a patient-centred care but also from the diversity of services needed and geographic locales as well as the variety of stakeholders. In addition to that, like any other ID care provider in the Netherlands, the organisation is faced with increasing demand for its services with limited resources available. Taking into account uncertainty of resources and the fact that ID care and treatment is not a commodity that can be stocked, resource capacity planning for ID providers is vital.

There are three divisions in the organisation that offer 24-h residential care for patients with multiple disabilities. The study was conducted in one of those divisions. While studying resource-allocation procedures in the division, the difficulty was to develop a systematic understanding of how factors influence each other.

One way was to focus on the detailed procedures related to patient care.

We started the study with the challenge that concerns the managers the most (Duryan et al., 2012). The interviews with senior management of the division indicated that interdivisional resource-sharing issues were of primary importance because of the scarcity of resources and increasing consumer demand. The interviews demonstrated that when there are budget gaps in the division due to the lack of the patients with severe disabilities (as they have bigger budget for care), the management cuts costs. The easiest way for them to do so is to reduce working hours of the front-line staff, the group leaders, with flexible contracts. Cutting costs via the reduction of working hours leads to shifts in the schedules of the group leaders. It also leads to the reduction of 
their income, which forces them to search for additional work elsewhere. In the long run, shifts in the schedules and salary reduction create tension and can compromise the employees' loyalty, which can then lead to an increase in employee turnover.

The majority of ID patients are totally dependent on personal assistance for their daily activities, education and recreation, because of the severity of their disabilities (Vlaskamp and van der Putten, 2009). At the same time, despite the severity of their disabilities, ID patients are capable of building and maintaining meaningful relationships that serve as a very important tool for them to express their needs and desires (Vlaskamp and van der Putten, 2009). Thus, relations of trust between the group leaders and the patients become a valuable indirect resource (Duryan et al., 2012). This intangible resource takes time to accumulate; however, it can be destroyed rapidly. Thus, shifts in employee schedules directly affect the patients because, especially in ID care, the care worker serves as the point of contact between the parents and the service system and plays the key role in the effectiveness of the service delivery (World Health Organisation, 2010).

The patients may not be satisfied with the shifts as well. They get stressed because of discontinuity in relations with the group leaders and frequent changes of people with whom they interact. The established relations between a care worker and the adult with ID are very important. This intangible resource that reflects the patients' feelings and expectations takes time to accumulate. Thus, the negative impact of frequent shifts cannot be underestimated. However, the delays in feedback of the system to managerial decisions do not allow them to see the immediate impact of their actions. Inefficient allocation of resources, especially considering their insufficiency and the fluctuations in the demand for services, may lead to a loss of capacity (Vissers et al., 2001). However, as it is not always possible to see the explicit connection between the cause and effect, the managers of an ID care provider keep applying symptomatic solutions that eventually throw the system out of balance. In complex systems, 'many actions yield irreversible consequences' (Sterman, 1994, p. 298).

The directors solve the problems from the perspectives of financial well-being of their divisions. However, the decision makers need to see the problems from the perspectives of the organisation as a whole. In order to apply a fundamental solution, they must develop a vision of the organisation they want to build up. Otherwise, the problem-solving attitude will push them to apply quick fixes.

Application of poorly drafted policies worsens the situation, which, in turn, leads to a need for more vigorous application of the policies (Forrester, 1980). The management of the division does not have well-established procedures that can enable consideration of soft variables (e.g. customer/employee satisfaction, employee burnout, stress and so on) during the decision-making process. However, soft variables have a big impact on the long-term performance of the organisation. In this case, decline in patient satisfaction may lead to financial losses and also may affect the image of the 
organisation. The organisation may no longer seem attractive for new customers. This can lead to a decrease in the number of people seeking its services.

The next step described in this paper was communicating the vision of the senior management to the key stakeholders of the organisation. The goal was to get to know how they perceive the challenges the organisation faces and subsequent improvement needed in order to deliver a patient-centred care in practice.

\section{The research model for the case study}

As the organisation's senior management indicated, because of the scarcity of resources and increasing consumer demand, resource-sharing issues (particularly waiting list sharing among the divisions) is of primary importance, we started our case study with analysing that problem situation (Duryan et al., 2012).

The following stage involved learning about the perspectives of the family members of ID patients and the group leaders. Both groups represent the key stakeholders of an ID care provider. The first group, the families as representatives of the patients, are the receivers of care. The second group of key stakeholders are those at the 'sharp end' of the system, because they deal with the patients on a daily basis. The ability of the group leaders to provide help to an ID patient has a strong influence on the patients' satisfaction with the services.

Following the SODA project guidelines (Eden and Ackermann, 2001), we conducted individual semi-structured interviews with eight group leaders working in the division. They were interviewed in a one-to-one environment (saturation of the information was achieved after the seventh interview). The following aspects were covered during the interviews:

- the impact of not sharing resources among divisions,

- the pros and cons of flexible versus fixed contracts for the group leaders,

- the organisation of the group leaders' work,

- the main reasons for the group leaders' dissatisfaction,

- the main reasons for the patients'/families' dissatisfaction and

- things to improve to be able to deliver a patient-centred care.

Each interview lasted about $1 \mathrm{~h}$ and was recorded. The interviews were transcribed and translated into cognitive maps by the facilitator with the help of Decision Explorer software. The following step involved checking individual cognitive maps with the interviewees in order to test and refine them. In all cases, there was no need to delete any construct. The second meeting with the group leaders helped obtain a deeper understanding of their views around the key ideas.

The individual maps were merged into a single map reflecting all the individual views (Figure 1; the heads of the maps are in red, and the potent options are in blue). 
The merged map allowed seeing contrasting opinions in context. It was reviewed and explored with the group leaders during group discussions conducted in small teams. The key options and assumptions were discussed and verified, also the redundancy was eliminated.

In order to learn about the ideas of the family members, two separate focus groups were conducted with the representatives of young and old ID patients because patients of different ages have different needs for treatment and leisure.

The first focus group was conducted with the family members of older ID patients (three families). The issues perceived by the senior management of the division and also the main highlights from the interviews with the group leaders were communicated to them.

Upon getting the feedback, the interviewees have been asked to share their ideas on how services can be improved. After the focus group, the cognitive map was designed. During the focus group with the families of young ID patients (four families), the ideas of families of older patients were communicated as well. The maps designed of the two focus groups were almost identical. Thus, the second focus group verified the ideas represented by the first focus group. Both maps with the feedback of younger and older patients' families were refined and merged (Figure 2). The analysis of both merged maps was conducted using the qualitative indicators provided by Decision Explorer software.

\section{Map analysis}

The objective of the analysis of the maps was to highlight the most important fields of concern from the perspectives of the key stakeholders. A comparison of the merged maps representing the perspectives of the group leaders (GL; Figure 1) and the families of the patients (Figure 2) should help identify the expectations of the two groups of the key stakeholders and their contrasting views. Furthermore, the purpose of the analysis of the maps was to establish whether or not the stakeholders agree with the senior management perceptions of the main strategic directions in solving the challenges. The maps were analysed with the help of Decision Explorer software (Brightman, 2002). Of the various analytic tools that were available, the most valuable ones for this case study were head, centrality, domain, hierarchical cluster, potency and cotail analyses (Ackermann and Eden, 2010). 


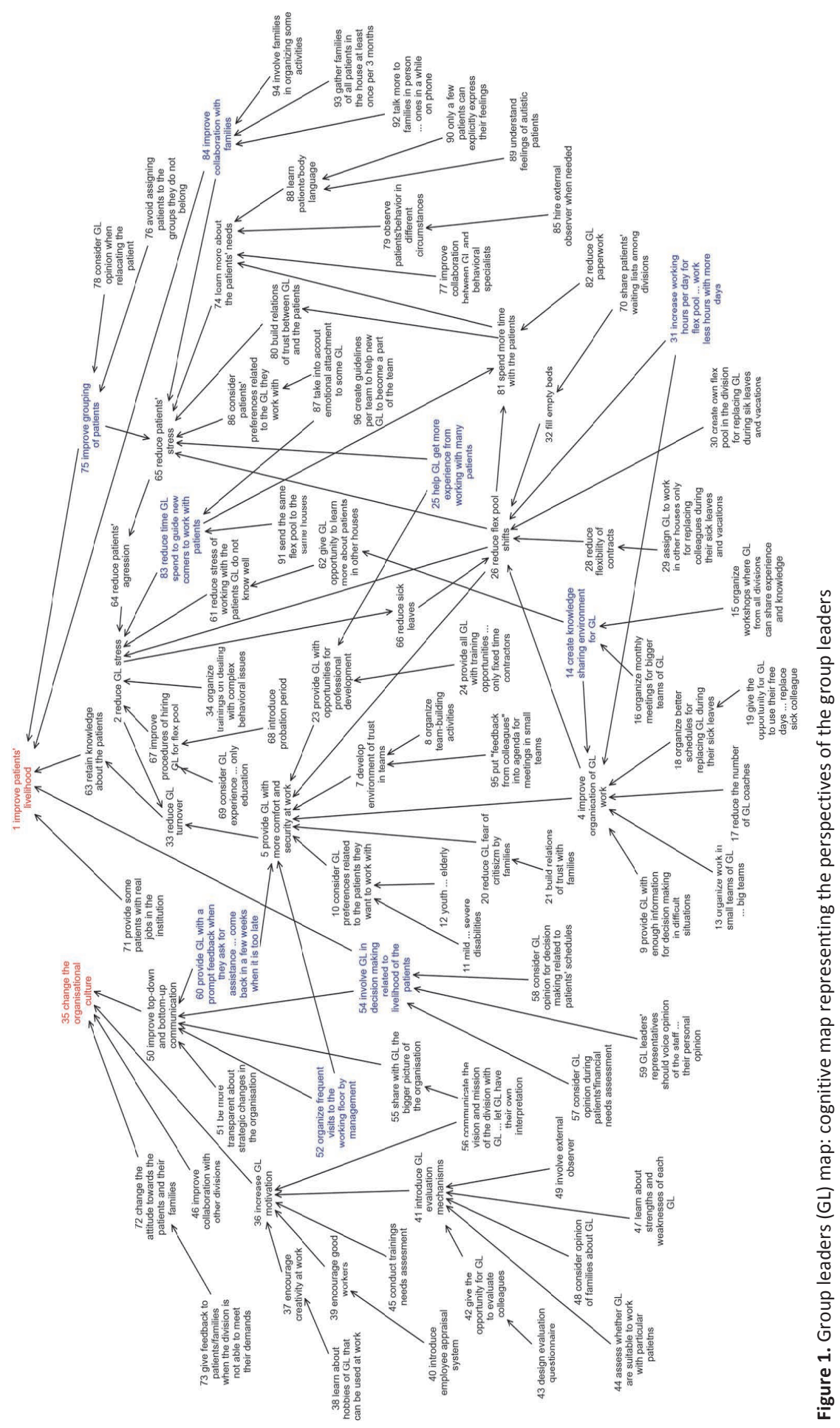




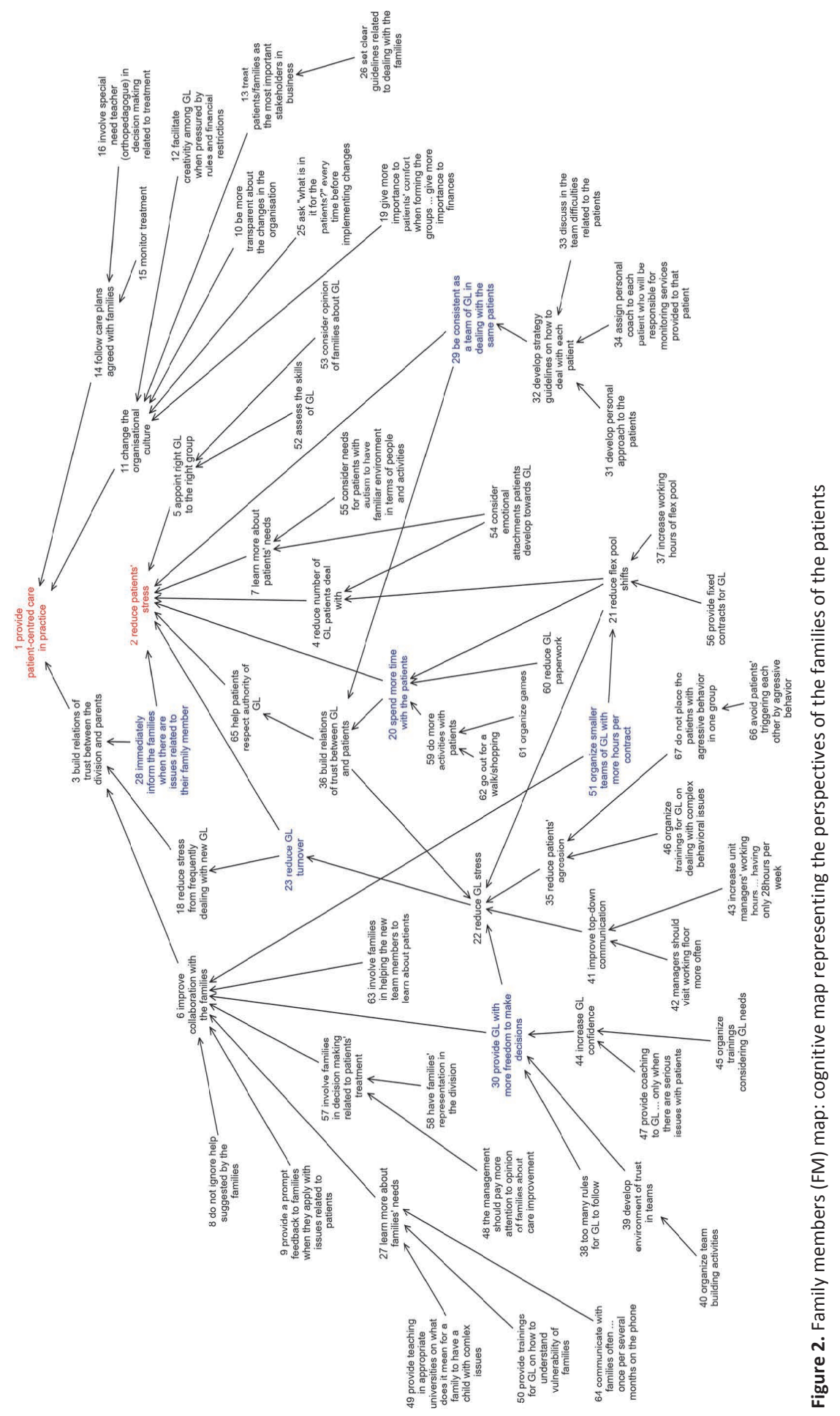




\section{Identifying goals}

Head analysis was conducted to identify goals and their interactions. The heads of a map are the concepts represented by the nodes that have only arrows going inside (no arrows go outside). They are the goals expressed in terms of final ends or effects. As a result of the analysis, the concepts ' 1 provide patient-centred care in practice' and ' 2 reduce patients' stress' were defined as the goals of the family members (FM) map (Figure 2). The concepts ' 1 improve patients' livelihood' and ' 35 change the organisational culture' were defined as the goals by the group leaders (Figure 1).

\section{Identifying key issues}

Domain and centrality analyses were used to identify the key issues in the models. Density of the direct links around the concepts helps in identifying best elaborated ones. The nodes with complex domain (high density) are considered to be the potential key issues from the perspectives of the interviewees (Eden, 2004). They can become the subjects for further examination. The top five concepts for GL and FM maps are presented in Table 1 in descending order of value. By analysing only the immediate domain of the concept by itself, we do not consider its wider context; hence, we also conducted centrality analysis. Centrality analysis extends the domain analysis by considering both, direct and indirect links. It reflects the downstream effect and allows a more accurate view of key issues than domain analysis (Ackermann and Eden, 2010). Centrality analysis measures the complexity of the concept's implication chain, considering that the greater the complexity, the more central is the concept (Eden et al., 1992). Concepts with the highest centrality scores usually strengthen the ideas expressed by concepts with the highest domain score. Most concepts that were characterized by the highest domain score also have the highest centrality score. Concepts with the top five highest centrality scores in both maps have been reported in Table 2 . If a concept appears in both analyses, it means that it is both 'locally and globally significant, confirming its position at the core of a potential key issue' (Ackermann and Eden, 1998, p. 405). Domain and centrality analyses of the FM map (Figure 2) found concepts 2, 6, 21 and 22 to be the potential key issues, but concept 2 is the goal of the model. Thus, the potential key issues are concepts 6,21 and 22 .

Table 1. Domain analysis (FM, family members; GL, group leaders.)

\begin{tabular}{|c|c|c|}
\hline & FM & $\mathrm{GL}$ \\
\hline 1. & 2 reduce patients' stress ( 8 links around) & 26 reduce flex pool shifts (10 links around) \\
\hline 2. & $\begin{array}{l}6 \text { improve collaboration with the families ( } 8 \\
\text { links around) }\end{array}$ & $\begin{array}{l}5 \text { provide GL with more comfort and security at work } \\
\text { ( } 9 \text { links around) }\end{array}$ \\
\hline 3. & $\begin{array}{l}11 \text { change the organisational culture ( } 6 \text { links } \\
\text { around) }\end{array}$ & 2 reduce GL stress (9 links around) \\
\hline 4. & 21 reduce flex pool shifts (6 links around) & 4 improve organisation of GL work \\
\hline 5. & 22 reduce $\mathrm{GL}$ stress (6 links around) & 65 reduce patients' stress \\
\hline
\end{tabular}


Table 2. Centrality analysis (FM, family members; GL, group leaders.)

\begin{tabular}{lll}
\hline & FM & GL \\
\hline 1. & 22 reduce GL stress (19 from 40 concepts) & 26 reduce flex pool shifts (31 from 62 concepts) \\
2. & $\begin{array}{l}30 \text { provide GL with more freedom to make } \\
\text { decisions (18 from } 39 \text { concepts) }\end{array}$ & $\begin{array}{l}5 \text { provide GL with more comfort and security at work } \\
\text { (27 from } 53 \text { concepts) }\end{array}$ \\
3. & 21 reduce flex pool shifts (18 from 37 concepts) & 65 reduce patients' stress (26 from 53 concepts) \\
4. & 6 improve collaboration with the families (18 & 4 improve organisation of GL work (24 from 48 \\
& from 35 concepts) & concepts) \\
5. & 2 reduce patients' stress (18 from 33 concepts) & 2 reduce GL stress (22 from 43 concepts) \\
\hline
\end{tabular}

Domain and centrality analyses of the GL map (Figure 1) demonstrated the same results, meaning that concepts 2, 4, 5, 26 and 65 have the biggest number of both direct and indirect links, and so they are potential key issues. Concept 4 has the fourth centrality score; however, it directly affects two other nodes (26 and 5) with higher centrality scores. Thus, the key issues for the GL map are concepts 2, 5, 26 and 65.

\section{Identifying potent options}

The hierarchical cluster analysis (hieset) suggested by the Decision Explorer software involves the identification of all the concepts in a map, which contributes to the achievement of a goal (Ackermann and Eden, 1998, 2010; Eden, 2004). The analysis takes the key issue specified by the modeller and drills down all the chains of argument impacting the key statement. The number of concepts constituting each hieset is indicative of the importance of a goal in an individual's cognition; and therefore, large hiesets reveal the most valued outcomes.

Hieset analysis allows a concept to appear in more than one cluster. That is why it is important to pay attention to the overlap between the sets. The more hierarchical is the set where the concept is present, the greater its potential influence on the goals. Hieset analysis should be focused around the concepts that are central in linkage terms and those concepts that are at the top of the hierarchy in order to ensure that all the nodes in the map are considered in the analysis (Eden et al., 1992).

Five individual hiesets for the FM map (concepts 1, 2, 6, 21 and 22) and six individual hiesets for the GL map (concepts 1, 2, 5, 26, 35 and 65) were defined for the key potential issues with the help of head, domain and centrality analyses. After the hieset test, a potency analysis on the sets was produced.

Potency analysis allows prioritizing options that have consequences for the bigger number of key issues (Eden, 2004; Ackermann and Eden, 1998, 2010). It builds on the results of hieset analysis. Potency analysis is based on the assumption that the more goals a concept supports, the more potent it is. The concepts that appear in more than one hieset were listed for each map (Table 3).

In order to refine the results of potency analysis, cotail analysis was conducted. 
Table 3. Potency analysis (FM, family members; GL, group leaders.)

FM $\mathrm{GL}$

\section{2 hiesets}

1. 20 spend more time with the patients

2. 23 reduce $G L$ turnover

3. 28 immediately inform the families when there are issues related to their family member

4. 29 be consistent as a team of GL in dealing with the same patients

5. 30 provide $\mathrm{GL}$ with more freedom to make decisions

6. 31 develop personal approach to the patients

7. 32 develop strategy guidelines on how to deal with each patient

8. 33 discuss in the team difficulties relate to the patients

9. 34 assign personal coach to each patient who will be responsible for monitoring services provided to that patient

10. 36 build relations of trust between GL and patients

11. 38 too many rules for $\mathrm{GL}$ to follow

12. 39 develop environment of trust in teams

13. 40 organize team building activities

14. 44 increase $G L$ confidence

15. 45 organize trainings considering $\mathrm{GL}$ needs

16. 47 provide coaching to $\mathrm{GL}$... only when there are serious issues with patients

17. 51 organize smaller teams of GL with more hours per contract

18. 59 do more activities with patients

19. 60 reduce $\mathrm{GL}$ paperwork

20. 61 organize games

21. 62 go out for a walk/shopping

\section{3 hiesets}

14 create knowledge sharing environment for GL

15 organize workshops where GL from all divisions can share experience and knowledge

16 organize monthly meetings for bigger teams of GL

\section{2 hiesets}

4 improve organisation of GL work

9 provide GL with enough information for decision making in difficult situations

13 organize work in small teams of GL ... big teams (“..." - rather than)

17 reduce the number of $\mathrm{GL}$ coaches

18 organize better schedules for replacing GL during their sick leaves

19 give the opportunity for GL to use their free days ... replace sick colleague

25 help GL get more experience from working with many patients

31 increase working hours per day for flex pool ... work less hours with more days

52 organize frequent visits to the working floor by management

54 involve GL in decision making related to livelihood of the patients

58 consider GL opinion for decision making related to patients' schedules

$59 \mathrm{GL}$ leaders' representatives should voice opinion of the staff ... their personal opinion

60 provide GL with a prompt feedback when they ask for assistance ... come back in a few weeks when it is too late

75 improve grouping of patients

76 avoid assigning patients to the groups they do not belong

78 consider GL opinion when relocating the patient 83 reduce time GL spend to guide new comers to work with patients 


\begin{tabular}{|c|c|}
\hline FM & $\mathrm{GL}$ \\
\hline 2 hiesets & 3 hiesets \\
\hline 22. & 84 improve collaboration with families \\
\hline 23. & 91 send the same flex pool to the same houses \\
\hline 24. & $\begin{array}{l}92 \text { talk more to families in person ... ones in a while } \\
\text { on phone }\end{array}$ \\
\hline 25. & $\begin{array}{l}93 \text { gather families of all patients in the house at } \\
\text { least once per } 3 \text { months }\end{array}$ \\
\hline 26. & 94 involve families in organizing some activities \\
\hline 27. & $\begin{array}{l}96 \text { create guidelines per team to help new GL to } \\
\text { become a part of the team }\end{array}$ \\
\hline
\end{tabular}

\section{Identifying composite tails}

Tails are the concepts represented by nodes that only have arrows going outside (no arrows go inside). Tails are the input into the model. They are the concepts that explain the causes of current situations or the means that are to be adopted to solve some problems. Composite tail analysis (cotail) is important because it indicates the single action that may cause multiple goals to be achieved. Composite tail analysis gives more insights into the key issues (Ackermann and Eden, 2010). The results of the cotail analysis refine the results of the potent analysis. The cotail analysis for the FM and GL maps determined the following concepts as possible potent options (Table 4). 
Table 4. Cotail analysis

\begin{tabular}{|c|c|c|}
\hline & FM & $\mathrm{GL}$ \\
\hline 1. & 20 spend more time with the patients & 2 reduce $\mathrm{GL}$ stress \\
\hline 2. & 21 reduce flex pool shifts & 4 improve organisation of GL work \\
\hline 3. & 23 reduce GL turnover & 14 create knowledge sharing environment for $\mathrm{GL}$ \\
\hline 4. & $\begin{array}{l}28 \text { immediately inform the families when there } \\
\text { are issues related to their family member }\end{array}$ & $\begin{array}{l}25 \text { help GL get more experience from working with } \\
\text { many patients }\end{array}$ \\
\hline 5. & $\begin{array}{l}29 \text { be consistent as a team of } \mathrm{GL} \text { in dealing with } \\
\text { the same patients }\end{array}$ & 26 reduce flex pool shifts \\
\hline 6. & $\begin{array}{l}30 \text { provide GL with more freedom to make } \\
\text { decisions }\end{array}$ & $\begin{array}{l}31 \text { increase working hours per day for flex pool ... } \\
\text { work less hours with more days }\end{array}$ \\
\hline 7. & $\begin{array}{l}51 \text { organize smaller teams of GL with more } \\
\text { hours per contract }\end{array}$ & $\begin{array}{l}52 \text { organize frequent visits to the working floor by } \\
\text { management }\end{array}$ \\
\hline 8. & $\begin{array}{l}54 \text { consider emotional attachments patients } \\
\text { develop towards GL }\end{array}$ & $\begin{array}{l}54 \text { involve } \mathrm{GL} \text { in decision making related to livelihood } \\
\text { of the patients }\end{array}$ \\
\hline 9. & & $\begin{array}{l}56 \text { communicate the vision and mission of the divi- } \\
\text { sion with } G L \text {... let } G L \text { have their own interpretation }\end{array}$ \\
\hline 10. & & $\begin{array}{l}60 \text { provide GL with a prompt feedback when they ask } \\
\text { for assistance ... come back in a few weeks when it is } \\
\text { too late }\end{array}$ \\
\hline 11. & & 75 improve grouping of patients \\
\hline 12. & & 81 spend more time with the patients \\
\hline 13. & & $\begin{array}{l}83 \text { reduce time GL spend to guide new comers to } \\
\text { work with patients }\end{array}$ \\
\hline 14. & & 84 improve collaboration with families \\
\hline
\end{tabular}

The list of the total potent options of two maps after synthesizing potent and cotail analyses is presented in Table 5 . 
Table 5. Potent options

\begin{tabular}{|c|c|c|}
\hline & FM & $\mathrm{GL}$ \\
\hline 1. & 20 spend more time with the patients & 14 create knowledge sharing environment for $\mathrm{GL}$ \\
\hline 2. & 23 reduce GL turnover & $\begin{array}{l}25 \text { help GL get more experience from working with } \\
\text { many patients }\end{array}$ \\
\hline 3. & $\begin{array}{l}28 \text { immediately inform the families when there } \\
\text { are issues related to their family member }\end{array}$ & $\begin{array}{l}31 \text { increase working hours per day for flex pool ... } \\
\text { work less hours with more days }\end{array}$ \\
\hline 4. & $\begin{array}{l}29 \text { be consistent as a team of GL in dealing with } \\
\text { the same patients }\end{array}$ & $\begin{array}{l}52 \text { organize frequent visits to the working floor by } \\
\text { management }\end{array}$ \\
\hline 5. & $\begin{array}{l}30 \text { provide GL with more freedom to make } \\
\text { decisions }\end{array}$ & $\begin{array}{l}54 \text { involve GL in decision making related to liveli- } \\
\text { hood of the patients }\end{array}$ \\
\hline 6. & $\begin{array}{l}51 \text { organize smaller teams of GL with more } \\
\text { hours per contract }\end{array}$ & $\begin{array}{l}60 \text { provide GL with a prompt feedback when they } \\
\text { ask for assistance ... come back in a few weeks } \\
\text { when it is too late }\end{array}$ \\
\hline 7. & & 75 improve grouping of patients \\
\hline 8. & & $\begin{array}{l}83 \text { reduce time } G L \text { spend to guide new comers to } \\
\text { work with patients }\end{array}$ \\
\hline 9. & & 84 improve collaboration with families \\
\hline
\end{tabular}

\section{Discussion}

Head analysis of the merged maps revealed two significant perspectives related to each group of the interviewees. The families mentioned the provision of a patientcentred care in practice and reduction of patients' stress as the main points of their concern. They also stressed that the main means of achieving these goals should include changes in organisational culture, reduction of group leaders' turnover and relationship of trust between them and the institution.

Organisational culture exerts a strong effect on the performance at the sharp end of the system. Thus, it was interesting to observe group leaders mentioning the need for the changes in the organisational culture as one of the goals as well. Both groups of the key stakeholders mentioned that they need better communication with the management and transparency related to strategic changes in the organisation.

Head analysis of the GL map also specified the improvement of the patients' livelihood as another goal. Another finding was that both the centrality and domain analyses of the GL and FM maps indicated the reduction of the patient's and the group leaders' stress and the reduction of flex pool shifts as the key potential issues.

Noticeably, '26 reduce flex pool shifts' concept had the highest domain and centrality scores in the GL map. This demonstrates that the quick fix the management of the division applies in order to deal with the budget gaps creates unnecessary stress and tensions to the patients and the group leaders. Therefore, it can be concluded that it is vital to consider the opinion of the key stakeholders while making decisions relat- 
ed to resource allocation. In order to succeed in delivering a patient-centred care, all stakeholders, including the patients with their families, should take part in designing the strategies.

Further analysis per cluster of the map considering the views of the key stakeholders of the organisation in designing effective strategic plans leading to the improvement of patients' livelihood and delivery of a patient-centred care in practice may help.

Potency and cotail analyses revealed the concepts that support the achievement of more than one goal. One of potent options of the FM map is related to time spent with the patients.

Making sense of the families' concerns in this environment is facilitated by an ongoing relationship of trust over time. It is evident, following the FM map, that spending more time with the patient not only reduces patients' stress but also helps building relations of trust between them and the group leaders. That, in turn, reduces group leaders' stress, one of the reasons for another potent option, group leaders' turnover, which, in turn, contributes to patients' stress and hinders building relations of trust between the division and the patients.

The importance of relations of trust between the group leaders and the patients is strengthened by another potent option (29) that relates to consistency in group leaders' behaviour towards the patients. There is another potent option (28) that affects relations of trust between the division and families. And that concept was mentioned by the families as one of the important indicators of a patient-centred care. Two other potent options (30 and 51) also contribute to building environment of trust between the division and parents of ID patients through the improvement of collaboration with the families. The families also indicated that group leaders' having more freedom to make decisions will reduce their stress.

Analysis of the GL map demonstrates that one area of concern for the front-line workers is improvement of top-down and bottom-up communication. Three out of 14 potent options $(52,54$ and 60 ) have direct links to that concept. And improvement of communication with the management affects directly one of the main goals indicated by the group leaders related to changes in organisational culture. Two of those three potent options (54 and 60) affect also group leaders' security and comfort at work, which, in turn, contributes to the group leaders' turnover.

Analysis of the maps demonstrated that not only the families but also the group leaders emphasized the importance of reduction of the patients' $(25,75$ and 84$)$ and the group leaders' (83) stress. The potent option '84 improve collaboration with families' contributes to the reduction of patients' stress. It is also directly linked to the improvement of patients' livelihood. Potent option 83 suggests the reduction of time spent by the group leaders to guide new workers in order to have more time the patients, which reduces their stress. Potent options 25 and 75 influence patients' stress (option 25 has a negative impact). Also, potent option 25 contributes to the group 
leaders' comfort and security at work alongside with potent options 52 and 60 through the provision of opportunities for professional development. Finally, potent options 14 and 31 suggest creating knowledge-sharing environment and having flex pool contracts with more hours per day in order to improve the organisation of the group leaders' work. Potent option 31 also influences the reduction of flex pool shifts.

\section{Conclusion}

This article has set out a methodology for learning the processes in a complex healthcare system such as ID organisations. The case study demonstrated the ability of SODA's cognitive mapping technique to enhance stakeholders' ownership feeling towards the planning process. The use of cognitive mapping facilitated an ongoing verification of the interpretation of the interviewee's statements because the researcher could ask the interviewee to verify the emerging relationships.

Cognitive mapping improved the communication between the facilitator and the interviewees. It also allowed the active involvement of the problem owners. The technique seemed to be quite helpful in shared understanding of ideas expressed by the interviewees. The cognitive mapping exercise allowed participants to critically reflect upon the dynamics of the process. They could see their own thoughts strategically organized, which made the discussion more constructive.

The maps stimulated new thoughts and ideas around the key issues and helped merging diverse viewpoints into a single representation. Moreover, cognitive mapping technique has helped reaching a consensus and managing disagreements during the focus group discussions. The participants could clearly see the issues and actions required to reach the specified goals.

The technique clearly demonstrated that the decision of the managers to reduce divisions' spending via the reduction of flex pool hours has many drawbacks. Moreover, those decisions eventually affect the main objective of the organisation to deliver a patient-centred care.

The organisation's senior management indicated sharing the waiting lists among the divisions as of primary importance. However, from the perspectives of the key stakeholders of the organisation, filling empty beds (concept 32 in Figure 1) and sharing waiting lists among the divisions (concept 70 in Figure 1) concepts are in the tails of the map. This indicates that what senior management perceived as one of the main strategic directions was only one of many options in solving issues from the perspectives of the key stakeholders. Importantly, cognitive maps can provide senior management with detailed feedback about how the results of strategic decisions are perceived at the front line.

This approach requires senior managers to take feedback seriously and to recognize the causal complexity that creates problems at the front line. Given the strengths 
of cognitive mapping in managing system's complexity, it would provide an essential precursor to the quantitative modelling phase.

\section{Further Steps}

Cognitive mapping is a qualitative technique, and it cannot be used to derive numerical assessments of the impact of strategic decision-making. However, it can be a necessary precursor to quantitative modelling. Moreover, the maps do not promote an understanding of strategic decision-making over time periods. Hence, System Dynamics causal diagrams can be useful in providing the senior managers with more information about the factors that generate dynamic behaviour of the system.

One of the further steps of this research project can be the identification of feedback loops in order to highlight powerful dynamics in the organisation, with the goal to design more effective intervention strategies.

Once a System Dynamics model has been quantified and demonstrated to be reliable, it may become a laboratory in which to experiment and learn. The managers can compare the results of different projections and see the relative impacts of different interventions that can help them identify decisive factors and challenge managerial intuition. 


\section{References}

Ackermann, F., Eden, C. (1994). Issues in computer and noncomputer supported GDSSs. Decision Support Systems, 12, 381-390.

Ackermann, F., Eden, C. (1998). Making Strategy: The Journey of Strategic Management. London, Sage.

Ackermann, F., Cropper, S., Eden, C. (1992). Getting started with cognitive mapping in $7^{\text {th }}$ Young OR Conference Tutorial Papers. Birmingham, UK: OR society.

Ackermann, F., Eden, C. (2010). Strategic Options Development and Analysis. In: M. Reynolds, \& S. Holwell (Eds.), Systems Approaches to Managing Change: A Practical Guide (pp. 135-190). London, UK: Springer.

Ackoff, R. L. (1974). Redesigning the Future: A Systems Approach to Societal Problems. Sydney, Canada: John Wiley \& Sons, Inc.

Begun, J.W., Zimmerman, B., Dooley, K. (2002). Health care organisations as complex adaptive systems. In S.S. Mick, M.E. Wyltenbach (Eds.), Advances in Health Care Organisation Theory (pp. 253-288). San Francisco, Calif: Jossey-Bass.

Brightman, J. (2002). An Introduction to Decision Explorer. Banxia Software Ltd.

Checkland, P. (1981). Systems Thinking, Systems Practice. Chichester, UK: Wiley.

Checkland, P. (1985). A Development of Systems Thinking for the 1990s. The Journal of Operational Research Society, 36, 757-767.

Duryan, M., Nikolik, D., van Merode, G., Curfs, L. (2012). System Dynamics Modelling for Intellectual Disability Care: A Case Study. Journal of Policy and Practice in Intellectual Disabilities, 9, 112-119.

Eden, C. (1990). Strategic thinking with computers. Long Range Planning, 23, 35-43.

Eden, C. (1992). On the Nature of Cognitive Maps. Journal of Management Studies, 29, 261-266.

Eden, C. (2004). Analyzing cognitive maps to help structure issues or problems. European Journal of Operational Research, 159, 673-686.

Eden, C., \& Ackermann, F. (2001). SODA - The Principles. J. Rosenhead, \& J. Minger (Eds.), Rational Analysis for a Problematic World Revisited (pp.21-41). Chicherster, UK: Wiley.

Eden, C., \& Spender, J. (1998). Managerial and Organisational Cognition: Theory, Methods and Research. London, UK: SAGE.

Eden, C., Ackermann, F., \& Cropper, S. (1992). The analysis of cause maps. Journal of Management Studies, 29, 309-324.

Eden, C., Jones, S., \& Sims, D. (1983). Messing About in Problems. UK: Pergamon Press.

Forrester, J. (1980). Information Sources for Modelling the National Economy. Journal of the American Statistical Association, 75, 567-569.

Forrester, J. (1994). System Dynamics, Systems Thinking, and Soft OR. System Dynamics Review, 10, 245-256.

Ghaffarzadegan, N., Lyneis, J., \& Richardson, G. (2011). How small system dynamics models can help the public policy process. System Dynamics Review, 27, 22-24.

Jackson, M. (2002). Systems Approaches to Management. New York: Kluwer Academic Publishers.

Jansen, D., Krol, B., Groothoff, J., \& Post, D. (2006). Towards Improving Medical Care for People with Intellectual Disability Living in the Community: Possibilities of Integrated Care. Journal of Applied Research in Intellectual Disabilities, 19, 214-218.

Mansell, J., \& Beadle-Brown, J. (2004). Person-centred planning or person-centred action? Policy and practice in intellectual disability services. Journal of Applied Research in Intellectual Disabilities, 17, 1-9.

Moore, M. (1995). Creating Public Value. Cambridge, MA: Harvard University Press.

Morrison, I. (2000). Health care In the New Millenium: Vision, Values, and Leadership. San Francisco: JosseyBass.

National Healthcare Quality \& Disparities Reports (2011). Retrieved 20 August, 2012 from http://www.ahrq.gov/qual/qrdr11.htm

Polder, J., Meerding, W., Bonneux, L., \& van der Maas, P. (2002). Healthcare costs of intellectual disability in the Netherlands: a cost-of-illness perspective. Journal of Intellectual Disability Research, 46, 168-178. 
Ras, M., Woittiez, I., van Kempen, H., and Sadirija, K. (2010). Steeds meer verstandelijk gehandicapten? (An inexorable rise in intellectual disability?) Den Haag: Sociaal en Cultureel Planbureau.

Rosenhead, J., Mingers, J. (Eds). (2001). Rational Analysis for a Problematic World Revisited. $2^{\text {nd }}$ ed. Chicherster, UK: Wiley.

Schoonheim, J. (2009). ANED country report on the implementation of policies supporting independent living for disabled people in the Netherlands. Retrieved on 19 September, 2012, from http://www.disabilityeurope.net/content/aned/media/NL-7-ANED\%20Request-

07\%20Task\%205\%20Independent\%20Living\%20NL\%2015-6_to\%20publish_to\%20EC.pdf

Sterman, J. (1994). Learning in and about complex systems. Systems Dynamics Review, 10, 291-300.

Van der Kwartel, A. (2009). Brancherapport Gehandicaptenzorg (Branch report Care for Disables) 2008. Utrecht: Prismant.

Vissers, J., Bertrand, J., \& de Vries, G. (2001). A framework for production control in health care organisations. Production Planning and Control, 12, 591-604.

Vlaskamp, C., \& van der Putten, A. (2009). Focus on interaction: the use of an Individualized Support Program for persons with profound intellectual and multiple disabilities. Research in Developmental Disabilities, 30, 873-883.

Wolstenholme, E. (1995). Systems Thinking, System Dynamics. System Dynamics Conference. Tokyo, Japan.

World Health Organisation. (2009). WHO patient safety curriculum guide for medical Schools. Retrieved 26 Sep., 2012 from http://www.who.int/patientsafety/education/curriculum/download/en/index.html

World Health Organisation. (2010). Better health, better lives: Children and young people with intellectual disabilities and their families. Retrieved 11 Nov., 2012 from http://www.euro.who.int/_data/assets/pdf_file/0003/126570/e94430.pdf 



\section{CHAPTER 4}

\section{Using cognitive mapping and qualitative system dynamics to support decision making in intellectual disability care}

Duryan, M., Nikolik, D., van Merode, G., Curfs, L. M. G. (2013). Using cognitive mapping and qualitative system dynamics to support decision making in intellectual disability care. Journal of Policy and Practice in Intellectual Disabilities: In press. 


\begin{abstract}
Provider organisations specializing in intellectual disabilities (ID) are under pressure because of planned reforms, changes in society and increased customer expectations. The combination of all these factors makes long-term decision making a challenge for the managers of such organisations. The majority of research examining decision making in ID care has commonly studied the issue from the perspective of health care providers. The authors contend that the degree of success of ID care providers depends on their ability to appreciate the views and interests of care receivers and frontline workers, the most important actors of the system. Having a comprehensive picture of key stakeholders' overall perspectives on problem situations can enhance managers' understanding of the behaviour of a complex system they manage. The authors suggest that the combination of qualitative system dynamics (SD) modelling and cognitive mapping techniques can facilitate collaborative representation of the stakeholders' views in a way that can support decision making in complex health care systems. The authors illustrate the application of this combined method via a case study in one of ID care providers in the Netherlands. The case study illustrates the possibilities of using structured stakeholders' perspectives related to flex pool schedule shifts, one of resource allocation dilemmas in the organisation, for organisational decision-making.
\end{abstract}




\section{Introduction}

ID care providers are complex health care service organisations as they have multiple stakeholders with often conflicting interests. Due to specifics of ID care, the relationship between the client and the care worker is a key factor in successful treatment outcome (Roeden et al., 2010). The need for a deeper involvement of care workers in their relations with the clients' families and other parts of society adds to their complexity and makes the management of ID care providers more difficult.

Uncertainty of resources is another challenge for ID organisations. Long-term residential care for people with ID is expensive, and the governments in OECD (Organisation for Economic Co-operation and Development) countries plan funding reductions in the field (OECD, 2013). However, costs for ID care are expected to increase even more because of a continuously growing patient population (Jansen, et al., 2006). Thus, now ID care providers in the Netherlands, as well as in other OECD countries, are challenged to improve efficiency and effectiveness of resource utilization in order to deliver high quality health and long-term care services to an ageing population in a cost-efficient manner (OECD, 2013).

In order to make correct long-term decisions, the management of ID care providers needs better understanding of the complexity of their organisation. They should understand the real nature of the processes in their organisations, their dynamics, their influence, their interconnections and the possible outcomes. The decision makers need approaches that can not only help them see complex interconnections between parts of the system but also provide better understanding for the interests of stakeholders (Adam and de Savigny, 2012). Without considering the viewpoints of the key stakeholders who are the ID clients, their families and the front-line workers (group leaders/personal coaches, personnel who work with the clients every day), any managerial decision can bring short-term gains at the expense of longer-term outcomes. Sometimes, such decisions may lead to more changes that can cause side effects that eventually may throw the system out of balance.

Available research in the field has not shown favourable results for individuals with ID when their health care decisions are determined by the appointed decision makers, support staff, and health care professionals (O'Dell et al., 2012). The authors suggest that the structured views and perspectives of the organisation's key stakeholders may help the management understand the reality of organisational life which can support them in long-term decision making. The stakeholders "have a stake in the organisation's future" (Ackermann \& Eden, 2011). Thus, the importance of stakeholders' contribution to problem conceptualization cannot be underestimated (McLucas, 2003).

In this article, the authors explore the possibility of assisting the managers in understanding their current reality. The authors state that the management of decision making process is the key to understanding and improving ID care. They contend 
that cognitive maps and SD causal loop diagrams (CLD) can be meaningfully combined to promote stakeholders' representation in modelling process which in turn can help senior management to take into account their concerns.

A case study, set in a healthcare service provider in the Netherlands, demonstrates the importance of structured key stakeholders' perspectives and views in supporting decision making in complex health care systems. The article describes how structural presentation of the mental models of the families of the clients and the front-line workers to the senior management of an ID care provider helped them see the best leverage points for intervention.

\section{Complexity of Healthcare organisations}

Healthcare organisations are increasingly recognised to be complex systems that involve many interacting components (Begun, et al., 2003; Holland, 2006; Adam and de Savigni, 2012).

Since viewing the organisations as open systems became popular starting in the 1960s, complexity of the organisations has been a central point of discussion for organisation scientists (Anderson, 1999). Open system is "a system in exchange of a matter with its environment" (Bertalanffy, 1968, p.141). From that perspective, the organisation is a part of a much larger network rather than independent self-standing entity. Thus, in order to understand the processes in the organisation it is critical to study interrelationships between those entities and their connections to a whole system.

Complexity of health care organisations is reflected in the number of stakeholders involved: customers, professionals, provider organisations, insurers and suppliers (Begun et al., 2003). The relationships among stakeholders are nonlinear and discontinuous, so even small changes in variables can have significant impact on the whole system. Thus, health care organisations require sophisticated analysis of their systemic nature.

As in any service organisation, people in ID care are the most important component of a system. The specifics of ID care that require deeper involvement of caretakers in their relations with the clients' families and other parts of society invariably add to the complexity of the organisation (Duryan et al., 2012). Thus, especially in ID care it is necessary to take into account unpredictability of expectations, attitudes, and behaviours of the main actors of the system.

Effective decision making is difficult in a world of dynamic complexity because dynamic systems change at many time scales and they are highly influenced by feedback. Forrester (1961) and Senge (1990) mentioned that often there is no explicit connection between cause and effect in complex systems due to time delays. Any interaction with any part of the system can feed back onto itself directly or after a number of stages. 
Time delays in feedback chain cause significant difference between the short-term and long-term responses of the system to actions (Sterman, 2000). Long-term decisions may cause worse behaviour of the system in the short run before it improves. That can make the managers question the impact of their decisions. It can also lead them to taking actions based on their short-term perspectives which may have unexpected side effects and may return to cause harm in the long run (Sterman, 2001).

In order to take actions that can have long-term impact, it is important to study both the complexity of the system under scrutiny and the mental models that the managers use for decision making (Sterman, 2001).

\section{Decision making in complex organisations}

Decision making is one of the most important functions of the managers in any organisation. Managerial decisions are deliberate choices made from a range of alternatives. Accordingly, in order to make the right decision in a complex world, the managers must evaluate each choice according to its projected outcome based on the amount of information and time available. However, there can be a huge amount of data which is difficult to convert into meaningful information for decision making.

Organisations are viewed as information processing systems that gather and interpret data from their environments and then learn by acting based on that interpretation (Daft \&Weick, 1984). This idea is central to the contingency perspective that underlies information processing theory. According to the contingency perspective, the fit between the information processing requirements and the information processing capacity of the organisation determines success in performance (Galbraith, 1973). Galbraith (1977) recommends two basic options for dealing with information: to reduce the amount of information processed or to increase the information handling capacity.

Information processing refers to gathering, interpreting, and synthesizing information in the context of organisational decision making. Managers are information processors and a key factor in the effectiveness of strategic actions made in response to environmental uncertainty is managerial interpretation of the cause and effect relationships. Decision makers usually face serious difficulties when approaching realworld dynamic systems. The main reason is that real-world systems are composed of a number of dynamic entities which are interrelated in complex ways, usually including feedbacks and time delays. However, traditional management approaches are limited in analyzing multiple interdependent processes operating simultaneously.

Management science suggests the application of quantitative techniques to managerial problems. However, problem solving in organisations is a social activity (Eden, 1994). Social systems are brought about through the interaction of people who act in accordance with their values and conceptions of reality (Jackson, 2002). The stake- 
holders of the organisation, which is a social system, have conflicting perceptions of what behaviour a system is exhibiting. Thus, it is necessary to examine their views.

Problem definition is one of the steps in decision making process alongside goal formulation, alternatives generation, and evaluation. Defining the nature of the problem is considered to be the most difficult and demanding (Rosenhead and Mingers, 2001). Moreover, the definition of the problem may change as soon as deeper understanding of the system is obtained. One of the reasons for complexity of problem definition is that each key actor has his own interpretation of the events the influences between them (Eden, 1994). The decision makers do interpretations intuitively, without realizing their role in defining the environment for other stakeholders. However, use of intuition and judgement can be inappropriate in dynamics situations. Managers should "apply structured Systems Thinking" to make sense out of ongoing events (Stacey, 2010, p.120).

In order to successfully manage information and avoid wrong solutions, the management has to consider multiple representations of problem situations. Thus, the degree of success of organisations depends on their ability to collaborate with their stakeholders.

The science of corporate governance reveals that information processing capacity of the organisation can be improved by introducing multiple boards representing different stakeholder groups to create the requisite feedback loops and ensure quality information processing at the board level (Turnbull, 2002). Porter (1992) recommends including diverse stakeholders in the information system of firms to provide competitive advantages. Eden and Ackerman (1998) stress the importance of stakeholder participation and stakeholder management in strategy-making for organisational change.

In order to organize effective collaboration with stakeholders there is a need for approach that will not only allow thinking about the problem but will contribute to decision making via eliciting structured stakeholders' thinking about the problem situation and their ideas about possible solutions. There is a need in methods and tools that can bridge the gap between stakeholders and decision makers. Sharing multiple views and perspectives among key stakeholders and decision makers can clarify confusion and reduce uncertainties "to an extent far greater than any one individual mind can do" (Burstein and Holsapple, 2008, p. 10).

Problem structuring methods has been widely used in the organisations (Rosenhead and Mingers, 2001). Cognitive mapping (soft OR technique) as one of problem structuring methods, helps organisational actors to come to a shared understanding on the problems in the organisation. Shared understanding of problem situations may foster commitment and enrolment of the stakeholders.

Because organisations are complex systems and many of their characteristics and behaviour are changing over time, there is also a need for models that can explicitly demonstrate feedback processes and time delays that determine the dynamics of the system. The authors propose combination of CLD and cognitive maps to present stake- 
holders' viewpoints in a structured way and to observe the dynamics of the system behavior.

\section{Methods}

Combination of SD with other systems approaches was seen as being very successful (Morecroft and Wolstenholme 2007). The worlds of soft OR and SD were put together by Senge (1990). The methodologies have many things in common as both disciplines aim at effective organisational intervention (Lane, 1994). Moreover, both soft OR and SD suggest tools that can be used to facilitate organisational learning processes.

Churchman (1968) developed systems theory to address social issues from an open systems point of view. Systems Thinking is an approach to problem solving that considers the nature of complex systems that are governed by feedback processes. Systems science considers dynamic relationships between the elements of the system and the impact that those relationships have on the entire system. In dynamic systems relationships are paramount. Systems thinkers use models in order to learn about system's behaviour (Stacey, 2010).

SD is a way of modelling individual's perceptions of a real world system. SD suggests a modelling language that can describe multiple feedback cycles that characterize the problem situation (Mingers and Rosenhead, 2004). Moreover, the methodology provides tools that help to get the most out of involvement of decision makers in the process of modelling (Jackson, 2002).

SD modelling has been considered to be an appropriate method for improving healthcare systems (Dumas, 1985; Homer \& Hirsch, 2006; Kommer, 2002; Sundaramoorthi et al., 2009; Wolstenholme, 2004). The qualitative phase of SD is an iterative process that involves drawing CLD in close collaboration with stakeholders. The aim of the diagrams is to translate the views and assumptions of "system actors" about the system into ideas that can be communicated to others (Jackson, 2002). Causal loops are immensely helpful in eliciting and capturing the mental models of the decisionmakers in a qualitative fashion.

The advantage of SD modelling is that it allows the use of powerful techniques for modelling. However, the approach is used to determine how to make improvements to well-defined problem situations and it does not consider aspects beyond the logic of the problem situation (Checkland, 1985; Forrester, 1961). Thus, SD modelling becomes less efficient when applied to decision support and modelling in ill-structured problem domains.

In the case study conducted in one of ID care providers we are dealing with multiple perspectives and bounded rationality so, a single causal SD model will not be able to fully present all the perspectives and views. Soft OR (or soft Systems Thinking) has been developed to deal with these kinds of situations. The advantage of 'soft' Systems 
Thinking is that it "keeps in touch with the human content of problem situations" (Checkland, 1985, p. 765). It offers a range of tools that can help in SD project (Lane, 1994).

The soft OR approach is defined as a learning process designed to determine what needs to be done in ill-defined problem situations (Checkland, 1981). The approach evolved as a reaction to the inability of classical operational research to deal with social systems (Checkland, 1981).

The modern soft OR approaches to the modelling and analysis of ill-structured problem domains is based on the notion of cognitive maps. A cognitive map, technique suggested by strategic options development and analysis (SODA), is a two-dimensional directed graph that represents the issue from perspectives of an interviewee (Eden and Ackermann, 2001). Cognitive maps have been widely used to represent subjective knowledge about perceived causes and perceived links between them (Eden, 1992). The maps provide a comprehensive picture of an individual's overall perspective, at the same time keeping all the details. The links between the concepts in cognitive maps do not imply cause-impact relations they rather indicate the way in which one concept can affect the other.

Cognitive maps do not allow seeing dynamic behavior of the system because they do not demonstrate feedback processes and time delays. At the same time, managerial decision making is a dynamic process. Managerial decisions alter the environment, giving rise to new information and leading to new decisions.

There are successful examples of using SD with cognitive mapping (Ackermann et al. 1997). The idea of using cognitive maps to help conceptualise SD models was first articulated by Colin Eden in 1988 (Eden, 1988). Cognitive mapping technique can promote better understanding of stakeholders' mental models and so they can support the development of CLD, which in turn can help studying complex interactions between the concepts. In CLD the variables are connected by cause-effects links while cognitive maps are composed by concepts which are directly elicited from what participants think about that problem. The analysis of cognitive maps allows identification of key concepts that can become an input for CLD.

To demonstrate how CLD combined with cognitive mapping can be useful for decision making in a long-term care setting, a case study was conducted in one of the big ID care service providers in the Netherlands.

\section{The case study}

We began the study with preliminary interviews with the senior management of an ID organisation to reveal the challenges related to resource allocation that concerns the managers the most (Duryan et al., 2012). The interviews were conducted in one of the divisions of the organisation that provides residential (24-hours) care services for clients with ID. Then, the vision of the senior management related to resource allocation 
was communicated to the group leaders and to the families of the clients of the same division during semi-structured interviews.

The goal for the interviews with the two groups of the key stakeholders was to get feedback from them regarding the resource allocation challenges the division faces. They gave comments on what and how in their opinion should be improved for the division to be able to deliver client-centred care in practice.

From perspectives of the managers, organizing frequent shifts of group leaders is the most convenient and quick way to solve the problem related to covering budget gaps, especially when there are not enough clients in the division. On the short run it helps to save money for the division. However, as there are delays involved with the feedbacks, it is not always possible to immediately see the impact of these actions on the long run (Duryan et al., 2012). For instance, as the interviews with the stakeholders demonstrated, frequent shifts cause stress to group leaders and the clients and could lead to increase in number of employee turnover with a few years of delay (Duryan et al., 2013). Thus, inefficient allocation of resources, especially considering their insufficiency and also fluctuations in the demand for services, may lead to a loss of capacity (Vissers, et al., 2001). However, as it is not always possible to see explicit connection between cause and effect, the managers keep applying symptomatic solutions that eventually may throw the system out of balance.

The individual in-depth interviews were translated into the language of cognitive maps (see part of a cognitive map as an example on Figure 1). 


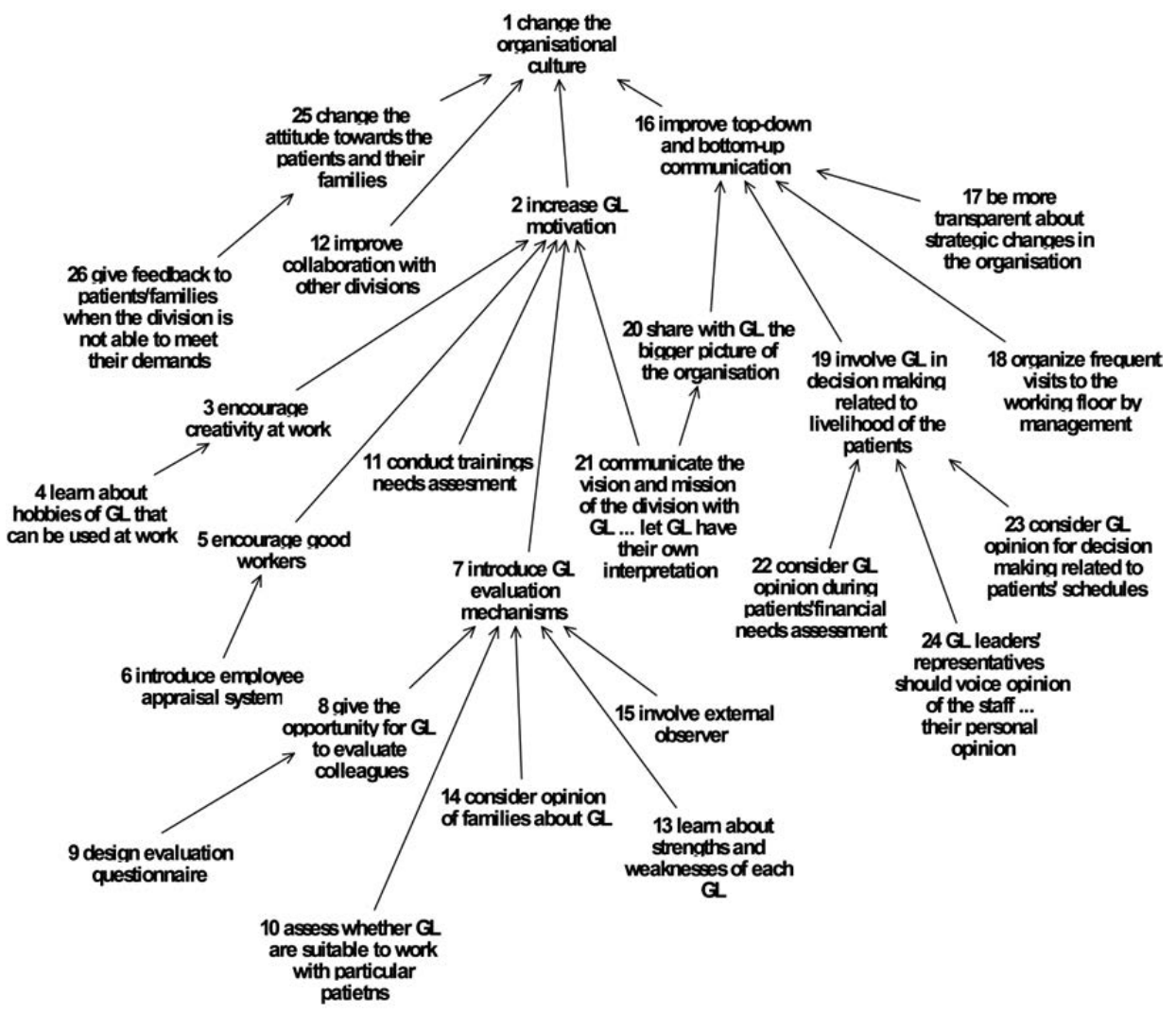

Figure 1. One cluster of group leaders' merged cognitive map

The links between nodes on the cognitive map represent logical implications between the concepts. For example the node 17 'be more transparent about strategic changes in the organisation' influences the node 16 'improve bottom up and top down communication'. Then, individual cognitive maps were merged into two maps reflecting the individual views of family members and group leaders to provide a framework for group discussions (Duryan et al., 2013). The merged maps were reviewed, corrected and elaborated with the group leaders and family members during group discussions conducted in small teams.

Cognitive mapping seemed to be quite helpful in shared understanding of ideas expressed by the interviewees. The technique allowed elicitation of individual points of view of problematic situations by the families and group leaders without losing the richness of multiple perspectives on the problem.

The merged cognitive maps were analyzed with the help of Decision Explorer ${ }^{3}$ software (Duryan et al., 2013). In order to identify the primary issues the organisation

\footnotetext{
${ }^{3}$ http://www.banxia.com/dexplore/
} 
should overcome to be able to deliver client-centred care (from perspectives of the key stakeholders), we have chosen the most valuable analytic tools for the case study (Head, Centrality, Domain, Hierarchical cluster, Potency and Cotail analyses) (Duryan et al., 2013). In addition to that Decision Explorer helped detecting causal feedback loops as perceived by the interviewees (Figure 2).

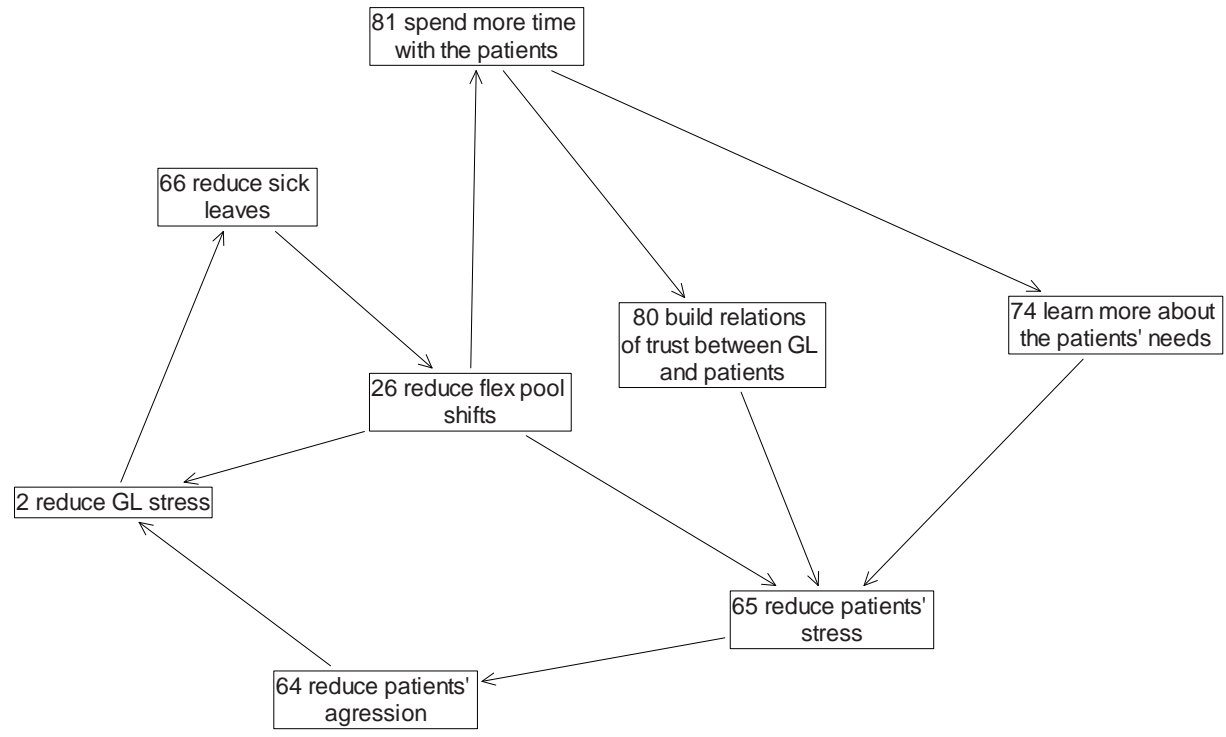

Figure 2. The result of loop analysis of merged cognitive map for Group Leaders

However, the maps did not promote understanding of strategic decision making over time periods. Consequently, in designing CLD, the authors aimed to providing the senior managers with more insight into the factors that generate dynamic behavior of the system in order to assist them in identification of more effective intervention strategies.

The loop (Figure 2) was modified in order to build SD CLD with the help of Ven$\mathrm{sim}^{4}$ software. There were many issues that the key stakeholders brought up; however, in order to demonstrate the process of communicating their ideas to the senior management, we considered the biggest areas of their concern based on analysis of both merged cognitive maps.

Modification of causal loops was important as there is no clear distinction between cause-effect relations in cognitive maps however understanding the nature of relations between variables is fundamental for development of CLD. The concepts were converted into CLD variables with causal linkages between one another (Figure

\footnotetext{
${ }^{4}$ http://vensim.com/
} 
3). Additional variables were introduced where it was necessary. The reinforcing (or balancing) feedback loops with time delays were also identified.

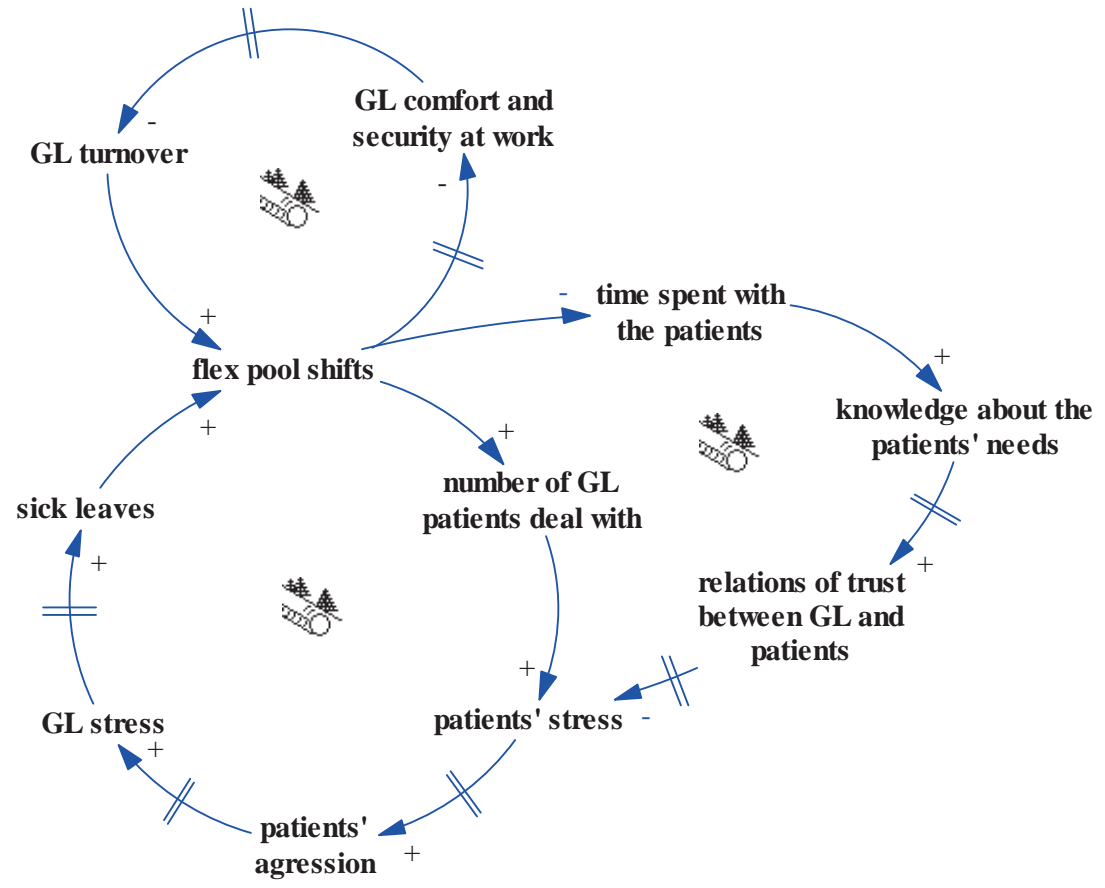

Figure 3. Modified SD causal loop diagram

With the help of causal loops, any organisation can be viewed as made up of two kinds of system building blocks-reinforcing (positive) and balancing (negative) processes. Arrows (Figure 3 ) denote the direction of causality between a cause and its effect, and the signs "+" and "--" at the arrowhead represent "same" and "opposite" directions of causality. And finally the " $=$ " sign denotes time delays.

Modelling the CLD helped determining the dynamics of a system as it teased out the feedback loop that underpinned some of the most puzzling behaviour in the system based on analysis of cognitive maps.

The description of SD causal loop diagram

Based on the interviews with the management of the division, the decision to reduce the workload of employees that have flexible contracts or reallocate them temporarily was the easiest and fastest solution to fill the gaps in budget when there are empty beds (Duryan et al., 2012). The causal loop diagram (Figure 3) demonstrates the consequences of that decision from perspectives of the families of ID clients and group leaders. 
All the loops on the diagram are reinforcing (vicious/virtuous cycles), which means that the feedback increases the impact of a change and leads to exponential growth and collapse. Reinforcing loops tend to amplify whatever is happening in the system. For instance, frequent 'flex pool shifts' lead to reduction of 'time spent with the clients' which reduces 'knowledge about the clients' needs'. That in its turn affects relations of trust between the group leader and the client which leads to increase in 'clients' stress' variable, because personal attachment that develops as a result of trust is especially important for people with ID due to the fact that they are less adept in dealing with stressful situations on their own (De Schipper \& Schuengel, 2010).

Moreover, it is important to take into account that the group leaders serve as the point of contact between parents and the service system and so they play an important role in the effectiveness of the delivery of services. In some cases the clients' stress increases their aggressive behavior which causes group leaders' burnout. As the loop demonstrates (Figure 3) group leaders' stress increases sick leaves, which causes even more increase in shifts to replace absent workers. Accumulated group leaders' stress makes them feel uncomfortable and insecure which may affect their loyalty to the organisation and eventually (with time delay) may lead to increase in number of their turnover. For example during five years period (2007-2011) 141 workers with flexible contracts left the division taking with them experience and knowledge of working with the clients with special needs. That stressed the clients as new group leaders should be hired or assigned from other teams to serve them. And it takes time (for some clients even years) to know the clients enough to make them feel comfortable. Assigning group leaders from other teams brings changes to the schedules of the whole team, increases their shifts which only contributes to the vicious circle that may eventually lead to collapse of the system.

The other loop demonstrates that because of the shifts the group leaders do not feel secure and comfortable with their work and so they cannot be loyal to the organisation. Group leaders' turnover only adds to necessity to increase shifts until the new group leaders are hired and trained enough to become a part of the team. And finally the third loop demonstrates increase in clients' stress due to increase in number of group leaders they deal with because of shifts. That eventually leads to even more increase in flex pool shifts.

These loops demonstrate that if the management keeps applying that symptomatic solution to the problem situation without considering the views and perspectives of the main players of the system, the system may be thrown out of balance on the long run. At the same time, if the management finds the ways to reduce shifts, the vicious cycles may turn into the virtuous cycles. Reduction of shifts can eventually lead to minimizing the stress for both groups of the key stakeholders.

After building CLD (Figure 3) a workshop with the directors of three divisions of the ID organisation was organized with the goal to get their feedback and see whether 
the structured key stakeholders' perspectives can help them in identifying potential points of intervention.

\section{The problem structuring workshop with the senior management}

The purpose of building SD diagrams is to learn about the causality in order to prevent reoccurrences of the unwanted events. Verifying a causal network by communicating it back to interviewees is a good way to strengthen the validity of the findings (Miles and Huberman, 1994). The CLD diagram (Figure 3) and other results of analysis of cognitive maps (Duryan et al., 2013) supported debate among senior managers of the ID organisation leading to identification of the most important aspects of the problems to be resolved in order to satisfy key stakeholders of the organisation.

The reinforcing feedback loops on the diagram clearly demonstrated the consequences of the quick fixes (frequent shifts) to the problem situation. During the debate, participants were encouraged to identify concepts which may become intervention points for changing loops from vicious circles into virtuous circles. So the challenge for the senior managers was to work out actions that would help to balance the system. The CLD on Figure 4 demonstrates how senior managers suggest breaking the perpetual feedback loops.

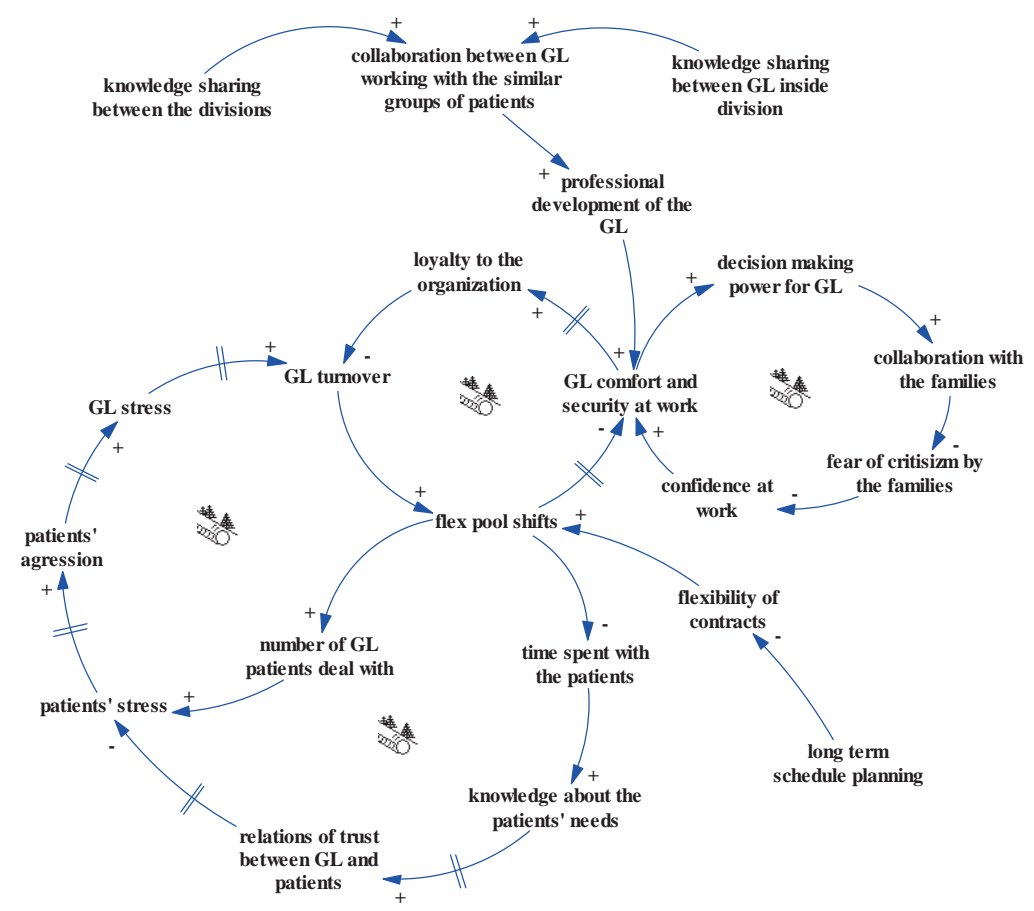

Figure 4. Revised SD causal loop diagram 
After getting aware of the results of the analysis of the merged cognitive maps (Duryan et al., 2013), the senior management was convinced that the reduction of the flex pool shifts is of high importance. One of the ways to reduce the shifts suggested by the directors was organizing a special group of flex pool workers who will replace group leaders on sick leave (only $20 \%$ of the workers in comparison with $70 \%$ as it is now). By doing so, the division will not need to increase shifts in schedules for the majority of group leaders.

Moreover, the management suggested another way to reduce group leaders' burnout which may significantly reduce their sick leaves. The division plans to turn from the short-term planning (three months) for flex pool schedules to long-term (one year) planning. Currently, the group leaders are notified about the changes in their schedules only one month before. Having 'Shift Roster' as suggested by the management, the schedules will be agreed with the group leaders one year ahead. Working this way may significantly reduce flexibility of contracts and so the shifts in the schedules. Thus, the 'sick leaves' variable can be removed from the CLD because due to decisions made by the senior management of the division the variable will not affect 'flex pool shifts'.

Reduction of shifts will reduce the client's stress which will reduce group leaders' burnout and will positively affect their turnover which in turn will reduce the need for the shifts even more. Reduction of shifts is very important not only for the group leaders. Dealing with many workers is very stressful for the clients causing more instability in their behavior which eventually adds to group leaders' stress. As one of the family members has mentioned: "about 50-60 group leaders worked with our son during a year, and it was too much!"

One of the factors affecting group leaders' comfort and security at work was fear of criticism by the families of the clients because of not collaborating with them and not involving them when there is a need (Duryan et al., 2013). The families also were unhappy with the speed of decision making when there was urgent need for help. The reason for that is that the group leaders are not secure to make decisions without first applying to the management for approval even in regards to minor issues.

The solution suggested by the senior management during the workshop was to provide group leaders with more freedom to make decisions. The group leaders should get more power to make decisions and get support and coaching from the management only when there are serious issues with the clients. Freedom to make decisions may promote collaboration with the families in a more effective and efficient way, may reduce group leaders' fear of criticism, and increase their confidence, which can make the working environment more friendly and comfortable. Of course there are limits in freedom to make decisions and limits in involvement of families, so the limiting factors will balance reinforcing loop which may eventually slow down at some level. 
More power in decision making leading to group leaders' comfort and security at work may reduce their turnover, the main reason for more needs for flex pool shifts after elimination of 'sick leaves' variable.

Another factors influencing group leaders' security at work was their professional development (Duryan et al., 2013). The senior managers suggested creation of knowledge sharing environment where not only the group leaders of the division that work on similar cases can work together time to time but also group leaders from the other divisions. For example some of the group leaders felt insecure working with clients with aggressive behavior, and they mentioned that practicing with colleagues who have many years of experience could be very helpful.

These were important steps that can be put into practice in order to help the division to restore balance and look to the future. The CLD model (Figure 4) presents managerial thinking about possible changes. It was verified by feeding it back to senior managers. And also, it was checked against the available literature to establish validity. However, it was not yet empirically tested.

\section{Discussion}

The application of combined cognitive mapping and qualitative system dynamics methodologies had several major benefits. First of all, cognitive maps made interpretation of the mental models of interviewees visual and so explicit. Cognitive maps allowed interviewees see their own thoughts expressed using their language strategically organized and it made discussion more constructive. Well structured maps made the process of testing and refining much easier. The maps also stimulated new thoughts and creative ideas around the key issues. They facilitated group leaders' and families' thinking from perspectives of the management of division as if they were decision makers themselves.

The second major benefit was that analysis of cognitive maps provided senior management with structured view of the stakeholders' perspectives on resource allocation issues in the division. Cognitive mapping helped the senior managers understand better the cultural, social and psychological implications of decisions made.

The directors of the divisions of the organisation believe they know the solution as they are concerned with financial wellbeing of their divisions. However, they do not perceive how their actions may affect the whole organisation. Without systemic view on the organisation as a whole their actions, based on short-term perspectives, can return to cause harm to the division on the long run.

Third, the ability of CLD to translate complex data into simple explanation and to demonstrate the set of non-obvious interdependencies between factors helped the senior managers of the organisation get deeper insight into important issues related to resource allocation policies. It helped them see the dynamic behaviour of the system 
from perspectives of their clients and front-line workers. The reinforcing feedback loops in CLD clearly demonstrated the consequences of the quick fixes to the problem situation. Understanding the interdependencies in the system helped the managers see the high-leverage points and to think of actions that can balance the system.

The fourth benefit of the combined approach was reduction of confusion the managers had due to the limited resources in the organisation. They were concerned with not having enough financial and human resources to implement changes. However, analysis of cognitive maps helped them see that even having limited resources more effective and efficient allocation policies that consider suggestions of the care receivers and those who work with them on daily basis may bring influential changes.

It also became clear that any strategic changes make little sense without first considering the perspectives and views of the key stakeholders. Because some of the decisions made lately have only escalated the problems. CLD helped senior managers not only see where is the best leverage point for intervention but also to see how their ideas can balance the system.

When the managers realized how their decisions reinforce the vicious cycles they were willing to take some ownership to break those cycles. As a result of these insights, senior management was able to address problem symptoms associated with declining families' satisfaction with the services and declining workers' loyalty to the organisation.

Since the introduction of various forms of client-centred planning in the late 1980s, ID care providers are obliged to provide services to persons with intellectual disabilities based on some form of client-centred planning. However, sometimes there is a problem of finding the right balance between the needs of care-givers and professionals and the needs of the customers (Shortell et al., 1995). At the same time it is important to keep in mind that in health care people are the most important component of the system. And survival of the organisation depends on satisfying the key stakeholders according to their definition of what is valuable. Thus, collaborative representation of the key stakeholders in decision making cannot be underestimated. The methodology applied clearly demonstrated that having good intentions but limited awareness and understanding of the full impact of senior management actions does not bring the changes they expected.

There is a need to acknowledge the fact that front-line workers and even customers, who are not experts, can help in understanding complex relationships in the organisation if their collaborative participation is properly managed. Involvement of families and group leaders into the organisational change process helps generating information relevant for decision making. Moreover, participation in decision making and contribution to the bigger picture can give the families and the group leaders' sense of ownership of the ideas for change. Their motivation is very important as the management needs stakeholders' commitment in order to implement changes. The case study demonstrated that a combination of qualitative system dynamics modelling 
and cognitive mapping techniques can act as a powerful tool in facilitating bottom-up knowledge for managerial decision making in long-term health care providers. As the study was conducted in an ID care provider in the Netherlands, it is worthwhile to test the methodology in a broader context i.e. in other long-term health service providers in different countries. 


\section{References}

Ackermann, F., Eden, C. \& Williams, T. (1997). Modeling for litigation: mixing qualitative and quantitative approaches. Interfaces 27(2), 48-65.

Ackermann, F. \& Eden, C. (2011). Making Strategy: Mapping Out Strategic Success. London: Sage Publication.

Adam, T., \& de Savigny, D. (2012). Systems thinking for strengthening health systems in LMICs: need for a paradigm shift. Health Policy and Planning, 27(4), iv1-iv3.

Anderson, P. (1999). Complexity Theory and Organization Science. Organization Science, 10(3), 216-232.

Begun, J., Zimmerman, B., \& Dooley, K. (2003). Health care organizations as complex adaptive systems. In: S. Mick, \& M. Wyltenbach, (Eds.), Advances in Health Care Organization Theory (pp. 253-288). San Francisco, Calif: Jossey-Bass.

Bertalanffy, L. V. (1968). General System Theory: Foundations, Development, Applications. New York: George Braziller.

Burstein, F., \& Holsapple, C. (Eds.) (2008). Handbook on Decision Support Systems 1: Basic Themes. Berlin: Springer-Verlag.

Checkland, P. (1981). Systems Thinking, Systems Practice. New York: John Wiley and Sons.

Checkland, P. (1985). From optimizing to learning a development of systems thinking for the 1990s. Journal of Operational Research Society, 36(9), 757-767.

Churchman, C. (1968). The Systems Approach. Delacorte Press, New York: Dell Publishing.

Daft, R., \& Weick, K. (1984). Toward a model of organizations as interpretation systems. Academy of Management Review, 9(2), 284-295.

Duryan, M., Nikolik, D., van Merode, G., \& Curfs, L. (2012). System Dynamics Modelling for Intellectual Disability Care: A Case Study. Journal of Policy and Practice in Intellectual Disabilities, 9(2), 112-119.

Duryan, M., Nikolik, D., van Merode, G., \& Curfs, L. (2013). Reflecting on the Efficacy of Cognitive Mapping for Decision Making in Intellectual Disability Care: A Case Study. International Journal of Health Planning and Management, http://onlinelibrary.wiley.com/doi/10.1002/hpm.2215/abstract

Dumas, B. (1985). Hospital bed utilization: An implemented simulation approach to adjusting and maintaining appropriate levels. Health Services Research, 20(1), 43-61.

Eden, C. (1992). On the Nature of Cognitive Maps. Journal of Management Studies, 29(3), 261-266.

Eden, C. (1994). Cognitive mapping and problem structuring for system dynamics model building. System Dynamics Review, 10(2), 257-276,

Eden, C. (1988). Cognitive mapping. European Journal of Operational Research, 36, 1-13.

Eden, C. \& Ackerman, F. (1998). Making Strategy, the Journey of Strategic Management. London: Sage Publications.

Eden, C., \& Ackermann, F. (2001). SODA - The Principles. In J. Rosenhead, \& J. Minger (Eds.), Rational Analysis for a Problematic World Revisited (pp.21-41). Chicherster, UK: Wiley.

Forrester, J. (1961). Industrial dynamics. Cambridge, MA: MIT Press.

Galbraith, J. R. 1973. Designing complex organizations. Reading, MA: Addison-Wesley.

Galbraith, J. (1977). Organizational design. Reading, MA: Addison-Wesley.

Homer, J., \& Hirsch, G. (2006). System dynamics modeling for public health: Background and opportunities. American Journal of Public Health, 96(3), 452-458.

Holland, J. (2006). Studying Complex Adaptive Systems. Journal of Systems Science and Complexity, $19,1-8$.

Jackson, M. (2002). Systems Approaches to Management. New York: Kluwer Academic Publishers.

Jansen, D., Krol, B., Groothoff, J., \& Post, D. (2006). Towards Improving Medical Care for People with Intellectual Disability Living in the Community: Possibilities of Integrated Care. Journal of Applied Research in Intellectual Disabilities, 19(2), 214-218.

Kommer, G. (2002). A waiting list model for residential care for the mentally disabled in the Netherlands. Health Care Management Science, 5, 285-290.

Lane, D. (1994). With a little help from our friends: how system dynamics and soft OR

can learn from each other. System Dynamics Review, 10(2-3), 102-134. 
Miles, M., \& Huberman, A. (1994). Qualitative Data Analysis. Thousand Oaks: SAGE publications, Inc.

McLucas, A. (2003). Decision Making: Risk Management, Systems Thinking and Situation Awareness. Canberra: Argos Press.

Mingers, J., \& Rosenhead, J. (2004). Problem structuring methods in action. European Journal of Operational Research, 152(3), 530-554.

Morecroft, J., \& Wolstenholme, E. (2007). System dynamics in the UK: a journey from Stirling to Oxford and beyond. System Dynamics Review, 23(2-3), 205-214.

O’Dell, R., Leafman, J., Nehrenz, G., \& Bustillos, D. (2012). Health Care Decision Making

and Adults with Intellectual Disability: A Descriptive Survey. AJOB Primary Research, 3(1), 8-13.

Organisation for Economic Co-operation and Development (OECD), Health Care Reform and Long-Term Care in the Netherlands. (2013). Economic Department Working Paper No. 1010. Retrieved from http://www.oecd-ilibrary.org/economics/health-care-reform-and-long-term-care-in-thenetherlands_5k4dlw04vx0n-en;jsessionid=5gq6e7o7w8v38.x-oecd-live-01

Porter, M. (1992). Capital Choices: Changing the Way America Invests in Industry. Boston: The Harvard Business School.

Roeden, J., Maaskant, M. \& Curfs, L.(2010). The views of clients with mild intellectual disabilities regarding their working relationships with caregivers. Journal of Applied Research in Intellectual Disabilities, 24(5), 398-406.

Rosenhead, J., \& Mingers, J. (Eds). (2001). Rational Analysis for a Problematic World Revisited. 2 nd ed. Chicherster, UK: Wiley.

Senge, P. (1990). The fifth discipline: The art and practice of the learning organization. New York: Bantam Doubleday, Dell Publishing Group, Inc.

Shortell, S., O'Brien, J., Carman, J., Foster, R., Hughes, E., Boerstler, H., \& O'Connor, E. (1995). Assessing the Impact of Continuous Quality Improvement/Total Quality Management: Concept versus Implementation. Health Services Research, 30(2), 377-401.

De Schipper, J., \& Schuengel, C. (2010). Attachment behaviour towards support staff in young people with intellectual disabilities: associations with challenging behaviour. Journal of Intellectual Disability Research, 54(7), 584-596.

Stacey, R. (2010) Complexity and Organizational Reality: Uncertainty and the need to rethink management after the collapse of investment capitalism, London: Routledge.

Sterman, J. (2000). Business dynamics: Systems thinking and modeling for a complex world. New York: McGraw-Hill.

Sterman, J. (2001). System Dynamics Modeling: Tools for Learning in a Complex World. California Management Review, 43(4), 8-25.

Sundaramoorthi, D., Chen, V., Rosenberger, J., Kim, S. B., \& Buckley- Behan, D. (2009). A data-integrated simulation model to evaluate nurse-patient assignments. Health Care Management Science, 12(3), 252-268.

Turnbull, S. (2002). The science of corporate governance. Corporate Governance: An International Review, 10(4), 256-272.

Vissers, J., Bertrand, J., \& De Vries, G. (2001). A framework for production control in health care organizations. Production Planning \& Control: The Management of Operations, 12(6), 591-604.

Wolstenholme, E. (2004). Using generic system archetypes to support thinking and modeling. System Dynamics Review, 20(4), 341-356. 


\section{CHAPTER 5}

\section{Facilitating Bottom-Up Knowledge to Support Decision-Making in Service Organisations}

Duryan, M., van Merode, G., Nikolik, D., Curfs, L. M. G. Facilitating Bottom-Up Knowledge to Support Decision Making in Traditional Service Organisations: A Case Study in a Health Care Service Provider: Submitted 


\section{Abstract}

Purpose - Service output in healthcare service organisations and especially in longterm care depends on collaborative efforts of frontline workers, management and the customers. However, the top-down style of management in traditional service organisations discourages participation of employees, customers and other stakeholders in decision making. Senior management of healthcare service organisations and policy makers need tools that will facilitate the collaborative input and will help them produce long-term policies shaped by evidence in order to tackle the causes of the problems and not the symptoms.

Design/methodology/approach - The case study, set in a healthcare service provider in the Netherlands, illustrates that cognitive mapping and qualitative system dynamics techniques can be meaningfully combined to promote stakeholders representation in managerial decision making.

Findings - Strategic changes in the organisations make little sense without considering the perspectives of the key stakeholders. Cognitive maps combined with qualitative system dynamics models allowed consideration of soft factors and provided senior management with detailed feedback from the stakeholders relevant for decision making which helped them reconsider their previous decisions.

Originality/value - Service experiences in long-term care are often intangible as they are the outcomes of interactions between organisations, the employees and the customers. They depend on soft factors like staff motivational levels, abilities and traits, role perceptions and management support. The study demonstrated that longterm health care service providers can improve their efficiency if they improve collaboration with the frontline workers and the customers with the help of the methodology that allows generating structured presentation of mental models of the key stakeholders appropriate for managerial decision making. 


\section{Introduction}

Healthcare provider is any individual, institution, or agency that provides health services to health care consumers (Mosby's Medical Dictionary). Rapidly changing markets, planned governmental reforms, shortages in resources, changes in society and increasing customer expectations make long-term decision making a challenge for healthcare service organisations having a traditional hierarchical structure. These organisations no longer provide a platform for effective and efficient management and operations.

Senior executives in hierarchical organisations usually rely on accountability, control of planning, and reinforcement of rules (Senge, 1990; Hoff, 2003). However, it is not always possible to control the working floor from the top.

Performance in service organisations depends on staff motivational levels, abilities and traits, and role perceptions among other factors (Mills et al., 1983; Porter \& Lawler, 1968). The frontline workers play an important role in the effectiveness of the delivery of services (Robertson et al., 2005; Sharrard, 1992; WHO, 2010). There is abundant evidence that service output depends on collaborative efforts of the service employees and the customers (Gwinner et al., 1998). Therefore, without considering the viewpoints of the frontline workers and the customers of a service organisation, any managerial decision is likely to bring short-term gains at the expense of longerterm results.

In order to get a better understanding of service performance it is necessary to analyze service delivery processes from the perspective of the transactions between the customer and the employee (Mills et al., 1983). The unpredictability and variability of customer demands and the intangibility of service delivery makes it difficult to monitor employee behaviour in service encounters. Competitive advantage can be achieved via transformation into a learning organisation by nurturing openness, creativity and commitment (Senge, 1990). The environment of a "passion for service excellence" in service providers can be created only if there is a mutual trust and effective top-down and bottom-up communication.

Organisational values begin with its leadership (Senge', 1990; Tsai, 2011). Usually managers of traditional organisations believe that employees do not need to see the big picture, knowing what is expected of them is enough. As a result, it is very difficult to inspire people and to get their full commitment to the organisational goals (Senge, 1990).

Service organisations need leadership, not just management, in order to capitalize on strengths and the abilities of employees and others to contribute to the accomplishment of organisational goals. The leaders of service organisations need tools that will allow them develop a "learning organisation", so that structured input from the frontline workers, the customers, and other stakeholders can be used for their decision making. In order to avoid short term symptomatic solutions, they need to know 
more about how soft factors (i.e. staff moral, motivation, stress and management support) affect organisational performance.

The central focus of this article is to understand the main reasons for inefficiency of resource allocation policies in long-term healthcare service providers. For that, we explored understandings and practices around decision making processes in one healthcare provider in the Netherlands. Understanding the factors that influence decision making process is crucial for understanding what decisions are made and how they impact the outcomes. To be able to study decision making processes in complex organisations we need to understand the real nature of the processes, their dynamics, their interconnections and the possible outcomes. Systems Thinking approach used in this research can help seeing complex interconnection between parts of the system.

The model used for the case study allows presentation of mental models of the key stakeholders to the senior management. It demonstrates the need for better resource allocation policies, especially considering increased consumer demand and diminishing resources in healthcare in the Netherlands and in other OECD (Organisation for Economic Co-operation and Development) countries.

\section{Building a strong service culture}

\section{Traditional service organisations}

Planning, organizing, and carrying out change processes can be particularly challenging for traditional services organisations because they are mainly oriented toward controlling rather than learning. It is very challenging for traditional hierarchical organisations to survive in a dynamic business environment because they are too slow in responding (Senge, 1990).

The service profit chain is about "developing an environment in which highly capable, engaged employees, acting as owners, interact with customers to create customer value far superior to that offered by the competition" (Maglio et al., 2010, p. 23). The quality of service experience for the customers will be dependent on employees, because service performance is often intangible and the organisations do not own any of the factors of service. As expectations of each customer are different, the employees need to be motivated enough to ensure that those expectations are met.

The environment of openness and transparency is critical for building trust in the organisation, which is one of the very important factors in building a strong organisational culture that is based on the shared values, beliefs, or perceptions held by employees (Robbins and Coulter, 2005).

The managers of traditional service organisations cannot control quality of services delivered to each customer on the working floor. Because of their distance from the frontline processes, they know less about how to implement strategies than those 
closer to the process (Hoff, 2003). The managers need to consider the views and perspectives of frontline workers in order to design more effective work processes.

The organisational culture "fills the gaps between what the organisation can train its employees to do and what the guest expects" (Bowen and Ford, 2002, p. 461). That is why it is crucial for building an organisation with a strong service climate where the employees can develop a "passion for service" (Bowen and Ford, 2002; Ford \& Heaton, 2000; Kane-Urrabazo, 2006; Van Maanen, 1989).

Acceleration of organisational learning, which moves beyond a simple employee training into organisational problem solving and innovation, can significantly contribute to establishment of a strong service culture (Paton and McCalman, 2000. It may enable the employees to do more value-adding work. Their knowledge can also be made available to support managerial decision-making

The organisations that lack learning culture are at the risk of repeatedly applying old practices, which can lead to application of merely cosmetic changes (Paton and McCalman, 2000; Warren, 2002).

\section{A learning organisation}

A learning organisation is one that learns and continually develops its capacity to create its future (Senge, 1990; Paton and McCalman, 2000). "Organisations learn only through individuals who learn" (Senge', 1990, p. 139).

In order to ensure that individual learning leads to organisational learning, the leaders of the organisations need to inspire the readiness of the employees for growth challenges. Therefore, the leaders are responsible for setting the strategic direction to help the employees see the big picture. Continuously learning employees develop an ability to see reality more accurately. The leaders' role is to clearly communicate the vision of the organisation and be transparent about the current state of affairs in the organisation. A shared vision offers employees sense of responsibility and commitment in developing shared images of the future (Senge', 1990).

Appropriate information for managerial decision making is interpreted according to the knowledge of people using it. So, the managers should deal with the dynamic processes using shared vision of their employees and customers to deal with bounded rationality (cognitive limitations of people's minds) and make appropriate decisions quickly and effectively.

\section{The power of intangible resources}

Service experiences are often intangible as they are the outcomes of interactions between organisations, the employees and the customers. Most managers realize that it is very important to build the organisational resources, both tangible and intangible. 
However they mainly focus on tangible factors that account for revenues and costs because they can easily be seen, counted, bought, and hired.

According to Deming (1986), the one who runs the organisation on visible figures alone may eventually have neither the organisation nor figures. The leaders of the organisations realize that soft factors play an important role, however, they know little about how they affect tangible factors and eventually organisational performance (Warren, 2002). When it comes to soft factors (i.e. staff moral, stress, burnout, management support) they are left with a little guidance (Warren, 2002).

Producing intangible products can be challenging for the managers of the service organisations, especially because the services are not commodities that can be stocked and stored. Failure or success of intangible products is typically identified by the employee interaction with the customer while the product is being consumed (Bowen and Ford, 2002).

There are two forms of intangible resources: indirect resources (feelings, expectations) and characteristics associated with tangible resources. In this article we focus on indirect resources. As Warren (2002) mentioned, intangible resources take time to accumulate, can be destroyed rapidly and have decisive effect on tangible factors (Warren, 2002).

The perceptions of the key stakeholders of a service organisation (the customers and the frontline workers) are the most common intangible resources. Deming (1986) mentioned that the quality of products or services is seen through the eyes of the workers, the customers and the managers. Many productivity problems of the service organisations can be related to the motivation of service employees. If employees are not motivated to produce better results, the organisation will have no gain in productivity (Jackson, 2003).

Frontline workers especially those who serve vulnerable population (i.e. elderly, physically and/or intellectually disabled) are expected to make and enforce the choices for those who are not able to choose for themselves. They share the responsibility with the management and their failures can cause burnout leading to staff turnover. Therefore, the leaders need to ensure that the employees are aware of their own values and that their input will be considered (Devine, 2010).

Service delivery process involves customers that is why the effectiveness of services, especially those with high customer contact, can be increased by paying more attention to their needs (Mills et al., 1983; Bowen and Ford, 2002). The customers' input in the process of service delivery is information that is transformed by the employee into service. They should be given the opportunity to participate at some level in creating the service and ensuring their own satisfaction. In order to involve the customers as temporary members, the boundaries of the service organisations have to be expanded (Mills and Morris, 1986).

The managers of the service organisations must develop communication strategies that enable their customers to take part in the co-production of the service. It may 
reduce the need for additional labour costs. Furthermore, customers' active involvement may reduce observer biases towards the quality of the services.

In order to achieve motivation and engagement of the frontline workers and the customers in building healthy service environment the organisations need to move from ordering and controlling (management) to designing and guiding (leadership).

\section{From management to leadership}

Senge (1998) defines leadership as the inner capacity of a human community to create its own future. In traditional organisations the managers "face the temptation of assuming too much control, making too many of the decisions, and excessively imposing their own will in making the change process work" (Hoff, 2003, p. 30). The image of a leader who makes the key decisions is a very common non-systemic worldview (Senge, 1990). The organisations need to recognize that management is part of a leadership that stimulates the growth of the company by preserving and communicating its core values and beliefs and by cultivating conditions for organisational growth and development (Lumsden and Wilson, 1981). Leaders initiate and reinforce continuous improvement (Deming, 1986). They are role models for their employees and their behaviour influences the commitment and performance of their employees, thereby shaping the development of the working environment in the organisation.

Deming (1986) with his $85 / 15$ rule contends that 85 percent of an employees' effectiveness is determined by the system within which they work and only 15 percent is determined by their own skill.

In order to build a strong foundation for effective leadership, an environment of trust among all parties involved is necessary. Communication is a cornerstone for development of the relations of trust between the leaders and employees. Effective leaders must be aware of daily experiences of the employees on the working floor.

In order to empower and motivate employees, the managers should give them the opportunity to participate in decision making. Frontline workers will definitely appreciate the attitude of trust as they need more freedom to make decision (Hoff, 2003). Providing clear direction should be accomplished through frequent and unambiguous top-down and bottom-up communication and development of a vision that allows employees to understand that changes are necessary and realistic (Hoff, 2003). Senge contends that if any idea about leadership has inspired organisations for thousands of years, it's the leader's capacity to "hold a shared picture of the future we seek to create" (Senge', 1990, p. 9). To this end some of the concepts of Systems Thinking are useful. 


\section{Intervention tool}

\section{Overview of Systems Thinking}

Systems Thinking is a theory addressing the interrelationships between parts and their connections to a whole system. Within the constructs of this theory, goals and resources are established with a view toward the whole system, rather than artificially allocating them to parts of the system (Plsek \& Wilson, 2001; Richmond, 1994; Senge, 1990). The theory was developed as a discipline, in the 1940 s and 1950 s, mainly as reaction to the reductionism of the traditional scientific method of dealing with the complexity "inherent in the biological and social domains" (Jackson, 2003, p. 11).

Systems Thinking (or soft Operational Research (OR)) approach is a learning process that can help to identify what needs to be done in ill-defined problem situations (Checkland, 1981). The approach is important when we work with mental models.

When we collaborate with the stakeholders, we deal with multiple perspectives and bounded rationality, and that is why it is very important to have the tools that can help fully represent all the perspectives and views. Individuals differ greatly in their views and experience of any situation. The same event impacts differently on each individual. People see things differently, based on all the experiences that have shaped their assumptions, responses and expectations (Hall and Keynes, 2010). In Systems Thinking we accept that we cannot know everything about problem situations which makes us value the different perspectives (Hall and Keynes, 2010).

One of the modern soft interpretive OR tools for studying the mental models is cognitive mapping, the technique suggested by strategic options development and analysis (SODA) developed by Colin Eden in the late 1980s (Eden and Ackermann, 2001). SODA recognizes the importance of human perceptions and interpretations while dealing with subjectivity and uncertainty (Rosenhead and Mingers, 2001). The core function of SODA is to allow problematic situations to be explored effectively, in order to arrive at good decisions

The single core technique at the heart of the SODA approach is cognitive mapping. Cognitive maps are based on personal construct theory (Kelly, 1955) and represent an individual's perspective on any particular situation (Hall and Keynes, 2010).

\section{Overview of cognitive mapping}

Research on the psychology of individual choice emphasized cognitive bounds among other limitations on human rationality that often produce systematic biases (Sterman, 1989). A cognitive map is a two-dimensional directed graph that has been widely used to represent subjective knowledge about perceived causes and perceived links between them (Eden, 1992; Eden and Ackermann, 2001). There are rules described in cognitive mapping guidelines that restrict each concept to 8-10 words (Ackerman and 
Eden, 2010). The links between the nodes represent logical implications between the concepts that are structured into a hierarchy that demonstrates the cause and effect between them.

The individual cognitive maps can be merged into a bigger one which represents the richness of different perspectives of the problem and also secures agreement about its nature among the interviewees during the focus groups.

The maps help capturing the rich complexity of the situation, and discover patterns in what is happening that others will find convincing (Hall and Keynes, 2010). The method allows multiple conflicting individual views to be revealed and reduces the level of conflict during subsequent discussions (Ackerman and Eden, 1994).

The technique can be used by the senior management of any service organisation as a tool to support strategic decision making. However, cognitive maps do not allow seeing dynamic behavior of the system. They do not demonstrate feedback processes and time delays. That is why we need System Dynamics (SD) causal loop diagrams (CLD). Cognitive mapping technique can promote better understanding of stakeholders' mental models and so they can support the development of CLD, which in turn can help studying complex interactions between the concepts.

\section{Overview of System Dynamics}

SD causal loop qualitative diagrams demonstrate circular causality and serve as a medium by which people can visualize and share mental models and assumptions (Wolstenholme, 1999). CLDs are visual tools for the feedback systems thinker. The diagrams provide a language for articulating our understanding of the dynamic nature of the system studied. They are analytical tools that are widely used in SD modelling (Reynolds and Holwell, 2010). Any organisation can be viewed as made up of reinforcing (positive) and balancing (negative) processes. CLDs can describe the organisation as a system via combination of reinforcing and balancing loops connected together with arrows. Particular combinations of reinforcing and balancing processes within the system can be the reason for system's complexity (Senge, 1990). CLDs also give insight into the phenomena that certain patterns of systems' behaviour recur repeatedly (Senge, 1990).

Faced with the complexity of problem situations, the managers can use CLDs to learn about the dynamic behaviour of the system. An understanding of how feedback loops interact to cause system behaviour can inform the managers about the consequences of decision made. The diagrams can help the management to see the side effects of their decisions and to better understand the interconnected nature of the problems. 


\section{The reasoning behind combination of two methodologies}

Combination of SD with other systems approaches was seen as being very successful (Morecroft and Wolstenholme, 2007). The idea of using cognitive maps to help conceptualise SD models was first articulated by Colin Eden in 1988 (Eden, 1988). Cognitive mapping technique can support the development of CLD via providing better understanding of stakeholders' mental models. CLD in turn can help studying complex interactions between the concepts. There is no doubt that a dynamic simulation is preferable to a static cognitive map diagram, however there are some situations where simulation is not possible. It is not easy and in some cases not possible to quantify "soft" variables and their relationships.

The idea to produce a working model for simulation might not be justified by the quality of the results. There is no doubt that even without "soft" variables a mathematically consistent model can be used to run simulations. However, when the soft variables have a big impact on the system, as it is in the case study described in this article, the simulations would not reflect the reality. That was the reason for building SD causal loop diagrams without simulation. It has been argued that building the models can be beneficial as an enhancement to linear thinking even without simulation (Coyle, 2000; Wolstenholme, 1999; Wolstenholme and Coyle, 1983).

\section{The demonstration of applied methodology via a case study}

\section{Background}

Healthcare organisations are complex entities because of multiple stakeholders with often conflicting interests and goals (Drucker, 1993). Intellectual Disability (ID) care providers can serve as an example of complex health care service organisations. The specifics of ID care require deeper involvement of the caretakers in their relations with the patients' families and other parts of society, which adds to their complexity.

Healthcare industry in the Netherlands is effective but costly. According to OECD report (2013), in 2009, the Netherlands was the second largest health spender after the United States. Nowadays, the Netherlands, as other OECD countries, faces the challenge of providing high quality health and long-term care services to an ageing population in a cost-efficient manner (OECD, 2013). A large share of total healthcare costs is taken up by healthcare for people with ID. In 2010, public expenditure on longterm care in the country accounted for about 3.7\% of GDP (OECD, 2013).

Funding for ID services in the Netherlands is mostly a central government responsibility. It is provided on the basis of the General Act on Exceptional Medical Expenses (Algemene Bijzondere Ziektekosten (AWBZ)). More than 800,000 older people and 
people with physical, mental, sensory or mental limitation, currently make use of longterm care under AWBZ.

Service output in care provider organisations depends much on the collaborative efforts of frontline workers and the customers. In order to increase efficiency of the ID care providers and improve long term decision making the managers should learn more about the interests of care receivers and frontline workers, the most important actors of a complex service provider system.

The case study in one of 135 ID care providers in the Netherlands illustrates the possibilities of the combined methodology (Figure 1) to assist the leaders of the service organisations in their decision making by presenting the structured key stakeholders perspectives.

\section{The case study in an ID care provider}

We started the study with the interviews with the top management of an ID care provider to learn about the main issues of their concern. The interviews indicated that the budget gaps in the division due to the shortages of the patients in residential care are the biggest challenge from their perspectives. The easiest and fastest solution for the managers to fill the budget gaps was to cut costs via reduction of the workload of the frontline care workers ("group leaders" in ID care in the Netherlands) with flexible contracts. We studied the factors that were considered for decision making to that problem situation and the consequences of that decision for the frontline employees and the customers.

As interviews with frontline workers demonstrated, they were unhappy with the decision made. Cutting costs via reduction of working hours leads to shifts in their schedules which in its turn causes reduction in their income forcing them to search for additional work elsewhere. In the long run, shifts in the schedules and salary reduction create tension and can compromise the employees' loyalty, which eventually leads to an increase in employee turnover.

The families of ID patients were against that decision as well. The established relations between a care worker and the adult with ID are very important. This intangible resource that reflects the patients' feelings and expectations takes time to accumulate. Hence, relations of trust between the care workers and the patients become a valuable indirect resource which takes time to accumulate; however, it can be destroyed rapidly. Thus, shifts in employee schedules directly affect the patients. They get stressed because of discontinuity in relations with the care workers because they have to interact with more people they do not know well. Thus the negative impact of frequent shifts cannot be underestimated.

However, the delays in feedback of the system to managerial decisions do not allow them to see the immediate impact of their actions. The management of the 
organisation solves the problems from the perspectives of organisational financial well-being.

However, they do not perceive how their actions may affect service receivers and those who deliver the services on the working floor. In service industry, especially in a long-term care, the soft factors have a big impact on long-term performance of the organisation. In this case, decline in patient and employee satisfaction may lead to financial losses and also may affect the image of the organisation.

We used the ability of CLD to demonstrate the set of non-obvious interdependencies between the factors that can be affected because of that decision. Thus, with participation of the management the CLD was designed (CLD 1 diagram, Figure 1). It demonstrated possible side effects of the decision to reduce workload of the care workers with flexible contracts. That symptomatic decision leads to reduction of employee income and might cause stress to patients due to the discontinuity in relation with care workers and frequent changes of people with whom they interact.

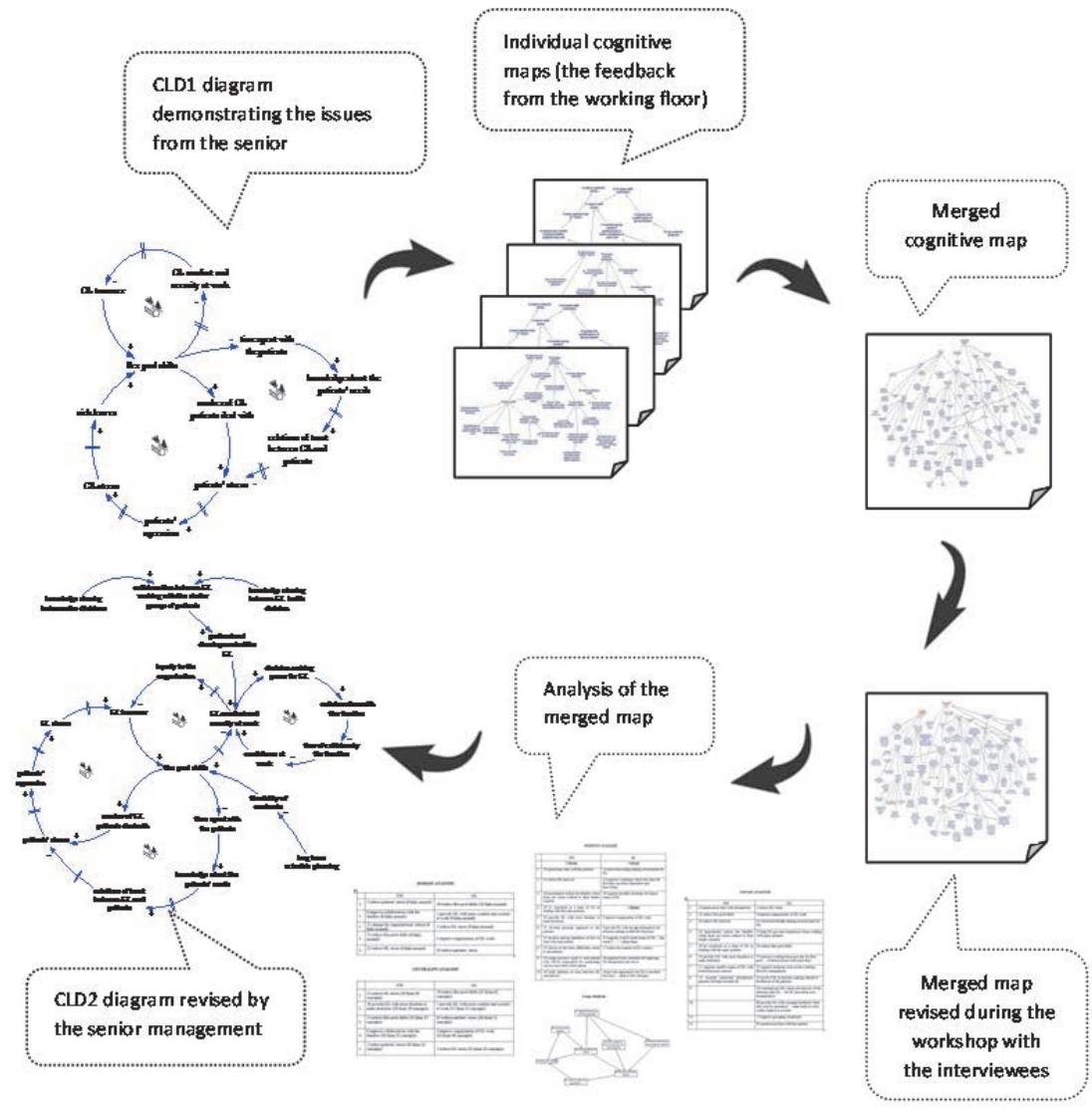

Figure 1. The process model used for the case study 
In order to learn about the perspectives of the care workers and family members of ID patients related to the challenges indicated by the senior management, the interviews and focus groups were conducted. The care workers represent the first group of the stakeholders because they are at the "sharp end" of the system as they deal directly with the patients. The second group of the key stakeholders are the families of ID patients, the receivers of care.

The individual semi-structured interviews were conducted with the eight care workers followed by the focus groups organized with them. Two focus groups were conducted with the families of young and old ID patients (seven families) considering the fact that patients of different age have different needs for treatment and leisure.

The issues perceived by the senior management of the division were communicated to them. Upon giving the feedback, the interviewees were asked to share their ideas on how services can be improved. The interviews with the key stakeholders were translated into the language of cognitive maps (Figure 1).

The maps were reviewed by the interviewees and were merged into a single map per each group of the stakeholders. After that they were refined and elaborated with the group leaders and family members during group discussions conducted in small teams.

They were analyzed using qualitative indicators provided by Decision Explorer software (Brightman, 2002). Of the various analytic tools we used the most valuable, which are Head, Centrality, Domain, Hierarchical cluster, and Potency analyses (Ackermann and Eden, 2010). Head analysis helps to identify goals and their interaction. Domain and centrality analyses were used to identify the key issues in the merged maps. Hierarchical cluster analysis involves identification of all the concepts in a map that contribute to achievement of a goal. Finally, Potency analysis allowed prioritising options that have consequences for the bigger number of key issues (Ackermann and Eden, 2010).

Cognitive mapping technique was quite helpful in facilitating shared understanding of the ideas expressed by the interviewees. It allowed participants to critically reflect upon the dynamics of the process. They mentioned the main areas of their concern and also seeing structured representation of their ideas and thoughts on the map, they came up with some recommendations for changes.

Based on the merged cognitive maps with their analysis, the new CLD diagram was designed (CLD 2 diagram, Figure 1). The diagram was explored with the senior management during a workshop. It helped them see the sight effects of their decision to reduce working hours of employees with the flexible contracts from perspectives of the care workers and the families of the patients. In order to demonstrate the process of gaining the structured feedback from the frontline to share it with the management we bring the part of the map analysis as an example.

The most crucial side effects, as perceived by the key stakeholders, were the decline in workers' loyalty to the organisation, leading to their turnover and the patients' 
stress. That is why the main factors influencing the concepts "care workers' turnover" and "the patients' stress" on the merged maps for the care workers and the family members were given particular attention.

\section{The care workers' cognitive map}

Based on the care workers' merged map, the main reasons for their turnover (how they perceive it) are stress and lack of comfort and security at work. Following the map, the most influential factors leading to the care workers' stress are: 1) the shifts in the schedules of the care workers with flexible contracts, 2) the patients' aggressive behaviour escalated by their stress, 3 ) insufficient training on dealing with the patients with complex behavioural issues, 4) working with patients the care workers do not know well and 5) time and efforts to teach the newly hired staff to deal with the patients (Figure 2).

Based on the analysis of the care workers' map, the concept "reduce the flex pool shifts" has the highest domain and centrality scores. That means the decision to cover the budget gaps via reduction of the workload of the care workers with flexible contracts is the biggest cause of stress for them. As one of the care workers mentioned: "I would suggest to the management to give us more job security by reducing the flexibility of our contracts".

The flexibility of contracts allows management sending the care workers to different residential care units in spite of their preference to work with the patients they know well (node 12 on Figure 2).

One of the interviewees mentioned that she would prefer to work with the patients in one unit as she knows them well. She even asked the management about it, however she was told that it is impossible: "...they explain why but I do not think that their arguments are valid".

As Figure 2 demonstrates, the shifts among other factors cause stress to the patients as well. As the care workers mentioned, it takes time for them to develop relations of trust with the patients with ID. "There are the patients with heavy disabilities who have combination of autism with other complex issues and it requires 4-7 years to develop relations with them".

Another care worker said: "I think that the patients need a feeling of a "home", which is not possible when you have too many people to deal with and when the ones you know leave you". One of the care workers mentioned "the patients get stressed when they have to work with someone who does not know them well". They try hard to explain themselves which makes them upset and some of them become even aggressive. Another interviewee said: "some of the patients with aggressive behaviour can get calm when they are with someone who understands them well". 


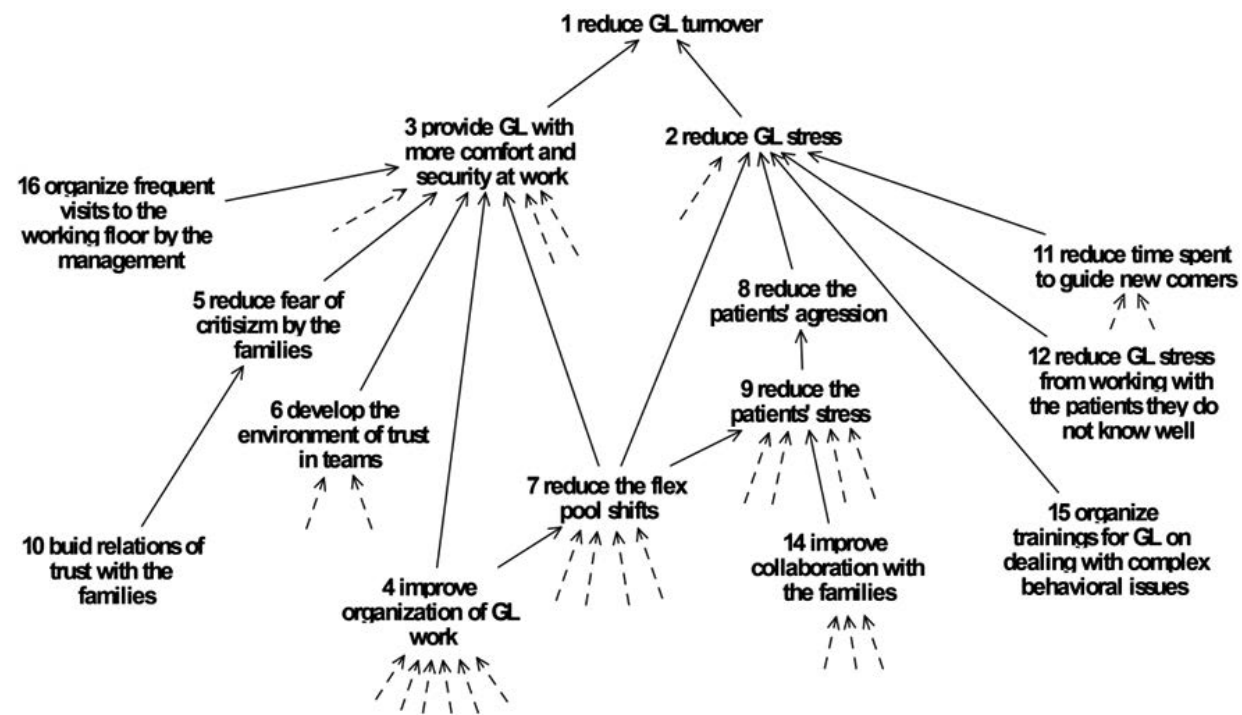

Figure 2. Segment of the care workers' (GL-group leaders/care workers) cognitive map related to their turnover (dashed arrows indicate the nodes that were hidden as they are less significant for the discussion)

Since not all the care workers are trained in dealing with patients with aggressive behaviour, they cannot handle situations with escalated aggression, which causes their stress. That is why the care workers emphasized the importance of getting appropriate training (node 15 on the map): "there is a need for special education as I do not know how to work with aggressive patients. It stresses $\mathrm{me}^{\prime}$. The other interviewee mentioned: "for many years we didn't have any training in dealing with aggression".

Turnover causes stress to the remaining employees also because they have to teach the newly hired care workers. "It always takes time to train a new recruit, once they learn to work another person arrives, it is really stressful for us".

As Figure 2 demonstrates, frequent shifts in the schedules not only increase the care workers' and the patients' stress, but also affect their comfort and security at work. Based on the interviews with the care workers, the main steps needed to be taken in order to provide the care workers with more comfort and security at work are: 1) more visits to the working floor by the management, 2) improvement in organisation of care workers' work, 3) reduction of fear of criticism by the families via building the relations of trust with them, 4) development of environment of trust in the teams and 5) reduction of the shifts in the schedules (Figure 2).

The care workers emphasized the importance of improved communication with the senior management. In their opinion, the managers do not really see how the work is organized as they are too far from the working floor. One of the care workers mentioned: "the biggest stress for me is the lack of communication among the managers and the care workers... I am tired of not getting a feedback from the senior management who can really influence how things work here". Another opinion about commu- 
nication with the management is: "because of bad communication with the management we do not understand the reasons for some changes and when we complain by not having necessary information to see the big picture, nobody listens to us". The care workers also expressed desire to participate in decision making related to possible changes in the patient's life in the institution: "they (the managers) need to talk to us before making the big changes; they should know what we think about the patients' needs".

The care workers emphasized the importance of the relations of trust not only among the team members (node 6) and with the families of the patients (node 10). Healthy environment in the team is very important, especially when the receivers of services are vulnerable. One of the family members mentioned: "the people who work together should trust each other. I do not see that among the care workers". Having good relations with the families is important too. Sometimes care workers do not feel comfortable sharing information about the patients with the families because of fear of being criticized. One of them mentioned: "we need care workers who can understand the parents and be open enough to handle what they tell them... some of my colleagues are not comfortable with that".

As some of the care workers mentioned, they are better informed about the patients' needs but they are not given enough freedom to do what they think is right. So they do what they are told to, and sometimes they are criticized by the families for that.

In opinion of one of the care workers: "it is important for us to build relations of trust with the families because they are important for the patient". Both the care workers and the families agreed changes are needed on how work is organized.

\section{The family members' cognitive map}

Following the family members' map the main sources of stress for the patients are: 1) the care workers' turnover, 2) the big number of the care workers the patients deal with, 3) insufficient time the care workers spend with the patients, and 4) insufficient knowledge about the patients' needs. 


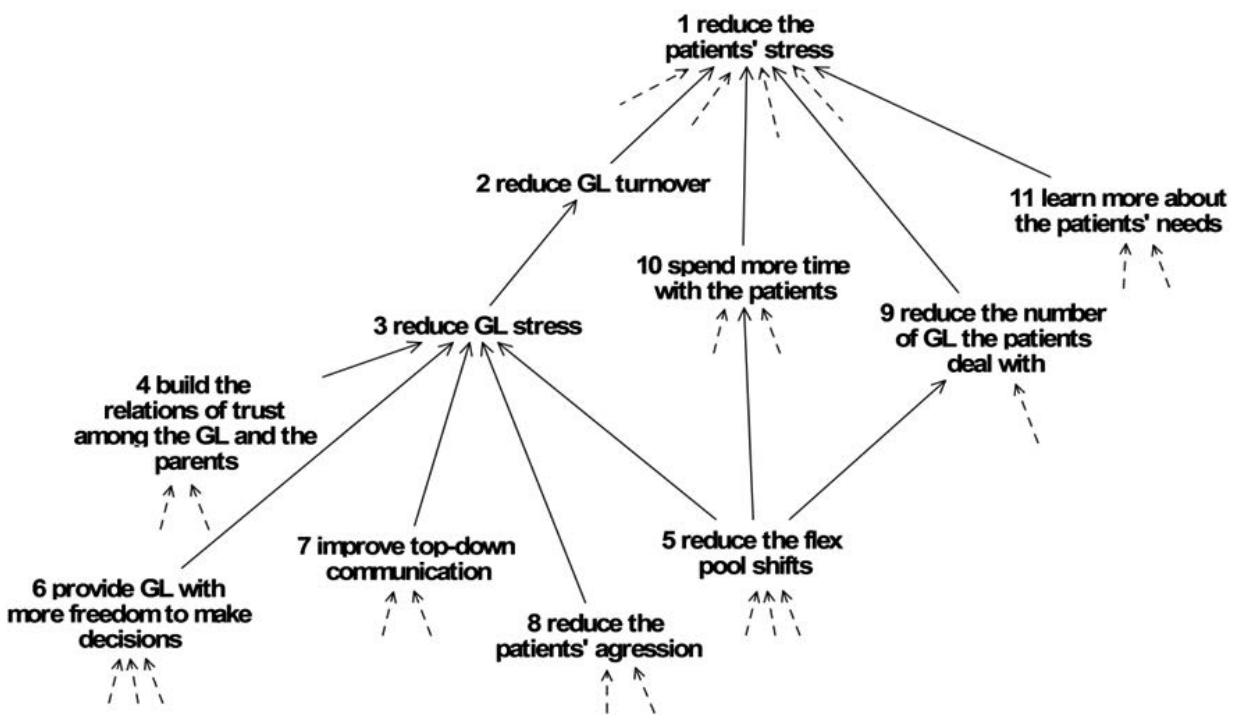

Figure 3. Segment of the family members' cognitive map related to the patients' stress and the care workers turnover

One of the factors causing care workers' turnover from the perspective of the families was the care workers' stress caused by the frequent shifts in their schedules, non efficient top-down communication, not enough freedom to make decisions and aggressive behaviour of the patients (Figure 3 ).

The families of the patients emphasized the importance of improvement of communication among the care workers and the management. They mentioned that the care workers are "trapped between what they know is right in their hearts and what they are told to do". The families suggested that the care workers need more freedom for decision making related to the patients' livelihood in the institution as they know better than the management what the patients need. They said that "the managers ought to trust the care workers more".

During the focus groups, the care workers' freedom to make decisions was mentioned as one of the crucial factors influencing their working environment. The families emphasized that "there are no rules in the organisation that clearly state when the care workers can involve the families, and when they fail to do so, it is their responsibility". In opinion of the families, the care workers try to avoid closer collaboration with them because they do not want to be criticized by the management and the families. However the families are not happy with the situation as they "need more transparency in the organisation".

Another factor that causes stress to the care workers as perceived by the families is the patients' aggressive behaviour. They voiced the opinion that some patients become aggressive because they do not trust their care workers. The families think that the management of the organisation "should be very careful in choosing the right 
people to work with the patients". They also mentioned that placing the patients with complex behavioural issues in one group does not do any good to them. The father of a young patient said: "staying in that group is kind of a vicious circle for my son". He tried to discuss that issue with the management; however they could not come to agreement. So the parents are upset seeing that their son becomes more aggressive and not being able to help him.

Another parent said that things can get better in the division if the management asks the question "what is in it for the patient?" every time when decision related to patients' livelihood in the institution is made.

All the families agreed that the frequent shifts in the care workers' schedules are not beneficial to the patients. According to the segment of the cognitive map (Figure 3 ), flex pool shifts affect a few concepts (nodes 3,9 and 10). They cause stress also to the care workers eventually increasing their turnover. The families see that it is difficult for the care workers to work with the patients they do not know well. The frequent changes in schedules do not allow the care workers to spend more time with the patients. Also as the families mentioned "it is very important for the patient to see the same people every day. The patients with autism are not flexible, they cannot make quick switches. They need familiar environment including the people and the tasks". The mother of one patient mentioned: "because of frequent shifts, about 50-60 care workers worked with our son during the year. It was too much!" It is difficult to learn about the patients with severe disabilities having frequent shifts. The parents said: "it is impossible to know the patients well and to build good relations with them if you do not spend enough time with them".

\section{Discussion}

As the analysis of the cognitive maps demonstrated, the quick fixes the management of the division applies in order to deal with the budget gaps creates unnecessary stress and tensions to the patients and the care workers and contributes to the care workers' turnover. Frontline jobs are consistently found to promote high turnover (Singh, 2000). It is widely acknowledged that stress, burnout and high turnover rates (about 44\%) among the frontline care workers are the problems for many residential care institutions for the patients with ID (Buntinx, 2008; Dunn et al., 2010; Robertson et al., 2005; Sharrard, 1992).

The indirect costs of workforce turnover in long-term care may be substantial and tend to be overlooked because they are less visible and harder to measure (Seavey, 2004). However it may also deteriorate the provider's community image. Employee turnover has an impact on quality of care for long-term care residents (Clement and Bigby, 2008). It produces staff shortages which result in "rushed, de-personalized, or unsafe care" (Seavey, 2004, p. 16). Mainly, because understanding the needs and 
wants of individuals with profound ID is often time and effort consuming (Zijlstra et al., 2001; Clement and Bigby, 2008). For instance a minimum of six months is required to understand and respond adequately to the signals of an individual with profound intellectual disability (Zijlstra et al., 2001).

Staff shortages not only affect continuity of care and relationships with the customer, but they also require the remaining staff to do additional work. That in turn affects organisational culture and employee morale and fosters further turnover because the remaining workers feel stressed, overworked and undervalued (Seavey, 2004). Throughout the study, many care workers expressed dissatisfaction with the way changes are implemented in their organisation. They felt that their opinion about many important aspect of their daily work was not considered. It made them feel alienated from the organisation.

Relations of trust between the frontline worker (a care worker/care worker in ID care provider) and the client become very important. ID patients are less adept in dealing with stressful situations on their own and so they are personally attached to the care worker whom they see every day (De Schipper \& Schuengel, 2010). Because of high employee turnover ID patients in long-term care may develop emotional insecurity leading to stress. Everyone must know and understand the customer in order to provide a satisfactory quality product. The customer must become the focus of the organisation. Well structured and coordinated input from the customers in service organisations can significantly increase their satisfaction with output.

The care workers mentioned about the need for more training. At the same time, simply conducting thousands of hours of trainings will not produce a learning organisation. The organisation must institutionalize learning and hold it up as a corporate priority.

Due to specifics of ID care, the frontline workers (i. e. care workers) serve also as the point of contact between the parents and the service system and play an important role in the effectiveness of the delivery of services (WHO, 2010). They take care of daily needs of patients with ID and they need appropriate support to work effectively (Sharrard, 1992). Furthermore, frontline workers play a very important role in delivery of individualized and efficient care to the patients on daily basis. High turnover causes the loss of this important source of information about the patients.

In order to apply a fundamental solution instead of symptomatic (e.g. frequent shifts), the top management must develop a vision of a learning organisation they want to build up. For instance, instead of increasing frequency of shifts, they need to put efforts in learning how to plan and coordinate the employee schedules (Clement and Bigby, 2008). The managers cannot do that without employees, whose collaborative efforts determine service output. They need to learn how to listen to the workers because the person doing a job is typically the one who knows the best way to do it.

The managers of the ID care provider should consider soft variables (e.g. customer and employee satisfaction, employee stress, burnout, and so on) during the decision 
making process, otherwise problem-solving attitude will always push them to apply quick fixes. However, the ID care providers do not have well established procedures for that.

Deming (1986) suggests that $85 \%$ of the problems in an organisation can be controlled by the management via creating necessary environment for the workers to participate in solving the problems. Organisational culture exerts a strong effect on the performance at the sharp end of the system. The managers of the organisation can improve working conditions of care workers if they address the causes of stress perceived by the workers.

The management should improve working environment via better top-down and bottom-up communication. The frontline workers should be involved in important decisions related to their schedules, training, and collaboration with the customers. They need more freedom to make decisions, because not everything can be planned or anticipated at the strategic or management level with respect to services to particular customers. They must be given the opportunity and tools to do a good job and take pride in their work.

More coordination between the frontline workers, the customers and the management of service provider organisations can significantly improve the quality of services. Team work between the customers and the frontline workers may reduce the stress for both, the customers and the employees. It may also help to drive out fear and encourage the workers to point out problems and recommend improvements. For any management system to succeed the fear must be replaced with an atmosphere of mutual respect. That requires a shift from the management to leadership. Instituting leadership is not an easy task and there are no simple answers to transforming the managers into leaders. However, there are some steps that can aid in this process. Senior leaders need to communicate with employees and be more sensitive to their needs and provide them the opportunity to excel. Maybe it is not easy for the leadership to make themselves available to employees at all times, however they could begin a program of frequent visits to the working floor. This would allow them to see firsthand what is happening at the working level and allow them to experience the problems of the employees. It may also help employees to openly discuss issues with the senior leaders in a non-threatening environment. Employees must be able to see that the management is committed to improving and ready to work together.

The differences between the CLD designed with participation of the senior management and the CLD still designed with them but based on the cognitive maps of the frontline workers and the customers demonstrated that any strategic changes make little sense without the perspectives of the key stakeholders. 


\section{Conclusion}

This article demonstrates that long-term health care service providers can improve their efficiency if they improve collaboration with the frontline workers and the customers. For that the management needs better tools that can help them to involve the key stakeholders in decision making. The solution to this situation can be application of principles of Systems Thinking, System Dynamics and Cognitive Mapping to formulate, model, and analyse these systems.

Services are not commodities that can be stocked and stored. Service experience is intangible, it involves a strong human element and the managers cannot fully control the process on the working floor. Hence, it is crucial to consider "soft" variables like staff motivation, productivity, burnout, trust, patient stress and anxiety and also responses of health care management to different pressures. These variables complicate problem analysis as they are not easily quantifiable and their effects are not subject to rapid consensus.

Initially, the most difficult challenge for our study was how to deal with soft variables. There is no objective methodology for the measurement for the variables that can describe terms such as "personal attachment", "commitment" and so on. However, a Systems Thinking approach to the problem situation provided additional insights onto the feedback processes.

This article suggests that the application of combined problem structuring techniques with consideration of system boundaries can be a powerful first step in interpreting situations and improving systemic decision outcomes. Combined SD modelling and $\mathrm{CM}$ techniques help not only to overcome the problems caused by bounded rationality, but they also allow considering soft variables.

Establishing a strong services culture that promotes organisational learning is also very important for organisational problem solving and innovation. The case study in an ID care provider in the Netherlands demonstrated that there is an urgent need in involving the frontline workers and the customers in defining resource allocation policies. The organisations must acknowledge the fact that frontline workers and customers, who are not experts, can help in understanding complex relationships in the organisation if their collaborative participation is properly managed. Better coordination between the frontline workers, the customers and the management of service provider organisations can significantly improve the quality of services leading to a better quality of life of the residence of long-term care institutions.

Cognitive mapping techniques enhanced stakeholders' ownership feeling towards the planning process. They allowed participants to critically reflect upon the dynamics of the process and helped them see their own thoughts strategically organized, which made their input more constructive.

The case study clearly demonstrated that cognitive maps combined with SD CLDs can provide senior management with detailed feedback about how the results of stra- 
tegic decisions are perceived at the frontline. CLD designed in collaboration with the senior management after the analysis of merged cognitive maps helped them see the best leverage points for intervention in order to balance the system. This approach requires senior managers to take feedback seriously and to recognise the causal complexity that creates problems at the front line.

Senior management of long-term care service organisations need tools that can help them produce long-term policies shaped by evidence in order to tackle the causes of the problems and not the symptoms. Decisions makers on the strategic and tactic level of the organisation will be able to use the model suggested in this article as a tool to support decisions on strategy related to process and work organisations. 


\section{References}

Ackermann, F., Eden, C. (1994), "Issues in computer and noncomputer supported GDSSs". Decision Support Systems, Vol. 12, pp. 381-390.

Ackermann, F., Eden, C. (2010), Strategic Options Development and Analysis. In: M. Reynolds, \& S. Holwell (Eds.), Systems Approaches to Managing Change: A Practical Guide (pp. 135-190), London, UK: Springer.

Bowen, J. and Ford, R. (2002), "Managing Service Organisations: Does Having a "Thing" Make a Difference?", Journal of Management, Vol. 28 No. 3, pp. 447-469.

Brightman, J. (2002), An Introduction to Decision Explorer, Banxia Software Ltd.

Buntinx, W. (2008), "The logic of relations and the logic of management", Journal of Intellectual Disability Research, Vol. 52 No 7, pp. 588-597.

Checkland, P. (1981), Systems Thinking, Systems Practice, Wiley, Chichester, UK.

Clement, T, Bigby, C. (2008), "Making life good in the community. Implementing person-centred active support in a group home for people with profound intellectual disabilities: Issues for house supervisors and their managers", Melbourne, Victorian Department of Human Services, available at: http://arrow.latrobe.edu.au:8080/vital/access/manager/Repository/latrobe:27740?exact=series\%3A \%22Making+life+good+in+the+community.\%22 (accessed 18 July 2013).

Coyle, R.G. (2000), "Qualitative and quantitative modelling in system dynamics: some research questions", System Dynamics Review, Vol. 16 No. 3, pp. 225-244.

Deming, W. E. (1986), Out of the crisis, Centre for Advanced Engineering Study, MIT.Cambridge, MA.

Devine, M.C. (2010), "Participation in Organisational Change Processes in Human Services Organisations: The Experiences of One Group of Frontline Social Workers", Administration in Social Work, Vol. 34, pp. 114-134.

Drucker, P. (1993), The new realities, Harper \& Row, New York.

Dunn, M. C., Clare, I. C. H. \& Holland, A. J. (2010), “Living 'a life like ours': support workers' accounts of substitute decision-making in residential care homes for adults with intellectual disabilities", Journal of Intellectual Disability Research, Vol. 54 No. 2, pp. 144-160.

Eden, C. (1992), "On the Nature of Cognitive Maps", Journal of Management Studies, Vol. 29, pp. 261-266.

Eden, C. (1988), "Cognitive mapping”, European Journal of Operational Research, Vol. 36, pp. 1-13.

Eden, C., \& Ackermann, F. (2001), "SODA - The Principles", J. Rosenhead, \& J. Minger (Eds.), Rational Analysis for a Problematic World Revisited, Wiley, Chicherster, UK, pp.21-41.

Ford, R. C., \& Heaton, C. P. (2000), Managing the guest experience in hospitality, Delmar, Albany, NY.

Gwinner, K. P., Gremler, D. D. and Bitner, M. J. (1998), "Relational benefits in services industries: the customer's perspective", Journal of the Academy of Marketing Science, Vol. 26 No. 2, pp. 101-14.

Hall, W. and Keynes, M. (2010), Thinking strategically: systems tools for managing change, Study guide, The Open University, UK.

Hoff, T. (2003), "The Power of Frontline Workers in Transforming Government: The Upstate New York Veterans Healthcare Network", The Centre for Healthcare Management Reports, available at: http://www935.ibm.com/services/us/gbs/bus/pdf/ibm_healthcaremanagement_power_it.pdf (accessed 25 June 2013).

Jackson, M. C. (2003), Systems Thinking: Creative Holism for Managers, Wiley, Chichester, UK.

Kane-Urrabazo, C. (2006), "Management's role in shaping organisational culture", Journal of Nursing Management, Vol. 14, pp. 188-194.

Lumsden, C. and Wilson, E. (1981), Genes, Mind and Culture. The Coevolutionary Process, Harvard University Press, Cambridge (MA).

Maglio, Kieliszewski, Spohrer (2010). Handbook of Service Science. New York: Springer.

Mills, P. K., Chase, R. B., and Margulies, N. (1983), "Motivating the Client/Employee System as a Service Production Strategy", The Academy of Management Review, Vol. 8, No. 2, pp. 301-310. 
Mills, K. and Morris, J. H. (1986), "Clients as "Partial" Employees of Service Organisations: Role Development in Client Participation", The Academy of Management Review, Vol. 11 No. 4, pp. 726-735.

Morecroft, J., and Wolstenholme, E. F. (2007), "System dynamics in the UK: a journey from Stirling to Oxford and beyond", System Dynamics Review, Vol. 23, pp. 205-214.

Organisation for Economic Co-operation and Development (OECD). (2013), "Health Care Reform and LongTerm Care in the Netherlands", Economic Department Working Paper No. 1010, available at: http://www.oecd-ilibrary.org/economics/health-care-reform-and-long-term-care-in-thenetherlands_5k4dlw04vx0n-en;jsessionid=5gq6e7o7w8v38.x-oecd-live-01 (accessed 3 July, 2013).

Paton, R. and McCalman, J. (2000), Change Management: A Guide to Effective Implementation, Sage publications, London, UK.

Porter, L. and Lawler, E. (1968), Management attitudes and performance, Homewood, III., Irwin-Dorsey.

Reynolds, M., \& Holwell, S. (2010), Systems approaches to managing change: A practical guide, London, Springer.

Robbins, S. and Coulter, M. (2005), Management, John Wiley \& Sons, New York, USA.

Robertson, J., Hatton, C., Felce, D., Meek, A., Carr, D., Knapp, Hallam, A., Emerson, E. (2005), "Staff Stress and Morale in Community-Based Settings for People with Intellectual Disabilities and Challenging Behaviour: A Brief Report", Journal of Applied Research in Intellectual Disabilities, Vol. 18, No. 3, pp. 271-277.

Seavey, D. (2004), "The Cost of Frontline Turnover in Long-Term Care. Better Jobs Better Care Practice \& Report", available at:

http://phinational.org/sites/phinational.org/files/clearinghouse/TOCostReport.pdf (accessed 29 June 2013).

Senge, P. (1990), “The Leader's New Work: Building Learning Organisations", Sloan Management Review, Vol. 32 No. 1, pp. 7-23.

Senge', P. (1990), The fifth discipline: The art and practice of the learning organisation, Bantam Doubleday, Dell Publishing Group, Inc, New York, US.

Senge, P. (1998), "The Leadership of Profound Change: Toward an Ecology of Leadership", in Pegasus Communications: System Thinking in Action Conference: Learning Communities: Building Enduring Capability, San Francisco, pp. 81-89.

Sharrad, H. (1992), "Feeling the strain: job stress and satisfaction of direct care staff in the mental handicap service", British Journal of Mental Subnormality, Vol. 1, pp. 32-8.

Singh, J. (2000), "Performance Productivity and Quality of Frontline Employees in Service Organisations", Journal of Marketing, Vol. 64 No. 2, pp. 15-34.

De Schipper, J., and Schuengel, C. (2010), “Attachment behaviour towards support staff in young people with intellectual disabilities: associations with challenging behaviour", Journal of Intellectual Disability Research, Vol. 54, pp. 584-596.

Sosik, J. and Dionne, S. (1997), "Leadership Styles and Deming's Behaviour Factors", Journal of Business and Psychology, Vol. 11 No. 4, pp. 447-462.

Sterman, J. (1989), "Modelling managerial behaviour: misperceptions of feedback in a dynamic decision making experiment", Management Science, Vol. 35 No. 3, pp. 321-229.

Tsai, Y. (2011), "Relationship between Organisational Culture, Leadership Behaviour and Job Satisfaction", Health Services Research, Vol. 11 No. 98, pp. 1-9

Van Maanen, J. (1989), "The smile factory: Work at Disneyland", in Frost, P. J. et al. (Eds), Reframing Organisational Cultures, Sage Publications, Newbury Park, CA, pp. 58-76.

Warren, K. (2002), Competitive strategy dynamics, Wiley, New York, US.

WHO. (2010), "Better health, better lives: Children and young people with intellectual disabilities and their families", available at: http://www.euro.who.int/_data/assets/pdf_file/0003/126570/e94430.pdf (accessed 14 June 2013).

Wolstenholme, E.F. and Coyle, R.G. (1983), "The Development of System dynamics as a Methodology for System Description and Qualitative Analysis", Journal of the Operational Research Society, Vol 34, pp. 569-581. 
Wolstenholme, E.F. (1999), "Qualitative vs. quantitative modelling: the evolving balance". Journal of the Operational Research Society, Vol. 50, pp. 422-428.

Zijlstra, R. H. P., Vlaskamp, C., and Buntinx, W. H. E. (2001), "Direct care staff turnover: An indicator of the quality of life of individuals with profound multiple disabilities", European Journal on Mental Disability, Vol. 22, pp. 38-55. 

CHAPTER 6

\section{Discussion}




\section{Discussion}

The study demonstrated that application of policies that do not consider interests and desires of the clients and the frontline care workers generates stressful environment for both groups of the stakeholders. As the merged cognitive maps demonstrated, the decision related to allocation of group leaders in the houses in residential care led to their discomfort and insecurity at the working place which may eventually affect their loyalty to the organisation. The decision also affected relations of trust between the group leader and the clients, which generated more stress to them.

According to the World Health Organisation's (WHO) definition, work-related stress is "the response people may have when presented with work demands and pressures that are not matched to their knowledge and abilities and which challenge their ability to cope". Having little support from the management and almost no control over work processes makes the situation even worse for the group leaders and eventually affects the patients.

The management of an ID organisation does not have well-established procedures that could enable consideration of soft variables (e.g. customer/employee satisfaction, employee burnout, stress and so on) during the decision-making process. However, soft variables may have a big impact on the long-term performance of a health care service organisation.

The managers' decision to bridge the budget gaps via reduction of the workload of the group leaders with flexible contracts was based on financial wellbeing of their divisions. The managers did not perceive how their actions could affect the patients' quality of life and the employees' working environment. For example, the study demonstrated that the symptomatic decision applied by managers did not consider soft factors like patients' personal attachments with care workers which caused more tension on the working floor. The reduction of the workload initiated higher frequency in schedule shifts which increased the patients' stress as they should deal with more group leaders whom they did not know well.

The reduction of the workload was the main cause of stress for the employees as well. It initiated more shifts and salary reduction which increased tension and compromised the frontline workers' (group leaders/personal coaches) loyalty to the organisation, leading to an increase in employee turnover rate. In this case, decline in patient satisfaction and burnout of frontline workers may lead to financial losses and also may affect the image of the organisation.

Service output especially in long-term care strongly depends on collaborative efforts of frontline workers, management and the clients. However, the top-down style of management in traditional health care service providers discourages participation of employees, customers and other stakeholders in decision making.

As many patients stay in the institution life-long, the long-term goals for their families and for service organisations inevitably coincide (Bigby and Fyffe, 2012). Both, 
the families and the service providers are interested in improvement of the livelihood of the patients. The service providers should determine how they can support the families to enable them to contribute better to improvement of quality of the patients' lives in the institution. Senior management of service organisations and policy makers need tools that can facilitate collaborative input of the families and care workers and will help them produce long-term policies shaped by evidence in order to tackle causes the problems and not the symptoms.

The methodology used in the case study illustrated that combination of qualitative SD modelling and CM techniques contributes to improvement of decision making via providing senior management with detailed feedback from the key stakeholders. Analysis of cognitive maps provided senior management with the structured stakeholders' perspectives on resource allocation issues in the division. CM technique helped the senior managers to have better understanding of the cultural, social and psychological implications of their decisions. Drawing SD causal diagrams with the senior managers helped them not only see where the best leverage point for intervention is but also how their ideas can balance the system.

With the help of the combined methodology senior management was able to address problem symptoms associated with declining families' satisfaction with the services and declining workers' loyalty to the organisation. The case study demonstrated how important it was for senior managers to receive a structured feedback from the key stakeholders and to recognize the causal complexity of their decisions that created problems at the working floor.

The chapters of the thesis were combined to form a line of research. We reflected on decision making processes and importance of considering soft factors for improvement of quality of life of the patients and working environment for the frontline workers (Chapters 2-5), advantages of using SD archetypes for managerial decision making (Chapter 2) and efficacy of CM technique for considering multiple perspectives of the key stakeholders of a health care service provider (Chapter 3 ). We illustrated the application of combined SD modelling and CM techniques via a case study in one ID care provider in the Netherlands (Chapters 4-5).

One of SD generic archetypes used in the research helped the management explore thinking around the problem situation (Chapter 2). The "shifting the burden" systems archetype facilitated understanding of the full range of feedbacks in the organisation and demonstrated possible side effects of the symptomatic decision to problem situation, i.e. increasing the employee schedule shifts. It also helped to realize how application of fundamental solution can help minimizing the side effects. In order to have a complete vision of the problem situation the next step of the research was gaining a feedback from the working floor.

$\mathrm{CM}$ methodology helped senior managers to learn about individual perceptions of the families of the patients and the group leaders (Chapter 3). It promoted shared understanding among them and enhanced their participation in decision making by 
improving the quality of their input. And, finally, the combination of qualitative SD and $\mathrm{CM}$ techniques facilitated bottom-up knowledge which was used by the senior management to address problem symptoms associated with declining families' satisfaction with the services and with declining workers' loyalty to the organisation (Chapter 4). Hence, the combined methodology (Chapter 5) facilitated efficient collaboration with the stakeholders by presenting visual and structured information for decision making. The managers were able to design a model with the help of qualitative SD causal loops based on structured information from the working floor presented by the merged cognitive maps. They used CLD diagrams to reflect on possible changes and see their dynamics. Understanding the interdependencies in the system helped the managers see the high leverage points and think of actions that can balance the system.

In this general discussion, the results of the research are discussed in a broader perspective and methodological considerations are addressed as well.

\section{Practical implications of applying System Dynamics archetypes for managerial decision making}

Organisational planning in complex health care systems is a challenge for the managers because they need to consider conflicting objectives and goals of multiple stakeholders (Begun et al., 2002; Jansen et al., 2006; WHO, 2010). A number of researchers have used generic systems archetypes as a first step in interpreting complex situations in healthcare (e.g., Dumas, 1985; Homer \& Hirsch, 2006; Kommer, 2002; Rohleder et al., 2007; Trochim et al., 2006; van Merode et al., 2002; Vissers, 1998; Wolstenholme, 2004).

As Chapter 2 demonstrated, generic system archetypes provided the language that helped the management of an ID care provider to explore thinking around a complex situation related to sharing of waiting lists among the divisions of the organisation. The "shifting the burden" archetype revealed some of unintended consequences of the decision to apply a symptomatic solution. System archetypes facilitated understanding of the full range of feedbacks operating in the system. They showed that attempts of the management to stabilize the system and reduce budget gaps via reducing the working hours of employees with flexible contracts without considering their and the patients' preferences may destabilize it even more. The archetype helped to realize that in order to minimize side effects caused by quick fixes the managers must apply fundamental solution.

Systems Thinking need the disciplines of building shared vision, mental models and personal mastery to realize its potential (Senge, 1990). The study demonstrated that $\mathrm{CM}$ technique helps considering multiple perspectives of the key stakeholders of the system and building a shared vision. 


\section{Efficacy of cognitive mapping technique in learning about the key stakeholders' mental models}

The $\mathrm{CM}$ technique described in the Chapter 3 can provide senior management with the detailed feedback about how the results of strategic decisions are perceived at the frontline. The CM technique is based on cognitive psychology and the theory of personal constructs. It helps dealing with multiple perspectives and bounded rationality.

The CM used during the interviews with the care workers/group leaders of an ID organisation and the families of the patients facilitated shared understanding of ideas expressed by the interviewees. The maps stimulated new thoughts and ideas around the key issues and helped merging diverse viewpoints into a single representation. They helped reaching consensus and managing disagreements during the focus groups. With the help of the maps, the interviewees could clearly see their own thoughts strategically organized, which made the discussion more constructive and useful for further decision making.

Map analysis was carried out by using the quali-quantitative indicators provided in Decision Explorer (www.banxia.com). The technique demonstrated the drawbacks of managerial decision to reduce spending via increasing the shifts in the schedules of employees with flexible contracts. As the analysis of the maps demonstrated, one of important findings was that what senior management perceived as one of the main strategic directions, was only one of many options to solve much bigger challenges from the perspectives of the key stakeholders. The CM technique helped senior managers recognize the causal complexity that creates problems at the frontline. They realized that there is an urgent need to rethink the resource allocation policies in the organisation and to involve the frontline workers and the clients in decision making.

\section{Practical implications of applying combined System Dynamics and Cognitive mapping techniques to support managerial decision making}

The third research question was addressed in Chapters 4 and 5, that demonstrate the benefits of application of combined CM and qualitative SD methodologies. The combined methodology facilitated collaborative representation of the stakeholders' views in a structured way which assisted senior management in finding the leverage point for intervention.

Cognitive maps allowed structural presentation of interviewees' own thoughts strategically organized, which made discussion more constructive. Structured views of the stakeholders' perspectives on resource allocation issues helped the senior management to obtain systemic view on the organisation as a whole and to understand better the cultural, social and psychological implications of decisions made. CM technique helps stakeholders learn about the situation they face before they reach consensus (Reynolds and Holwell, 2010). The exploration of the maps with the help of Deci- 
sion Explorer software allows uncovering self-sustaining vicious or virtuous cycles. Identification of cycles and events that are triggering them is very helpful for designing a SD model (Reynolds and Holwell, 2010).

SD CLD designed for an ID care provider demonstrated the dynamic behaviour of the system from the perspectives of clients and frontline workers. The managers of the organisation could see that the quick fix they applied in order to deal with the budget gaps created unnecessary stress and tension to the patients and the group leaders leading to the staff turnover.

The combined SD and CM methodology helped the managers overcome confusion they had due to not having enough financial and human resources to implement changes. They could clearly see that even having limited resources more effective and efficient staff allocation policies that consider suggestions of the care receivers and those who work with them on a daily basis may bring influential changes. Seeing the results of the $\mathrm{CM}$ analysis, senior management was able to address problem symptoms associated with declining families' satisfaction with the services and declining workers' loyalty to the organisation. As the case study demonstrated, what senior management of an ID care provider perceived as one of the main strategic directions was only one of many options in solving bigger problems from the perspectives of the key stakeholders.

Importantly, cognitive maps combined with SD CLDs provided senior management with detailed feedback about how the results of strategic decisions are perceived at the frontline. They clearly demonstrated how important it was to consider soft variables (e.g. customer and employee satisfaction, employee stress, burnout, and so on) during the decision making process.

Chapter 5 has set out a methodology for studying the processes in a complex health care system like ID care providers. It demonstrated that a combination of qualitative SD modelling and CM techniques can act as a useful tool in facilitating bottomup knowledge for managerial decision making in long-term health care providers.

\section{Limitations, recommendations and suggestions for future research}

Systems Thinking assists the managers in identifying where some serious challenges lie in the organisation. However, it is crucial to acknowledge that application of Systems Thinking does not mean that the challenges an organisation is facing will be easily solved without considerable changes (Paton and McCalman, 2000; De Savigny and Adam, 2009).

It is vital also to acknowledge that in Systems Thinking there is never one correct verdict on a situation or issue. The best one can do is to try to capture the rich complexity of the situation and discover patterns in what is happening that others find convincing. 
Soft OR methods are intended to support senior management in dealing with messy, complex, wicked problems by adding structure (Ackoff, 1974; Ackermann et al., 1997). They extend the use of OR but, at the same time, they do not meet all the needs of managers struggling with problems that contain also hard elements (Ackermann et al., 1997).

SD models with their CLDs and CM are soft OR techniques that provide a qualitative view of a system. The methodology cannot be used to derive numerical assessments of the impact of strategic decision making but it can be a necessary precursor to quantitative modelling.

One of the further steps of this research project can be identification of feedback loops in order to highlight powerful dynamics in the organisation with the goal to design more effective intervention strategies using quantitative modelling as well. For instance, stocks and flows of a computer simulated SD model, along with feedback, can give us quantitative perspective of a system. A SD quantitative diagram can become a laboratory in which to experiment and learn. And still, it is important to recognize that models are not reality.

In order to realize potential of SD modelling we need CM for understanding mental models and building shared vision. CM technique helps the organisational leaders to manage complexity inherent in complex problems, however, there are some peculiarities related to application of methodology that should be considered.

First of all, the process of designing cognitive maps is important because it influences the outcome and requires certain skills from the facilitator. The facilitator is taken to have a central role in designing and managing negotiation among the stakeholders in the group. S\he should help the group of stakeholders to work efficiently and effectively in order to come up with workable agreements (Reynolds and Holwell, 2010). In order to be a catalyst for the interaction of expertise and conceptualization and to construct visually interactive models, a facilitator needs knowledge and skills in cognitive mapping, system dynamics modelling and creative thinking methods.

Mapping demands active listening as it is important to not only capture the points but also to understand what interviewees mean; otherwise it will not be possible to show the relationships between the statements. The importance of surfacing unrealised or unspoken perceptions is a key part of CM methodology.

The statements in cognitive maps represent the perception of an objective world (Reynolds and Holwell, 2010). Hence, in order to ensure that CM technique is well suited for a problem situation a facilitator needs to spend some time exploring the aim and objective of the intervention (Reynolds and Holwell, 2010).

A facilitator also needs to map the interviews, for which knowledge of a mapping software is necessary. Situations that are worth modelling are always complex and it is crucial to make a right choice about what to model (Eden, 1994). For that, it might be useful to conduct preliminary interviews with frontline workers, customers and the 
back office employees. It might also be useful to meet policy makers in the field in order to define the boundaries of the system under scrutiny.

Overall, the process of combined CM and SD modelling is time consuming and usually the managers of the organisations are under time pressure which may discourage their active participation in model building. One of the solutions can be defining short-term and long-term deliverables and discussing them with the leadership of the organisation.

The model presented in this thesis (Chapter 5, Figure1) does provide a useful step in designing policies for service organisations that consider the perceptions of the key stakeholders. The goal of this research was to see whether the visual and structured input from the key stakeholders is relevant for managerial decision making. Also it was important to see whether there is a tool that can help to bridge the gap between the frontline workers and the back office.

It will be reasonable to conduct a research testing whether the implementation of decisions based on the structured input from the key stakeholders with the help of combined CM and SD tools facilitated better outcomes. Testing the methodology with a bigger sample size may allow drawing more accurate conclusions about the effectiveness of the tool in a larger scale. It is also recommended to use the model in several organisations operating in the same field to test its effectiveness for studying interorganisational collaboration. 


\section{References}

Ackoff, R. L. (1974). Redesigning the Future: A Systems Approach to Societal Problems. Sydney, Canada: John Wiley \& Sons, Inc.

Ackerman, F., Eden, C. and Williams, T. (1997). Modelling for litigation: mixing qualitative and quantitative approaches. Interfaces 27(2), 48-65.

Begun, J.W., Zimmerman, B., Dooley, K. (2002). Health care organisations as complex adaptive systems. In S.S. Mick, M.E. Wyltenbach (Eds.), Advances in Health Care Organisation Theory (pp. 253-288). San Francisco, Calif: Jossey-Bass.

Bigby, C. \& Fyffe, C. (2012). Services and Families Working Together to Support Adults with Intellectual Disability. Proceedings of the Sixth Roundtable on Intellectual Disability Policy. Bundoora: La Trobe University.

Diehl, E. and Sterman, J. (1995). Effects of feedback complexity on dynamic decision making. Organisational Behavior and Human Decision Processes, 62(2), 198-215.

Dumas, B. (1985). Hospital bed utilization: An implemented simulation approach to adjusting and maintaining appropriate levels. Health Services Research, 20, 43-61.

Eden, C. (1994). Cognitive mapping and problem structuring for system dynamics model building. System Dynamics Review, 10, 257-276,

Homer, J., \& Hirsch, G. (2006). System dynamics modelling for public health: Background and opportunities. American Journal of Public Health, 96, 452-458.

Jansen, D., Krol, B., Groothoff, J., \& Post, D. (2006). Towards Improving Medical Care for People with Intellectual Disability Living in the Community: Possibilities of Integrated Care. Journal of Applied Research in Intellectual Disabilities, 19, 214-218.

Kommer, G. J. (2002). A waiting list model for residential care for the mentally disabled in the Netherlands. Health Care Management Science, 5, 285-290.

Van Merode, G., Groothuis, S., Schoenmakers, M., \& Boersma, H. (2002). Simulation studies and the alignment of interests. Health Care Management Science, 5, 97-102.

Paton, R. and McCalman, J. (2000), Change Management: A Guide to Effective Implementation, Sage publications, London, UK.

Reynolds, M. and Holwell, S. (2010). Systems Approaches to Managing Change: A Practical Guide. London, UK, Springer.

Rohleder, T., Bischak, D., \& Baskin, L. (2007). Modelling patient service centres with simulation and system dynamics. Health Care Management Science, 10, 1-12.

De Savigny D., Adam, T. (2009). Systems Thinking for health systems strengthening. Alliance for Health Policy and Systems Research, WHO.

Senge, P. M. (1990). The Fifth Discipline: The Art \& Practice of the Learning Organisation. Dell Publishing Group, Inc.

Shortell, S., O'Brien, J., Carman, J., Foster, R., Hughes, E., Boerstler, H., O'Connor, E. (1995). Assessing the Impact of Continuous Quality Improvement/Total Quality Management: Concept versus Implementation. Health Services Research, 30, 377-401.

Sterman, J. (2001). System Dynamics modelling: tools for learning in a complex world. California Management Review, 43(4), 8-25.

Vissers, J. (1998). Patient flow-based allocation of inpatient resources: A case study. European Journal of Operational Research, 105, 356-370.

World Health Organisation. (2010). Better health, better lives: Children and young people with intellectual disabilities and their families. Retrieved 11 Nov., 2012 from http://www.euro.who.int/_data/assets/pdf_file/0003/126570/e94430.pdf

Wolstenholme, E. (2004). Using generic system archetypes to support thinking and modelling. System Dynamics Review, 20, 341-356. 



\section{SUMMARY}

While health care systems are dynamic and complex in nature, the methods guiding decision making in these systems do not capture adequately the effects of the most important elements in these systems and their interconnections resulting in their observed poor performance.

Managerial thinking is based on the linear and open loop view of the world (Sterman, 2001). At the same time, health care providers are constructed of complex networks consisting of feedback loops in which time delays and non-linear relationships are important sources of dynamic complexity and policy resistance. Hence, the response of the system to an action is not always linearly proportional. Furthermore, all humans suffer from the bounds of rationality due to the limited information processing capabilities and cognitive skills and memory limitations of the human mind. Our mental models are not an accurate representation of the real world because we are insensitive to the non-linearity between system's elements as it evolves over time (Diehl and Sterman, 1995). Understanding the mental models of employees is especially important in service organisations because service experience is intangible and involves a strong human element.

Service experiences are the outcomes of interactions between organisations, related processes, service employees and clients. The clients and the frontline workers of service organisations have important roles to perform in the production of complex service output. It is not always possible to fully control the processes on the working floor. Hence, the organisations need to acknowledge the fact that frontline workers and customers, who are not experts, can help in understanding "soft" factors and complex relationships in the organisation if their collaborative participation is properly managed.

The solution to this situation can be application of principles of Systems Thinking, System Dynamics and Cognitive Mapping to formulate, model, and analyse these systems. Application of combined problem structuring techniques with consideration of system boundaries can be a powerful first step in interpreting situations and improving systemic decision outcomes. A structured approach to knowledge elicitation based on combined SD modelling and CM techniques helps overcoming the problems caused by bounded rationality, and allows considering "soft" variables.

As the study in an ID care provider in the Netherlands demonstrated, the frontline care workers in ID institutions are expected to make and enforce the best possible choices for clients who are not able to choose for themselves. That makes them responsible along with their leaders, so their failures can cause high stress and burnout leading to staff turnover. Hence, it is crucial to consider "soft" variables like staff moti- 
vation, productivity, burnout, trust, patient stress and anxiety and also responses of health care management to different pressures. These variables complicate problem analysis as they are not easily quantifiable and there is no direct consensus about their effects on the organisational performance.

The case study revealed an urgent need in involving the frontline workers and the clients in decision making processes related to resource allocation. Based on the analysis of cognitive maps, the decisions made by the management without involvement of the representatives of the patients and the group leaders generated unnecessary stress and tensions in residential units. Moreover, the analysis showed that there are issues and challenges on the working floor not visible for the managers. And without seeing the set of non-obvious interdependencies it might be very difficult for the managers to come up with a long-term solution to the problem situations.

We suppose that better coordination between the frontline workers, the customers and the management of long-term care institutions can significantly improve the outcome of decision making related to human resource allocation in ID care.

Two soft OR approaches used for this thesis informed and enriched one another providing better models than an individual technique could elicit on their own. A combination of qualitative SD modelling and CM techniques provided decision makers with an efficient and structured way of identifying and evaluating options.

The methodology is not entirely simple to use. However, it allows exploring problems in all levels in a flexible and transparent manner. The combined tool can be useful for facilitating bottom-up knowledge in a visually structured way relevant for managerial decision making in long-term health care providers. Decisions makers on the strategic and tactic level of the organisations can use the model suggested in this thesis as a tool for engagement of stakeholders in the process of decision making related to process and work organisation. 


\section{SAMENVATTING}

Gezondheidszorgstelsels zijn dynamisch en complex van aard. De kwaliteit van de besluitvorming daarbinnen is zeer afhankelijk van goede ondersteuning door ICT, organisatie-inrichting e.d. aan de ene kant en methoden om het beslissingsproces zelf te ondersteunen aan de andere kant. De gebruikte methoden voor het ondersteunen van de besluitvorming binnen deze systemen houden niet voldoende rekening met de effecten van de meest belangrijke elementen in de zorgorganisatie en hun onderlinge samenhang. Het denken van het management is veelal gebaseerd op een lineaire en 'open loop' zienswijze van de werkelijkheid (Sterman , 2001). Zorgsystemen kennen complexe netwerken van terugkoppelingen, waarin vertragingen en niet-lineaire verbanden belangrijke bronnen van 'dynamische complexiteit' en weerstand tegen beleidsmaatregelen zijn. Vandaar dat het antwoord van het systeem op een actie niet altijd gemakkelijk te verklaren is. Bovendien heeft de mens bij het nemen van besluiten vaak last van beperkingen in zijn capaciteit om informatie te verwerken. Onze beperkte mentale modellen geven de werkelijkheid niet nauwkeurig weer, omdat wij niet gevoelig zijn voor de niet-lineariteit tussen systeemelementen, die zich in de loop van de tijd ontwikkelt (Diehl en Sterma, 1995). Inzicht in de door de medewerkers gehanteerde modellen is vooral belangrijk binnen zorginstellingen, daar ervaringen met dienstverlening niet altijd direct meetbaar zijn en sterk persoonlijk gekleurd kunnen zijn.

Hoe de zorg wordt ervaren is de resultante van interacties tussen organisaties, processen, hulpverleners en cliënten. De cliënten en de hulpverleners op de werkvloer van de zorginstellingen spelen bij het verwezenlijken van de complexe dienstverlening een belangrijke rol. Het is niet altijd mogelijk om de processen op de werkvloer volledig te controleren. Daarom moeten managers van zorginstellingen oog hebben voor het gegeven dat hulpverleners en cliënten, die geen experts zijn, een bijdrage kunnen leveren in het begrijpen van niet-direct tastbare factoren en complexe relaties.

De oplossing kan gezocht worden in de toepassing van principes van 'System Thinking', 'System Dynamics' en 'Cognitive Mapping' en door het analyseren van deze systemen. Toepassing van gecombineerde probleemstructureringstechnieken en daarbij rekening houden met het beperkte bereik van de systemen, kan een krachtige eerste stap zijn bij het interpreteren van situaties en het verbeteren van beslissingsuitkomsten. Een gestructureerde aanpak voor kennisvermeerdering, gebaseerd op gecombineerde SD modellering en CM technieken draagt bij aan het oplossen van problemen die veroorzaakt worden door de beperkingen van het rationeel denken. Het biedt ook mogelijkheden rekening te houden met 'zachte' variabelen. 
In zorginstellingen voor mensen met verstandelijke beperkingen wordt van de begeleiders verwacht dat zij samen met de leiding de belangen behartigen van cliënten en de best mogelijke keuzes met en voor hen maken. Het in dit proefschrift beschreven onderzoek in een Nederlandse zorginstelling voor mensen met verstandelijke beperkingen liet zien, dat het onvoldoende invulling geven aan deze gezamenlijke verantwoordelijkheid van management en begeleiders kan resulteren in veel stress en 'burn-out', met als gevolg personeelsverloop. Daarom is het cruciaal om rekening te houden met 'zachte' variabelen, zoals motivatie van het personeel, productiviteit, ' burn-out' , vertrouwen, stress en angst van cliënten en ook met de reacties van het management op allerlei invloeden en druk. Deze variabelen compliceren de probleemanalyse omdat ze niet eenvoudig te kwantificeren zijn en er niet gemakkelijk consensus over hun effect wordt bereikt.

De case studie liet ook zien dat het zeer belangrijk is de groepsleiding en de cliënten te betrekken bij de besluitvorming over de toewijzing van middelen. Uit de analysen van de grafische weergave van het besluitvormingsproces bleek, dat beslissingen van de directie die genomen waren zonder inbreng van de cliëntvertegenwoordigers en de groepsleiding, resulteerden in onnodige stress en spanningen op het niveau van de wooneenheden. Bovendien kwam uit de analyse naar voren dat problemen en uitdagingen op de werkvloer vaak niet zichtbaar zijn voor de managers. Zonder goed begrip van de reeks minder voor de hand liggende, onderlinge afhankelijkheden kan het voor het management heel moeilijk zijn om voor probleemsituaties met een lange termijn oplossing te komen.

Wij veronderstellen dat een betere coördinatie tussen groepsleiding, cliënten en het management van instellingen voor langdurige zorg de toewijzing van personele middelen aan de zorg voor mensen met verstandelijke beperkingen wezenlijk kan verbeteren.

Twee in dit proefschrift gehanteerde 'soft OR' benaderingen geven beter inzicht, vullen elkaar aan en leveren betere modellen op dan de toepassing van de technieken afzonderlijk. De combinatie van kwalitatieve SD modellering en CM technieken voorziet het management van een efficiënte en gestructureerde manier van werken voor het identificeren en evalueren van handelingsmogelijkheden.

De gecombineerde techniek is niet eenvoudig te gebruiken. De toepassing maakt echter een verkenning van knelpunten op alle niveau's op een flexibele en transparante wijze mogelijk.

Het gecombineerde instrument kan nuttig zijn voor het op een visueel gestructureerde wijze zichtbaar maken en benutten van 'bottum-up' kennis, die relevant is voor bestuurlijke besluitvorming bij de instellingen voor chronische zorg. Managers op het strategische en tactische niveau van de organisatie kunnen het in dit proefschrift voorgestelde model dus hanteren als hulpmiddel voor het betrekken van belanghebbenden bij besluitvormingsprocessen binnen de instelling. 


\section{ACKNOWLEDGEMENTS}

This thesis is the end of my journey in obtaining a doctoral degree at Maastricht University Medical Centre. One of the joys of completion is to look over the journey and remember all those who have helped and supported me along this long but fulfilling PhD endeavour.

First and foremost I offer my heartfelt gratitude to my supervisor, Prof. Leopold Curfs, who supported me throughout this thesis with patience and knowledge whilst allowing me the room to work in my own way.

I would like to show my gratitude to Prof. Dragan Nikolik for the opportunity to work in this group and for all support throughout the process of research.

This thesis has been kept on track and been seen through to completion with the support and guidance of Prof. Godefridus van Merode to whom I offer my sincere gratitude.

I gratefully thank the members of the jury: Prof. Gerjo Kok, Prof. Henk Nies, Prof. Wim Groot and Prof. Jacques Scheres for refereeing my thesis and accepting to serve in the jury.

I gratefully acknowledge the funding received towards my PhD from Koraal Group, an Intellectual Disability care provider. I would like to convey many thanks to Dr. Hank van Geffen, the president of the organisation's board of directors, for his collaboration and constructive comments. I am also thankful to Mr. Chrik Diemel, $\mathrm{MPH}$, the former president of the board of directors of Koraal Group, who in collaboration with Prof. Leopold Curfs initiated this project to stimulate decision making processes in health care in the Netherlands.

I would like to show my gratitude to Dr. Guus Feron, a former director of st. Anna division who in the midst of his activity devoted his time to help me understand the field of Intellectual Disability and the decision making processes in the organisation.

I am very thankful also to the managers, employees and also the families of the patients of Koraal Groep and St. Anna division who contributed considerably to this study.

I owe sincere and earnest thankfulness to all those who shared their knowledge and experience with me: to Prof. Bruce Schneider, who often reminded me about the real purpose of the research project during the inevitable ups and downs of a PhD endeavour; to Geoff Elliott for providing me with resources that significantly enriched my knowledge of Systems Thinking theory and SODA methodology; to Gary Hirsch first of all for his articles on System Dynamics modelling in healthcare and second, for a practical session with me on drawing SD causal diagrams; to Ass. Prof. Hubert Korzilius, for sharing his knowledge related to SD modelling; to Prof. Suresh Ankolekar for ex- 
changing valuable ideas on the modelling process; to Ass. Prof. Wil Buntinx for helping me see the bigger picture of ID care in the Netherlands; to Joris Stadhouders for sharing his knowledge on software tools used for System Dynamics modelling and to Marco Manca for being a living example of a systems thinker to me.

I am indebted to my colleagues. First of all I would like to thank my colleagues from Governor Kremers Centre and especially Hanneke Trines for all their support.

I owe sincere thankfulness to Prof. Martijn Berger for welcoming me in the Department of Methodology and Statistics and providing me with the opportunities to work on the project. I thank also my colleagues Marga Doyle, Mickey Chenault, Valeria Lima Passos and Jimmie Leppink who's warm and friendly hearts were always there for me.

Of course no acknowledgments would be complete without giving thanks to my family for supporting me and giving me so many happy and beautiful memories throughout this journey.

Lastly, I offer my regards and blessings to all those who supported me in any respect during the completion of the project and I express my apology that I could not mention all of them personally one by one. 


\section{CURRICULUM VITAE}

Mrs. Meri Duryan was born in 1970 in Yerevan, Armenia. She holds an MBA in Management Information Systems, MS in Computer and Information Science and BA in Computer Engineering. She has over 15 years of experience in strategic planning, project management, change management and educational development working in multicultural teams with different international organisations (World Bank, UNDP, AED, USAID).

Prior to joining University of Maastricht as a researcher she acted as the Deputy Director of the Union of Information Technology Enterprises where she took a leading role in association's strategy development and became a Stockholm Challenge Award2008 finalist for the best IT project on behalf of the organisation.

She started her career in the IT field with the Haykapal Commercial Stock Company as a software developer for the Department of Finance. After she held position of an assistant to training manager on a World Bank Project. From 2000, she managed a one-year large-scale educational program for 800 workers in social services for the Academy for Educational Development, served as Information Support Center Manager for the UNDP/FAO Unit and as a consultant on Project Harmony's Armenian Education Quality and Relevance Program.

In 2009 she decided on a step back from the hectic activity that characterized her managerial career in order to study the changes we are undergoing in economics and management. The research project, originally seeded during her MBA dissertation work at MSM, has involved the Maastricht University Medical Centre, Governor Kremers Centre and one of the biggest long-term health care providers in the Netherlands. She has been researching systems thinking and co-production of change, while honing her managerial skills at the interface of institutions with multifaceted and nonsynergistic goals. In the scope of the project, she developed a model that can help decision makers in improving efficiency of their operations via close collaboration with the key stakeholders while designing organisational strategy. 


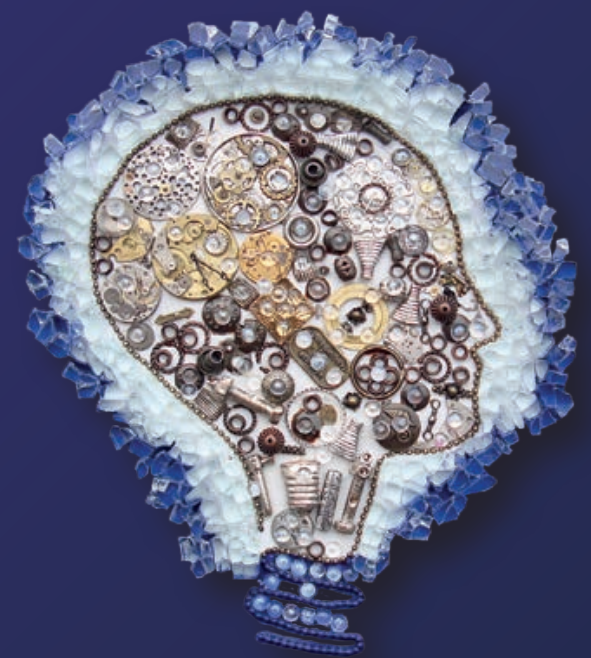

